ANL-77-89
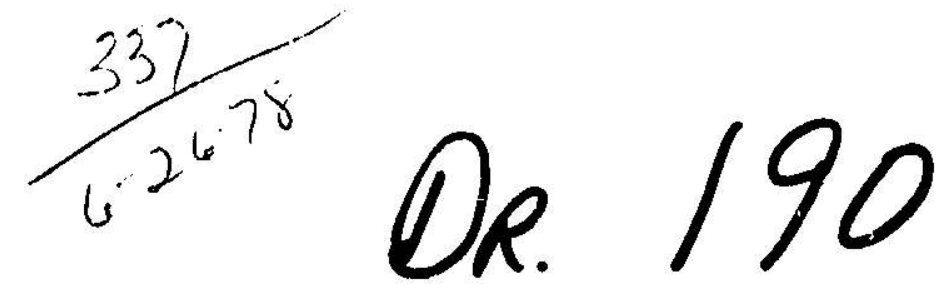

ANL-7 7-89

\title{
PRELIMINARY EVALUATION OF
}

SEVERAL NONDESTRUCTIVE-EVALUATION TECHNIQUES

FOR SILICON NITRIDE GAS-TURBINE ROTORS

D. S. Kupperman, C. Sciammarella,

by

N. P. Lapinski, A. Sather, D. Yuhas,

L. Kessler, and N. F. Fiore

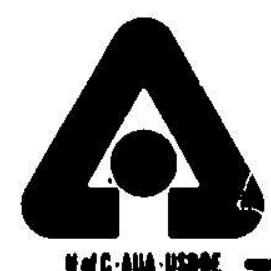

ARGONNE NATIONAL LABORATORY, ARGONNE, ILLINOIS

Prepared for the U.'S. DEPARTMENT OF ENERGY

under Contract W-31-109-Eng-38 
The facilities of Argonne National Laboratory are owned by the United States Government. Under the terms of a contract (W-31-109-Eng-38) between the U. S. Department of Energy, Argonne Universities Association and The University of Chicago, the University employs the staff and operates the Laboratory in accordance with policies and programs formulated, approved and reviewed by the Association.

\section{MEMBERS OF ARGONNE UNIVERSITIES ASSOCIATION}

The University of Arizona Carnegie-Mellon University Case Western Reserve University The University of Chicago University of Cincinnati Illinois Institute of Technology University of Illinois Indiana University lowa State University The University of lowa
K. nsas State University Th University of Kansas Lc yola University Marquette University Michigan State University I he University of Michigan University of Minnesota University of Missouri Northwestern University University of Notre Dame
The Ohio State University Ohio University

The Pennsylvania State University

Purdue University

Saint Louis University

Southe rn Illinois University

The University of iexas at Austin Washington University

Wayne State University

The University of Wisconsin

NOTICE

This report was prepared as an account of work sponsored by the United States Government. Neither the United States nor the United States Department of Energy, nor any of their employees, nor any of their contractors, subcontractors, or their employees, makes any werranty, express or implied, or assumes any legal liability or responsibility for the accuracy, completeness or usefulness of any information, apparatus, product or process disclosed, or represents that its use would not infrange privately-owned rights. Mention of commercial products, their manufacturers, or their suppliers in this publication does not imply or connote approval or disapproval of the product by Argonne National Laboratory or the U. S. Department of Energy.

Printed in the United States of America Avallable from

National Technical Information Service

U. S. Department of Commerce

5285 Port Royal Road

Springfield, Virginia 22161

Price: Printed Copy $\$ 6.00$; Microfiche $\$ 3.00$ 


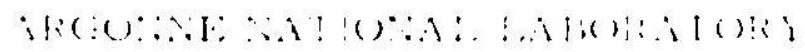

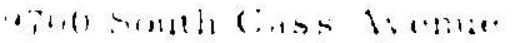

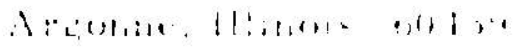

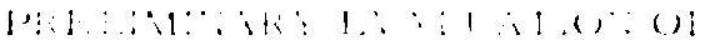

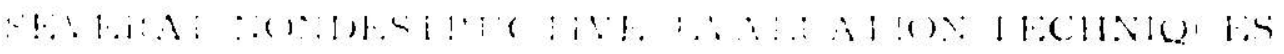

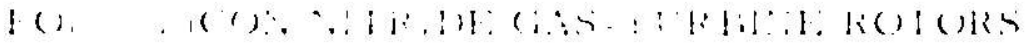

!):

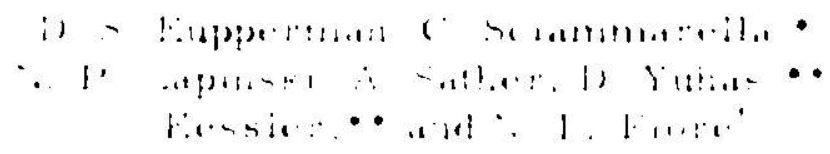

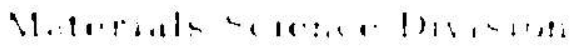

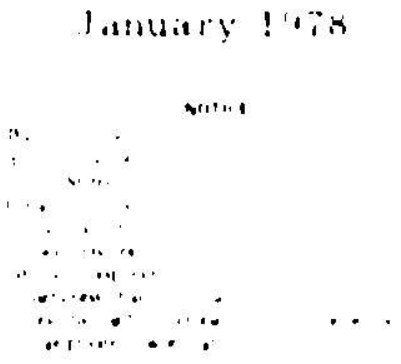

*Ilinois Institute of lechnology, Chicifo. Illinuss

- Sonohcan Inc.. Bensenville. Illinos:s

tUniversity of Notre lame. Notre l)ame, Indiana 

TABLE OF CONTENTS

Page

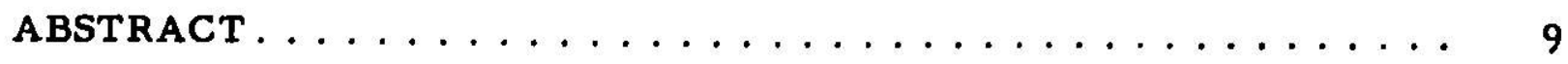

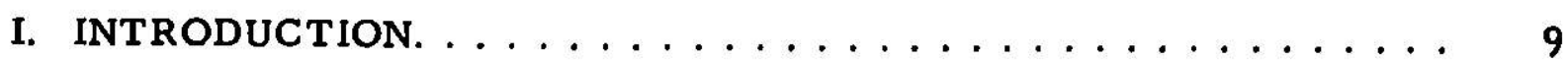

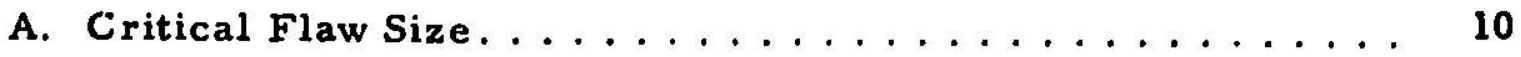

B. Limitations of Available Methods . . . . . . . . . . . 11

1. Ultrasonics .................... 11

2. Radiography. . . . . . . . . . . . . . . 11

3. Penetrants. . . . . . . . . . . . . . 12

4. Overload Proof Testing ............... 12

5. Statistical Analysis. ................ 12

6. Acoustic Emission . . . . . . . . . . . . 12

C. Samples. . . . . . . . . . . . . . . . . 13

II. HOLOGRAPHIC INTERFEROMETRY $\ldots \ldots \ldots \ldots \ldots$

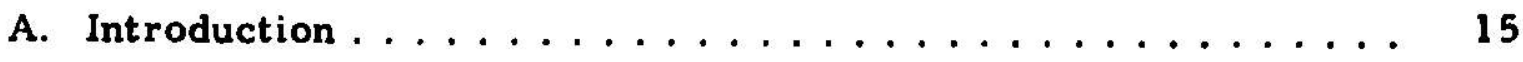

B. Basis for Crack Detection. . . . . . . . . . . . 15

1. Stress and Displacement Fields in the Vicinity of a Crack

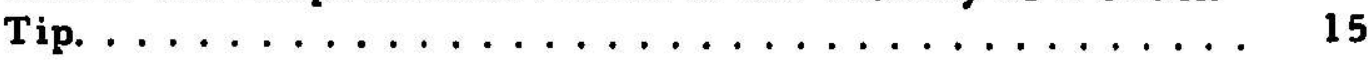

2. Equations of Holography. . . . . . . . . . . . . 16

3. Crack Detection by Observation of Displacements in Vicinity of Crack Tip. . . . . . . . . . . . . . 19

C. Optical System for Crack Detection . . . . . . . . . . 23

D. Multiplication of Holugraphic Fringes to Increase Sensitivity in Detection of Displacements . . . . . . . . . . 26

1. General Discussion. . . . . . . . . . . . . . . . 26

2. Derivation of Equations Corresponding to Process of Fringe Multiplication. . . . . . . . . . . 28

E. Experimental Verifications. . . . . . . . . . . . 30

1. Thermal Loading . . . . . . . . . . . . . . 30

2. Mechanical Loading. .................. 32

3. Detection of Smaller Cracks. . . . . . . . . . . . . 34

F. Application of Fringe Multiplication; Crack Detection on Components Other than Blades. . . . . . . . . . . 36

G. Summary and Conclusions. . . . . . . . . . . . . . . 38

III. ACOUSTIC MICROSCOPY . . . . . . . . . . . . . . . . 40

A. Experimental Procedure. . . . . . . . . . . . . . . . 40 
TABLE OF CONTENTS

Page

B. Results . . . . . . . . . . . . . . . . . 43

1. Sample Preparation and Scanning Procedure . . . . . 43

2. Documentation . . . . . . . . . . . . . . 44

3. Defect Confirmation $\ldots \ldots \ldots \ldots \ldots \ldots$

C. Summary ................... 59

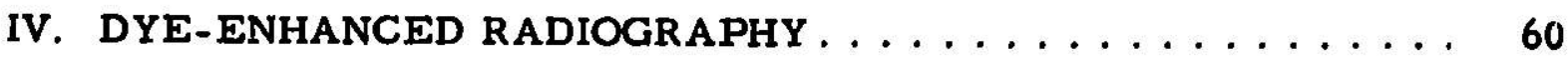

A. Discussion. .................... 60

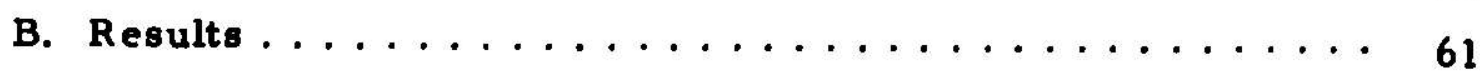

C. Summary ....................... 63

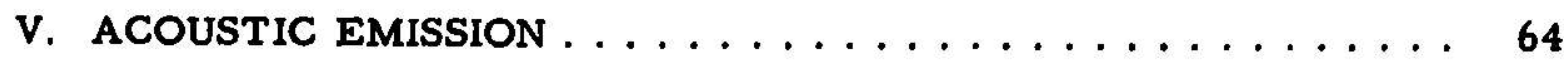

A. Discussion. .................. 64

B. Results ..................... 65

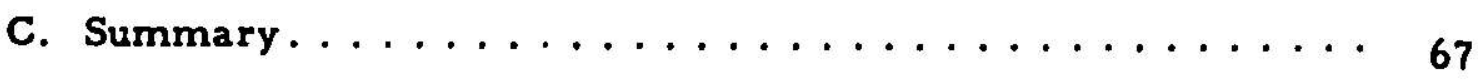

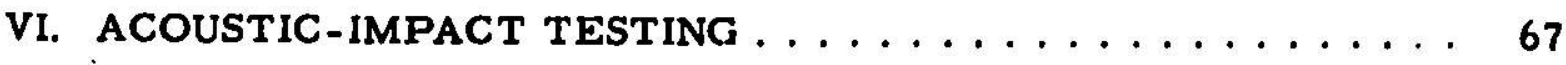

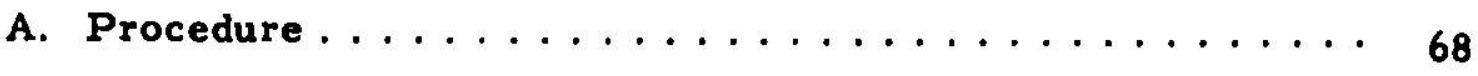

B. Results ....................... 69

C. Summary . . . . . . . . . . . . . 70

VII. POSSIBILITY OF FLAW DETECTION BY MEASUREMENT OF VIBRATIONAL DAMPING . . . . . . . . . . 70

A. Impacting Individual Blades. . . . . . . . . . . 70

B. Resonance of Entire Assembly. . . . . . . . . . 72

C. Summary of Measurement Procedures . . . . . . . . . 74

D. Estimation of Magnitude of Effect. . . . . . . . . . 75

E. Conclusion. . . . . . . . . . . . . . . . 76

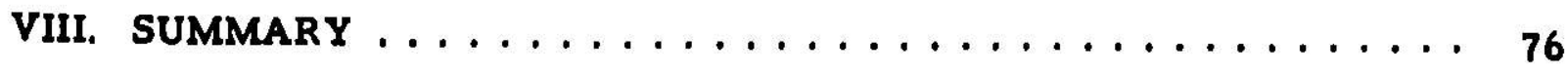

ACKNOWLEDGMENTS $\ldots \ldots \ldots \ldots \ldots \ldots \ldots \ldots \ldots \ldots$

REFERENCES. . . . . . . . . . . . . . . . 78 


\section{LIST OF FIGURES}

No.

1. Two Reaction-sintered Blade Rings with and without Center

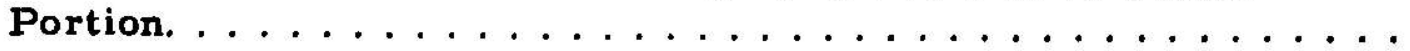

2. Determination of Displacements at a Point by Means of Holographic Interferometry . . . . . . . . . . . .

3. Holographic Determination of In-plane Displacements. . . . . . 19

4. Fringe Orders in Neighborhood of a $100-\mu \mathrm{m}$ Crack. . . . . . . . 20

5. Crack Loaded in Antiplane Strain . . . . . . . . . . 21

6. Modes of Loading of a Turbine Blade. . . . . . . . . . . 22

7. Light-sensing Device for Measuring Fringe Contrast in Neighborhood of Localization Point . . . . . . . . . . . 24

8. Experimental Setup for Fringe Multiplication . . . . . . . 27

9. Filtering System for Fringe Multiplication . . . . . . . . . 27

10. Blade Subjected to Thermal Load, Showing Deflections Produced by Heating the Blade with a Torch. . . . . . . . . . . 31

11. In-plane Displacement Pattern for Blade Subjected to Thermal Load . . . . . . . . . . . . . . . . . . 31

12. Crack Detection by Evaporation of a Very Volatile Fluid. . . . . 32

13. Pattern of the $w$ Displacement for a Cracked Turbine Blade Loaded Perpendicular to Its Own Plane . . . . . . . . . 33

14. Plot of Fringe Orders vs Position. . . . . . . . . . . . 33

15. Profile of Dimple Produced by Presence of Crack on Blade of Fig. $12 \ldots \ldots \ldots \ldots \ldots \ldots \ldots \ldots \ldots \ldots \ldots \ldots \ldots \ldots \ldots \ldots \ldots$

16. Plot of Fringe Orders vs Position along Line of Angular

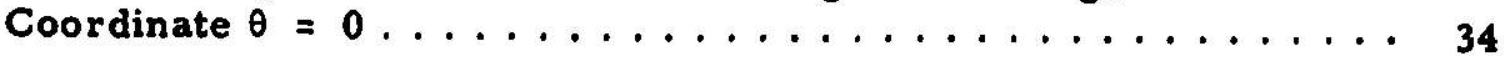

17. Holographic System Used for Observation of Real Images with a Magnifying System .................... 34

18. Lack of Resolution of Holographic Reconstruction When Viewed with $\times 10$ Magnification . . . . . . . . . . . . .

19. Plot of Fringe Orders va Position for Several Sections, Showing Presence of Dimple in Region of Root of Crack . . . . . . . . . 36

20. Fixture for Testing Turbine Rotor. . . . . . . . . . . 37

21. Picture of Blade Loaded in Bending in Ite Own Plane . . . . . 37 


\section{LIST OF FIGURES}

Title

22. Circular Plate Loaded with Concentrated Load . . . . . . . . . .

23. Successive Multiplications of Pattern Cor responding to Deflection of Central Region of a Circular Plate Loaded with a Concentrated Load

24. Sonoscan 100 Acoustic Microscope . . . . . . . . . . . . 40

25. Schematic Diagram Illustrating Detection Scheme Used by Scanning Laser Acoustic Microscope (SLAM) . . . . . . . . 41

26. Standard Stage Cells . . . . . . . . . . . . . . . . . 41

27. Schematic Diagram of Acoustic Microscope Stage . . . . . . . 42

28. Schematic Diagram of Sample Configuration . . . . . . . . . . 43

29. Schematic Diagram of Blades Examined. . . . . . . . . . . 44

30. Am and I of Defect Cluster Observed in Flatter Portions of

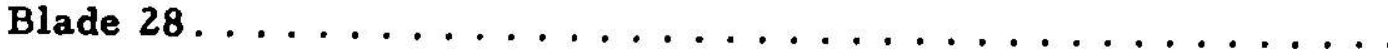

31. Cross Section of Blade 28 at $1.8 \mathrm{~mm}$ from End of Blade at Location of Pore Indicated by Radiography and in General Region of Defect Indicated by Acoustic Microscopy. . . . . . . . .

32. Am and I of Blade 28, Showing Large Area of Abnormal Structure .......................47

33. Am and I Obtained on Curvedmost Portion of Blade $28 \ldots \ldots \ldots$

34. Am and I of Large Subsurface Void Seen in Curved Portion of

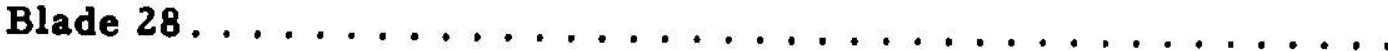

35. Am and I of Normal Structure Observed in Blade $18 \ldots \ldots \ldots \ldots$

36. Am and I of Obvious Cluster Defect in Blade 18 . . . . . . . 51

37. Am and $I$ of Interesting Structure in Blade $14 \ldots \ldots \ldots 5$

38. Am and $I$ of Blade 14 in an Area Directly Adjacent to Field of View Shown in Fig. $37 \ldots \ldots \ldots \ldots \ldots \ldots \ldots \ldots \ldots \ldots \ldots$

39. Am and $I$ of Normal Structure Observed in Blade $16 \ldots \ldots 54$

40. Am and I of Extended Area of Darkening Observed in Blade 16. . 55

41. Am and $I$ of Normal Structure Observed in Blade 15 . . . . . . . 56

42. Am and $I$ of Blade $36 . \ldots \ldots \ldots \ldots \ldots$

43. Schematic Diagram of Dye-enhanced Radiography Technique for Silicon Nitride Rotors . . . . . . . . . . . . . . . . . . 


\section{LIST OF FIGURES}

No. $\underline{\text { Title }}$ Page

44. Anomaly Revealed in Blade-root Region of SN Rotor. . . . . . . . 62

45. Sketch of Indications Revealed by Dye-enhanced Radiography Techniques for Blade Ring . . . . . . . . . . . . . . 62

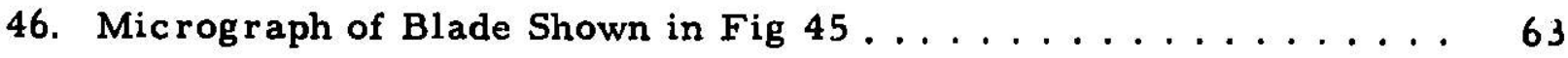

47. Scanning Electron Micrograph of Crack Indicated in Fig. 46. . . . 63

48. Schematic Diagram of Experimental Apparatus for Acousticemission (AE) Experiments . . . . . . . . . . . . . . 64

49. Photograph of SN Rotor, SN Stand, Amplitude-distribution Analyzer, and Signal Processor for Acoustic-emission (AE) Experiments . . . . . . . . . . . . . . .

50. Amplitude-distribution-data Cumulative Log and Total Counts for Thermal Stressing of Blades 16 and 20 of Ring $1957 \ldots \ldots 6$

51. Blades 16 and 20 of Blade Ring $1957 \ldots \ldots \ldots 6$

52. Acoustic-emission Amplitude-distribution Data and Total Counts for Five Blades of Blade Ring $2319 \ldots \ldots \ldots \ldots 67 \ldots \ldots \ldots$

53. Schematic Diagram of Acoustic-impact-testing Technique..... 68

54. Frequency Spectra of Blades 16 and 20 of Blade Ring 1957, Indicating Variation in Blade Quality . . . . . . . . . 68

55. Six Consecutive Impacts and Resulting Frequency Spectrum from Blade 12 of Blade Ring $2319 \ldots \ldots \ldots 69 \ldots \ldots \ldots$

56. Schematic Diagram for Blade Vibration . . . . . . . . . 70

57. Damped Oscillation for Blade. . . . . . . . . . . . 71

58. Response of Blade Driven at Frequency near Resonance . . . . . 73

59. Decay of Vibration after Driving Force Is Removed . . . . . . . . 74

60. Response of Body Initially at Rest, Then Forced into Resonance. . 74

\section{LIST OF TABLES}

No. 'ritle

I. Physical Propurties of Hot-pressed Silicon Nitride. . . . . . . . . 14

II. NDE Techniques for Silicon Nitride Rotors $\ldots \ldots \ldots \ldots \ldots \ldots$ 



\begin{abstract}
PRELIMINARY EVALUATION OF
NONDESTRUCTIVE-EVALUATION TECHNIQUES

FOR SILICON NITRIDE GAS-TURBINE ROTORS
\end{abstract}

by

D. S. Kupperman, C. Sciammarella, N. P. Lapinski, A. Sather, D. Yuhas, L. Kessler, and N. F. Fiore

\begin{abstract}
Sever al nondest ructive-evaluation (NDE) techniques have been examined to establish their effectivenes s for detecting critically sized flaws in silicon nitride gas-turbine rotors.

Preliminary results have been obtained for holog raphic interferometry, acoustic microscopy, dye-enhanced radiography, acoustic emission, and acoustic-impact testing techniques. This report discusses the relative effectivenes $s$ of these techniques in terms of their applicability to the rotor geometry and ability to detect critically sized flaws. Where feasible, flaw indications were verified by alternative NDE techniques or destructive examination. This study has indicated that, since the various techniques have different advantages, ultimately a reliable interrogation of ceramic rotors may require the application of several NDE methods.
\end{abstract}

\title{
I. INTRODUCTION
}

There is an important need to develop ceramics for high-temperature engine components. Ceramic materials that do not necessarily require cooling can be used to decrease fuel consumption and improve ongine operating efficiency. In addition, ceramic materials are often less costly than metals and more corrosion-resistant, and are normally fabricated from abundant elements. Specifically, a major goal of planned DOE programs is to identify problems associated with hot-pressed and reaction-bonded ceramic components. Nondestructive evaluation should play an essential role in their evaluation.

Nondestructive-evaluation techniques employing uitrasonic, penetrating radiation or optical techniques are capable of detecting flawe such as cracks, porosity, and nonbonding in ceramic componente as well as variations in material properties such as deneity and elestic moduli. The application of these techniquen can help ensure reproducible mechanical and phyoical properties, thus improving the ceramic procesesing techniques and the operational reliability. One specific important area for application of nondestructive evaluation ie ceramic rotore for the vehicular gas turbine program (Ford Motor Company) 
Ford Motor Company (as well as Westinghouse Electric Corporation) has applied nondestructive-testing techniques to ceramic engine components.' Conventional $X$-radiography and ultrasonic techniques have been used as well as some limited efforts employing acoustic-emission technology. Critical flaw sizes are estimated to be about $10 \mu \mathrm{m}$ in hot-pressed silicon nitride and $100 \mu \mathrm{m}$ in reaction-bonded components.

Flaws approaching critical sizes in ceramics can be detected in geometrically simple objects under ideal conditions. These flaws are about 10-100 $\mathrm{m}$, whereas grains have characteristic lengths of the order of several microns. However, components (i.e., vanes and hubs) with complex geometries still cannot be inspected adequately. In-service tests will also require special effort. Furthermore, component failures do not necessarily originate at cracks, voids, or bonding sties. Failure may occur in areas of high stress not necessarily coincident with the presence of detectable flaws.

In addition to examination of the finished component, attention must be paid tocharacterizing and checking the component at various steps in the fabrication to ensure that destructive flaws or failure-initiating material properties are not introduced by the fabrication process.

The most extensively developed nondest:uctive-evaluation (NDE) techniques that may be applicable to ceramic components include X-radiography, ultrasonics, penetrants, overload proof testing, and statistical analysis.

Other techniques with at least a rcmote chance of detecting one or more types of anomalies in silicon nitride and silicon carbide components are acoustic emission, holographic interferometry, acoustic holography, dyeenhanced radiography, computerized tomography, corona discharge, internal friction, eddy current, and microwave testing.

\section{A. Critical Flaw Size}

Ceramic components may fail by the propagation of existing flaws to critical size. Thus, the determination of the initial defect distribution and flaw characteristics in a component is very important. The minimum flaw size that must be detected to ensure reliable operation depends on many factors such as operational time desired, operating atres s, temperature, stress intensity factor, geometry of part, susceptibility of part to crack growth, and type of flaw.

The defects that are necessary to detect are pores, inclusions, cracke, and large grains. Flaws with dimensions of 10-100 $\mathrm{mm}$ must be detected in silicon nitride if it is to operate as a structural material for a gas turbine for example, at temperatures as high as $1400^{\circ} \mathrm{C}$ and at etreseses up to $300 \mathrm{MPa}{ }^{2}$ This size flaw $(10-100 \mu \mathrm{m})$ is a fow orders of magnitude smaller than critical flaw sizes in metals. Thue, the techniques developed for inepection of metallic components must be significantly.improved, or alternative methode must be applied to atructural ceramic syatems. 


\section{B. Limitations of Available Methods}

The most highly developed NDE techniques still have limitations when applied to silicon nitride (SN) components and thus, less conventional techniques may have to be developed. No one technique is expected to be used as a universal detcction method. Several techniques may be required to thoroughly assess ceramic components.

The limitation of several common techniques are discussed below.

\section{Ultrasonics}

Detection and characterization of critically sized defects in silicon nitride components via ultrasonic methods appear feasible, even though numerous obstacles must be overcome. Because of the necessity to detect small flaw sizes $(10-100 \mu \mathrm{m}$ ), much higher frequencies (up to $400 \mathrm{MHz}$ ) may have to be employed than are conventionally used now $(<50 \mathrm{MHz})$. Studies by Evans et al. ${ }^{2}$ show, however, that the attenuation may be low enough to allow the practical use of ultrasonics even to $400 \mathrm{MHz}$ in SN. Other studies indicated that frequencies much below $400 \mathrm{MHz}$ may be sufficient. For example, Derkacs et al. ${ }^{3}$ have experimented with hot-pressed and reaction-bonded silicon nitride billets seeded with low- and high-density particles $(125 \mu \mathrm{m})$. In hotpressed $\mathrm{SN}$, indications were detected using $45-\mathrm{MHz}$ ultrasonic waves which appeared to correlate with pores not larger than $20 \mu \mathrm{m}$. The smallest defect reported as unambiguously identified with an ultrasonic signal was a $25-\mu \mathrm{m}$ void detected at $25 \mathrm{MHz}$ (longitudinal mode).

Nevertheless, practical application of high-frequency ultrasonics still may be limited by transducer design, the difficulty in producing good acoustic coupling to the sample interrogated, and the sample geometry. Inspection of SN rotors will be very complex because of the difficult geometry involved. Nevertheless, the successes in detecting small flaws $(>10 \mu \mathrm{m})$ in laboratory samples of hot-pressed SN will undoubtedly stimulate further ultrasonic work.

\section{Radiography}

The important variables in establishing the sensitivity of $X$-ray methods for flaw detection are the image contrast and resolution. The resolution of conventional X-ray systems is $-100 \mu \mathrm{m}$, but more sophisticated oystems using electron focusing techniques are a few orders of magnitude better in resolving power. The ultimate limitation of $X-r$ ay systems is not with the resolution; it is in the image contrast. ${ }^{2}$ The image contrast is determined by the relative values of the absorption coefficients of the flaw and the SN. For an SN ample about $6.5 \mathrm{~mm}$ thick, ${ }^{2}$ iron and tungaten carbide defects (inclusions) less than $25 \mathrm{~mm}$ can be resolved, whereas silicon or silicon carbide inclusions are not detectable bolow $1 \mathrm{~mm}$ in size. Tight cracks, in general, are difficult if not imposeible to detect, since the $X$ - ray beam must be exactly parallel to the crack plane in order to 800 the flaw. 


\section{Penetrants}

Penetrants yield information on surface defects, mainly cracks, and probably are not capable of resolving flaws with critical dimensions less than $300 \mu \mathrm{m} .^{2}$ Information concerning flaw depth is also not obtained.

\section{Overload Proof Testing}

In this technique, overload tests are run to eliminate weak components that would not survive in service. The limitation here is that, in the process of testing, cracks may grow (slow crack growth) and the flaw population may not be constant while the part is in service.

\section{Statistical Analysis}

Statistical analysis relies on the ability to characterize the flaw strength distribution (the stress needed to cause the flaw to grow). The ability to predict fracture probability depends on an invariance in flaw population between samples. Apparently this is not likely for ceramic components; thus, high levels of confidence for predicting failures are not readily achievable. Some improvement in this method may be possible by using ultrasonic attenuation measurements to establish the flaw population variation in a collection of SN samples. ${ }^{2}$

\section{Acoustic Emission}

Two papers on acoustic emission ${ }^{4-5}$ indicate the potential for identifying flaws in ceramic components. Evans and Linzer ${ }^{4}$ show a correlation between crack velocity and acoustic emission in porcelain under load and suggest that by introducing second-phase particles into a material such as $\mathrm{SN}$, acoustic emissions will be generated as the particles fail under load. Thus, failure may be predictable. Schuldies ${ }^{5}$ has shown that acoustic emissions are generated when induced surface flaws in dense $\mathrm{SN}$ are activated by thermal stresses generated with a $\mathrm{CO}_{2}$ laser. This implies that unknown surface flaws may be detectable by thermally stressing SN components. Specimen damage in these tests were confined to areas $1 e s 8$ than 20 mils in diameter.

These discussions indicate that various NDE methods have different advantages and disadvantages and that it will be necessary to develop other techniques for application to actual ceramic components. This will ensure that an adequate selection of NDE techniques is available for use with ceramic gas turbines or other structural ceramic systems. This report discusses several techniques not extensively tried for ceramics. These include dyeenhanced X-radiography, acoustic emission, holographic interferometry, acoustic microscopy, and acoustic impact testing.

These techniques have been evaluated because of their usefulness for detecting flaws in complex geometrical shapes such as turbine rotors. 


\section{Samples}

To effectively assess the capability of various NDE techniques to detect critically sized flaws in ceramic rotors requires the use of actual components with known flaws.

The ideal situation could not be realized in this stuciy, because of the lack of availability of completed rotors. However, Ford Motor Company was able to provide Argonne National Laboratory with five reaction-sintered SN blade rings. These rings were of various quality and had known flaws determined by visual or X-radiog raphy techniques. Cracks at the root of the blades were of particular interest, because of the critical nature of that type of defect. The weakest points in the rotor are the blade roots and the bond between the hub and the blade ring. Critical flaws may be subsurface or surface anomalies. Attempts were made to detect the known defects by the various NDE methods considered in this investigation to help establish their effectiveness for actual rotor inspection. A completed rotor (two-piece duo-density design) would consist of two parts: the reaction-sintered $S N$ blade ring with the center removed, and a hot-pressed SN hub. The center of the blade ring is removed, and the hub is formed and bonded to the remaining portion of the blade ring to form the completed rotor. The hub is more dense than the ring, and the ultrasonic attenuation in the hub is considerably lower than that in the ring. ${ }^{2}$ Figure 1 shows two blade rings before and after machining out the center portion.

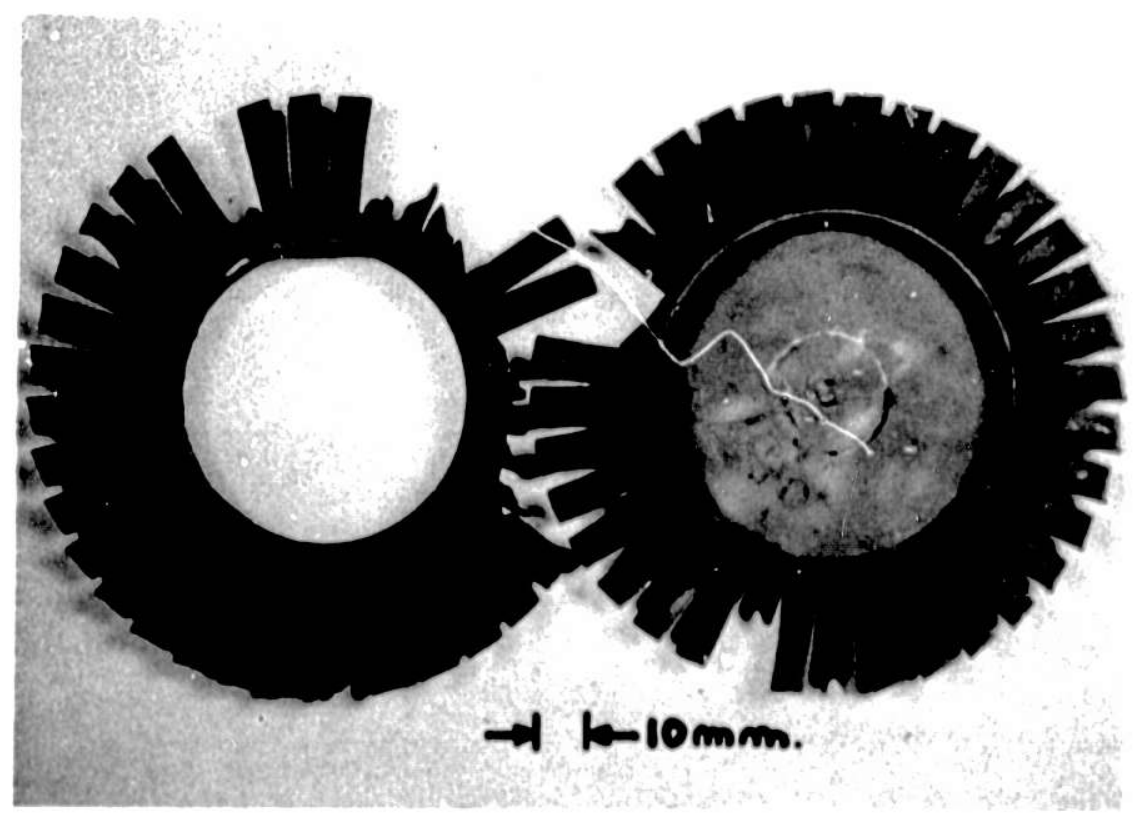

Fig. 1. Two Reaction-sintered Blade Rings with and without Centet Portlon. AN!. Neg. No. 306-77-492. 
Typical properties of the hot-pressed SN are listed in Table I. TABLE I. Physical Properties of Hot-pressed Silicon Nitride

\begin{tabular}{lcc}
\hline & $\begin{array}{c}\text { Room } \\
\text { Temperature }\end{array}$ & $800^{\circ} \mathrm{C}$ \\
\hline Coefficient of linear expansion, $10^{-6} /{ }^{\circ} \mathrm{C}$ & 1.8 & 3.7 \\
Thermal conductivity, watts $/ \mathrm{MC}^{\circ}$ & 29 & 14 \\
Elastic modulus (E), GPa & 290 & 290 \\
Poisson ratio, & 0.26 & 0.22 \\
Shear modulus, GPa & 120 & 120 \\
\hline
\end{tabular}

The several NDE techniques are discussed and results of the current program are presented in the following sections. Some techniques are discussed in much greater detail than others, reflecting the complexity of the technique, the total time involved, and the success of the method in detecting .taws. 


\section{HOLOGRAPHIC INTERFEROMETRY}

A. Introduction

Holographic interferometry is a useful technique in NDT, and numerous works have been published in this area. Reference 6 contains a chapter by $M$. Vest devoted to the crack detection. This chapter briefly outlines the nature of the surface displacements induced by the presence of a crack and describes some preliminary attempts of crack detection. The chapter is mostly qualitative. This section of the present report discusses quantitative a spects. Another attempt to use holog raphy in crack detection is presented in Ref. 7, a report describing a one-year project concerned with the mechanics of surface-flaw cracks.

B. Basis for Crack Detection

1. Stress and Displacement Fields in the Vicinity of a Crack Tip

The magnitude and nature of the surface displacements produced by the presence of a crack determine the pos sibility of detecting a crack. A crack or a flaw present in a strain field produces a stress and therefore a strain-concentration effect. The fields of the stresses and strains will depend on material properties such as the modulus elasticity and Poisson's ratio and on plastic or viscoelastic behaviors. Besides the material properties, the geometry and the loading of the element contaising the crack or flaw will influence the distributiuns of the stresses and strains. However, in many technically important problems, the size of the crack or flaw with respect to the size of the structural component $s$ in which they are located is so small that some important simplifications can be introduced. The flaw or crack can be considered embedded on an infinite medium, and the stress field remote to the crack can be considered uniform. If we consider two-dimensional problems, the gtress and displacement fields in a small region in the vicinity of a crack tip can be represented in a simple manner. The solution for the stresses near an elliptical hole was obtained by Inglis. ${ }^{8}$ By using complex functions, Westergaard obtained solutions for the displacements and stress fields in the vicinity of a crack tip.

Irwin ${ }^{10-12}$ used Westergaard's solution but modified it by introducing an important concept, the stress intensity factor $K$, as a characteristic quantity defining the stress field near a crack tip. Irwin ${ }^{13}$ distinguished three different singular stress fields, according to the opening mode: mode $I$, crack in tension; mode II, crack in shear or In-plane sliding; mode III, crack in out-c,f-plane sliding. All other forms of the opening of a crack can be reduced to combinations of these three basic modes. 
For mode I, the singular stress field near a crack tip is given by

$$
\begin{aligned}
& \sigma_{x}=\frac{K_{I}}{\sqrt{2 \pi r}} \cos \frac{\theta}{2}\left(1-\sin \frac{\theta}{2} \sin 3 \frac{\theta}{2}\right) ; \\
& \bar{\sigma}_{x y}=\frac{K_{I}}{\sqrt{2 \pi r}} \sin \frac{\theta}{2} \cos 3 \frac{\theta}{2} ; \\
& \sigma_{y}=\frac{K_{I}}{\sqrt{2 \pi r}} \cos \frac{\theta}{2}\left(1+\sin \frac{\theta}{2} \sin 3 \frac{\theta}{2}\right) .
\end{aligned}
$$

The associated displacements are given by

$$
u_{x}=\frac{K_{1}}{2 G}\left(\frac{r}{2 \pi}\right)^{1 / 2} \cos \frac{\theta}{2}\left(u-1+2 \sin ^{2} \frac{\theta}{2}\right)
$$

and

$$
u_{y}=\frac{K_{1}}{2 G}\left(\frac{\pi}{2 \pi}\right)^{1 / 2} \sin \frac{\theta}{2}\left(x-1-2 \cos ^{2} \frac{\theta}{2}\right) \text {. }
$$

where $x=3-4 v$ for plane strain and $x=(3-v) /(1+v)$ in generalized plane stress.

Similar expressions can be written for modes II and III; the corresponding stress intensity factors are called $\mathrm{K}_{\mathrm{II}}$ and $\mathrm{K}_{\mathrm{III}}$, respectively.

The stress intensity factor $K$ is a measure for the stress singularity at the crack tip. The stress intensity factor for a crack on an infinite plate in tension can be expressed as

$$
K_{I}=f \sigma \sqrt{\pi a},
$$

where $f$ is a function that depends on the geometry of the element considered, $a$ is the semicrack length for an inside crack or the crack length for an edge crack, and $\sigma$ is the tensile stress of the specimen. All other factors involved being equal, the value of $\mathrm{K}$ depends on the square root of the crack length and on the stress $\sigma$.

\section{Equations of Holography}

Holography is a technique that measures displacements on the surface of bodies. The basic equation of holographic interferounetry is

$$
8=g \cdot d
$$

where $b$ is an optical path change, $g$ is called the sensitivity vector and $d$ is the displacement vectur of the coneldered point. To explain this equation, we 
can resort to Fig. 2. In Fig. 2, a point $P$ moves through a displacement given by the vector $\mathrm{d}$. The illumination direction is characterized by the propagation vector $\mathrm{k}_{1}$, the observation direction by $\mathrm{k}_{2}$. The resulting holographic fringe pattern is indicative of a path change, 6 , which gives information about one projected component of displacement. This component is shown in Fig. 1. As shown in Fig. 2,

$$
\mathbf{g}=\underset{\sim}{\mathbf{k}_{1}}-\mathbf{k}_{2} \text {. }
$$

This equation indicates that the obtained projected component depends on the direction of illumination and on the direction of observation. If we select the direction of illumination normal to the surface and the direction of observation al so normal to the surface,

$$
\mathbf{k}_{1}=\mathbf{n}
$$

and

$$
\mathbf{k}_{2}=\mathbf{n},
$$

and $\mathrm{Eq} .4$ becomes

$$
\delta=2 n \cdot d .
$$

And if we call

$$
\underline{\mathrm{n}} \cdot \stackrel{\mathrm{d}}{=}=\mathbf{w},
$$

we obtain

$$
\delta=2 w .
$$

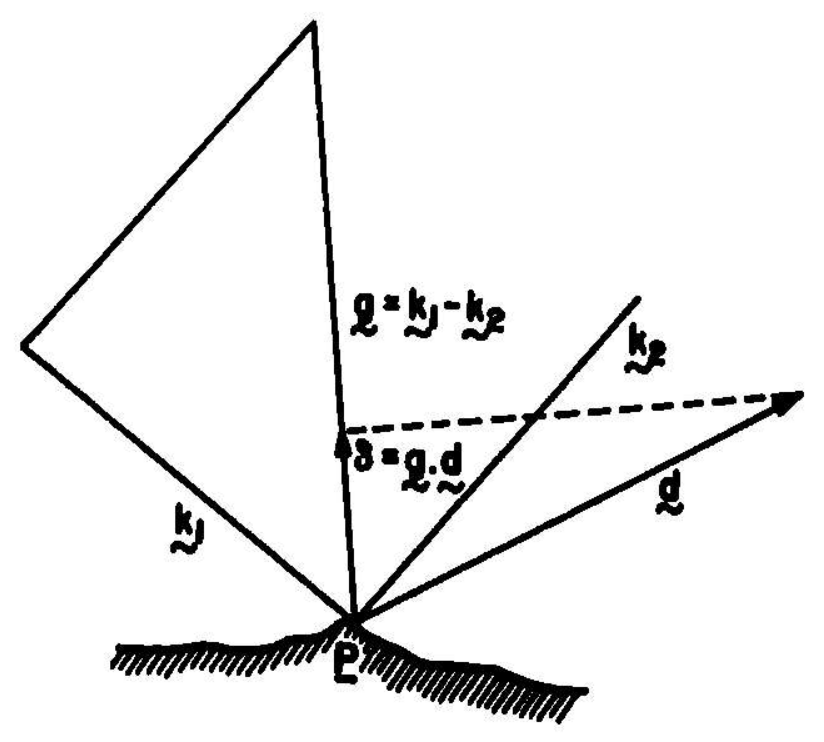

EIg. 2

Determination of Dlsplacements at a loint by Means of Holographlc Interferometry 
The above quantity expressed as a phase angle of the fringe pattern is given by

$$
2 \mathrm{w} \frac{2 \pi}{\lambda}=\mathrm{n} 2 \pi,
$$

from which

$$
\mathbf{w}=\mathrm{n} \frac{\lambda}{2} .
$$

That is, under the above-mentioned conditions of observation and illumination, eacit fringe corresponds to a half-wavelength of light. If the illumination and the observation directions are inclined of equal and opposite angles with respect to the normal and calling this angle $\theta_{i}$, in place of Eq. 12 we obtain

$$
\mathbf{w}=\mathbf{n} \frac{\lambda}{2 \cos \theta_{\mathbf{i}}} \text {. }
$$

In general, we can write

$$
\mathbf{w}=\mathrm{Mn} \lambda,
$$

where the factor $M$ depends on the illumination and observation directions.

Equations 12-14 deal with the determination of displacements in the direction normal to the observed surface. Displacements parallel to the surface can also be measured by applying the technique described in Refs. 1416. These method $s$ can be briefly described in the following way. Let us as sume that in Fig. 3, we illuminate a point $P$ with two symmetrical beams. We can write, for the illumination beam $\mathbf{r}_{1}$,

$$
\delta_{1}=\left(k_{1}-k_{2}\right) \cdot d,
$$

and for the illumination beam $k_{1}^{\prime}$,

$$
b_{2}=\left(k_{i}^{\prime}-k_{2}\right) \cdot d .
$$

Subtracting Eq. 16 from Eq. 15, we obtain

$$
\delta_{1}-\delta_{2}=\left(\underset{\sim}{k_{1}}-\underset{\sim}{k_{1}^{\prime}}\right) \cdot \underset{\sim}{\mathbf{d}} \text {. }
$$

The sensitivity vector becomes independent of the direction of observation and is parallel to the surface. If we call $\alpha$ the angle the illuminating beamo make with the normal, the equation that gives the displacements is 


$$
\mathbf{u}=\frac{\mathrm{n} \lambda}{2 \sin \alpha} \text {, }
$$

where $u$ is the component of this placement in the $x$ direction, if $x$ is assumed to be the projection direction.

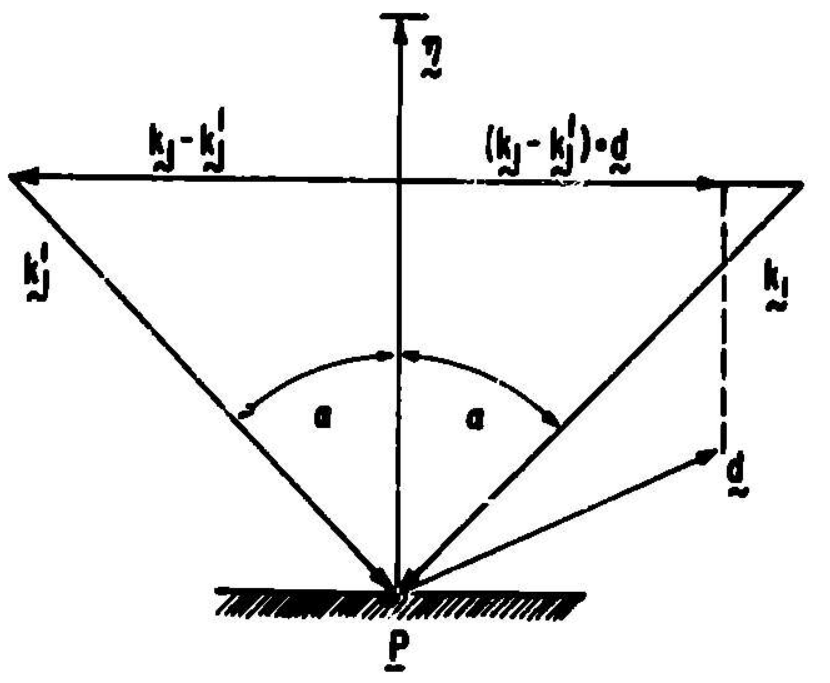

Fig. 3

Hologiaphic Determination of In-plane Displacements

3. Crack Detection by Observation of Displacements in Vicinity of

Having obtained expressions for components of displacement in the direction perpendicular to the surface and on the surface, we can go back to Eqs. 1 and 2. Let us first consider displacements that are observed perpendicular to the surface. We as sume that the crack is an edge crack in a tension field and that we are dealing with plane stress. In this case, Eq. la can be written

$$
\sigma_{x}=\frac{k_{1}}{\sqrt{2 \pi x}} \cos \frac{\theta}{2}\left(1-\sin \frac{\theta}{2} \sin 3 \frac{\theta}{2}\right)-\sigma_{0 x} \text {, }
$$

where $\sigma_{0 x}$ is the axial stress remote from the vicinity of the crack tip. If we call w the displacement perpendicular to the surface of the model, then, in view of the plane-stress condition,

$$
w=v t \frac{\sigma_{x}+\sigma_{y}}{E},
$$

where $\nu$ is Poisson's ratio, $t$ the thickness of the specimen, and $E$ the modulus of elasticity. If we take into consideration Eqs, $1 \mathrm{a}, 1 \mathrm{c}, 3,14$ and 19 and we consider that for an edge crack in a semi-infinite plate $f=1$, we obtain

$$
n=\frac{v \sigma_{0 x t}}{\operatorname{M\lambda E}}\left(0.76 \sqrt{\frac{a}{x} \cos \frac{\theta}{2}}-1\right) \text {. }
$$


Equation 21 gives us the fringe orders in the neighborhood of the root of a crack located in a tensile region. Equation 21 tells us that, all other quantities being equal, the observed orders depend on the squa re root of the crack length. As an example, Fig. 4 is a plot of the wield for a $100-\mu \mathrm{m}$

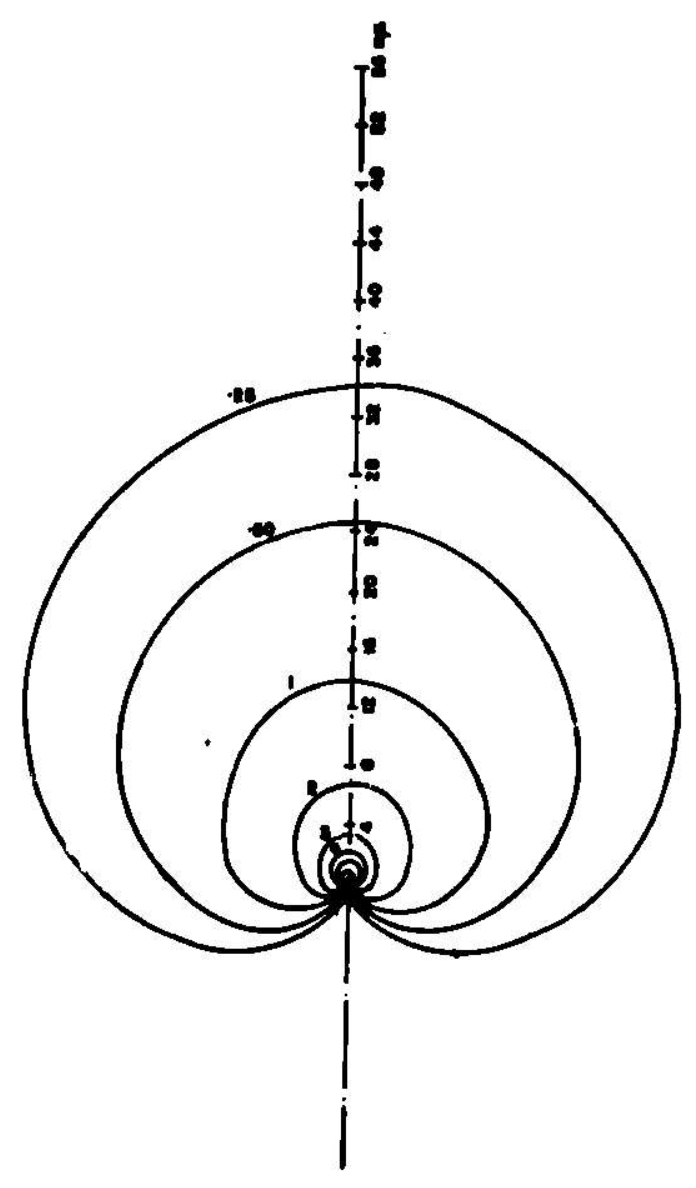

Fig. 4. Fringe Orders in Neighborhood of a $100-\mu \mathrm{m}$ Crack. Theoretical values are according to the Itwin model mode I. ANI, Neg. No, 306-77-406. crack length, in a ceramic turbine blade loaded to about $80 \%$ of the corresponding critical stress intensity factor.

The following constants have been assumed: $\nu=0.22, \mathrm{t}=1.72 \mathrm{~mm}, \sigma_{0 x}=$ $11.2 \mathrm{~kg} / \mathrm{mm}^{2}, \lambda=6328 \times 10^{-7} \mathrm{~mm}, \mathrm{M}=1 / 2$, and $\mathrm{E}=1.4 \times 10^{4} \mathrm{~kg} / \mathrm{mm}^{2}$.

Figure 4 shows the plot of the fringe orders versus position in the neighborhood of the crack tip. This theoretical pattern can be used to discuss the feasibility of detection of a crack of $100 \mu \mathrm{m}$ if the crack is in a tensile field.

Let us assume that we load the crack in antiplane st rain or mode III, as shown in Fig. 5. The displacement $w$ is giver by

$$
w=\frac{2 K_{\amalg I}}{G}\left(\frac{r}{2 \pi}\right)^{1 / 2} \sin \frac{\theta}{2} \text {. }
$$

If we consider an edge crack of length $a$ in a semi-infinite plate

$$
\mathrm{K}_{\mathrm{III}}=\mathrm{q} \sqrt{\pi \mathrm{a}},
$$

where

$$
q=\bar{\sigma}_{\mathbf{x z}},
$$

Eq. 22 becomes

$$
w=\frac{2 \bar{\sigma}_{x z} \sqrt{\pi a}}{G}\left(\frac{r}{2 \pi}\right)^{1 / 2} \sin \frac{\theta}{2} .
$$

Introducing the fringe orders, we obtain

$$
n=\frac{2 \sigma_{x z} \sqrt{\pi a}}{M \lambda G}\left(\frac{r}{2 \pi}\right)^{1 / 2} \sin \frac{\theta}{2} \text {. }
$$




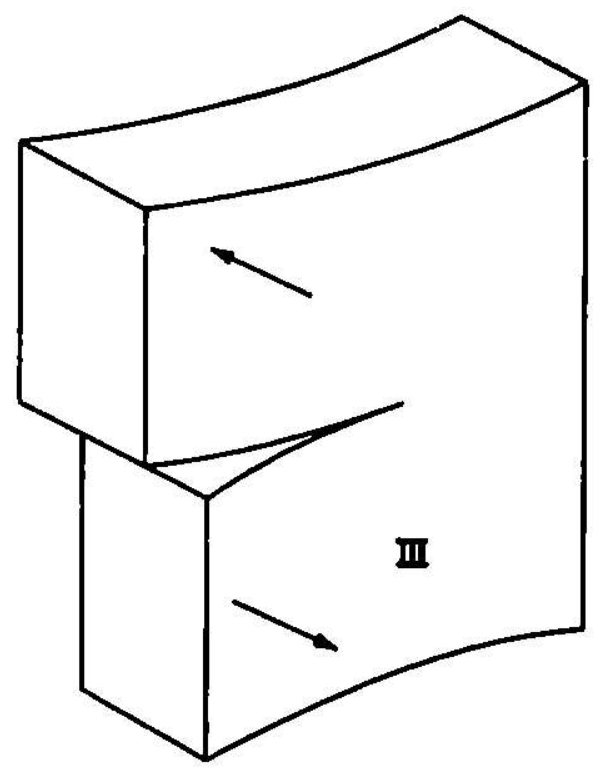

Fig. 5

Crack Loaded in Antiplane Strain

Taking the same values used for mode $I$ and assuming that $\bar{\sigma}_{x z}$ is equal to half the tensile stress applied for mode $I$, we obtain the following expression for $n$, if we assume $M=1 / 2$ :

$$
n=4.392 \sqrt{r} \sin \frac{\theta}{2}
$$

with $\mathbf{r}$ in millimeters.

If we compute the order of a point at the edge of the blade, the coordinates are $r=100 \mu \mathrm{m}$ and $\theta=\pi$. Then,

$$
\mathrm{n}=4.392 \sqrt{0.100}=1.39 \text {. }
$$

If we consider the point at the other side of the crack, the value of $n$ is

$$
n=-1.39 \text {, }
$$

and we have across the crack a jump of 3.78 orders.

mode I.

We can see that detection is more favorable in mode III than in

Let us consider now that by applying the techniques previously described, we measure the in-plane displacement.

Considering again mode $I$, and measuring the displacement in the $y$ direction, we obtain

$$
v=\frac{K_{I}}{G} \sqrt{\frac{r}{2 \pi}} \sin \frac{\theta}{2}\left(\frac{2}{i+v}-\cos ^{2} \frac{\theta}{2}\right) \text {. }
$$


If we take into consideration Eq. 18, the expression for the fringe orders is

$$
n=\frac{2 K_{I} \sin \alpha}{\lambda G} \sqrt{\frac{r}{2 \pi}} \sin \frac{\theta}{2}\left(\frac{2}{1+\nu}-\cos ^{2} \frac{\theta}{2}\right) \text {. }
$$

Replacing $\mathrm{K}_{\mathrm{I}}$, we obtain

$$
\mathrm{n}=\frac{\sigma \sqrt{\pi a} 2 \sin \alpha}{\lambda \mathrm{G}} \sqrt{\frac{\mathrm{r}}{2 \pi}} \sin \frac{\theta}{2}\left(\frac{2}{1+\nu}-\cos ^{2} \frac{\theta}{2}\right) \text {. }
$$

Assuming $\theta=\pi / 2$, we obtain

$$
\mathrm{n}=\frac{2 \sqrt{2} \sin \alpha \sqrt{2}}{(1+v) \lambda G} \sqrt{\mathrm{r}} \text {. }
$$

If $\alpha=45^{\circ}$ and we take the same values used to plot the graph of Fig. 3, we get

$$
n=5.09 \sqrt{\mathbf{r}} \text {. }
$$

For a point of $r=100 \mu \mathrm{m}$,

$$
\mathrm{n}=1.5811 \text {, }
$$

and for a point of $r=200 \mu \mathrm{m}$,

$$
\mathrm{n}=2.24 \text {. }
$$

We can see that if we use the in-plane displacement measurement, mode I will give us also very good results.

Summarizing the theoretical analysis: (a) Either mode I or mode III can be used for crack detection, (b) if the $w$ displacements are measured, mode III gives the best sensitivity, and (c) if the in-plane displacements are measured, mode I gives a very good sensitivity.

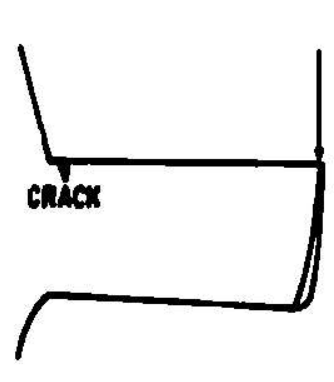

(e)

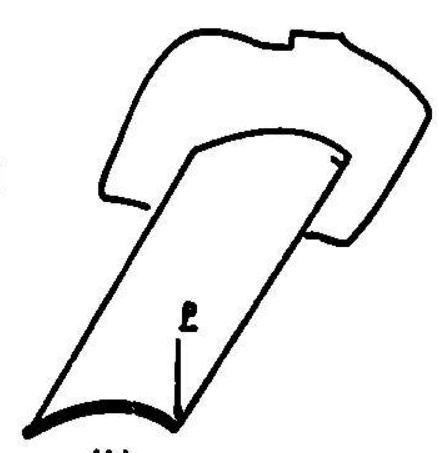

(b)

Fig. 6

Modes of Loading of a Turbine Blade

If we consider a turbine blade (see Fig. 6) the loading can be applied as shown in Fig. 6a. In this case, cracks in the neighborhood of the blade root will bo subjected to tensile stresses. If we consider a 100-um crack, the crack is vory emall as compared with the blade size and the crack can be ascumed to be subjected to a uniform tensile fleld. If we load as thown in Fig. 6b, we will Introduce a torsion torgue and then mode III will be operative. Since the loading also produces bonding stresses, 
and since as it has been concluded that in the case of bending, ${ }^{17}$ the $\mathrm{K}_{\mathrm{I}}$ mode can also be applied, the resultant displacement field will be a combination of modes I and III. Consequently, loading the blade as shown in Fig. 6b will give the best results.

\section{Optical System for Crack Detection}

If we analyze the field of displacements shown in Fig. 4, we can conclude that, to observe the perturbations produced by the crack, we must resort to magnification of the image. This means that, instead of an ordinary holographic system, we must use the methods of holographic microscopy. In holographic microscopy, three basic methods can be identified: (1) holography on magnified images by means of lens holography; (2) lensless holography where the object beam and the reference beam are incident on the emulsion from the same side of the film; and (3) lensless holography where both beams reach the emulsion from opposite sides of the film. In these two cases, magnification can be produced by appropriate selection of the radius of curvature of the reconstruction beam. An alternative is the reconstruction of real images with magnification ratios $1: 1$ and subsequent observations by a magnifying microscope.

Microscopic-lens holography was studied by Van Ligten and Osterberg ${ }^{18,19}$ and Ellis. ${ }^{20}$ Lensless holographic microscopy has been studied by Leith and Udpanieks ${ }^{21}$ and by Stroke. ${ }^{22}$

The general experience concerning lensless holographic microscopy is that poor results are obtained. In general, the smallest detail that can be reconstructed is about $12 \mu \mathrm{m}$. The main reasons for the poor results are the emulsions and the substrates supporting it.

Small changes in the emulsion during processing will cause the rays corresponding to high spatial frequencies to suffer high aberrations. The same observations can be applied to the glass substrate. These problems can be circumvented by magnifying the image first, that is, reducing the image aperture first and then recording the hologram. When high magnifications are needed, this method is limited by two factors: the diameter of the objective lens and the fact that the Abbe sine condition and the Hershel condition cannot be satisfied for sharp imaging in the transverse and in the axial conditions simultaneously.

For the initial recording, Toth and Collins ${ }^{23}$ used a lens of a high numeri cal aperture, with the quality of the lens sacrificed to obtain a large numerical aperture. The aberrations introduced during the recording are cancelled out by reveral of the path of the ray during reconstruction. The image rnay be explored laterally and in depth by a conventional microscope. Of course, the quality of the reconstruction depends on the accurate reversal of the beam. Reforence 24 gives an example of the application of this technique. In Ref. 25, 
the authors have developed a "reversed-field" technique that uses reflecting optics to reduce the frequency bandwidth required for good hologram recording. The technique can be extended to coherent or incoherent fiber optics, multiple-lens arrangements, reflecting optics, or various combinations of them. The basic idea of this procedure is to scramble the rays in quite arbitrary fashions before recording, provided that the high-angular-divergency rays are first converted to low-angular-divergency rays.

To this point, we have concerned ourselves with holographic recording of images. If we consider the problem from the point of view of interferometry, the necessity of enlarging the image produces an additional critical problem. To understand this problem, we must now consider the factors affecting the contrast of fringes in hologram interferometry. We can define the fringe contrast with a given region by means of

$$
C=\frac{I_{\max }-I_{\min }}{I_{\max }+I_{\min }},
$$

where $I_{\max }$ and $I_{\min }$ are the maximum and minimum intensities of the fringes in that region. The fringe contrast can be related to the properties of the two interfering wave fronts.

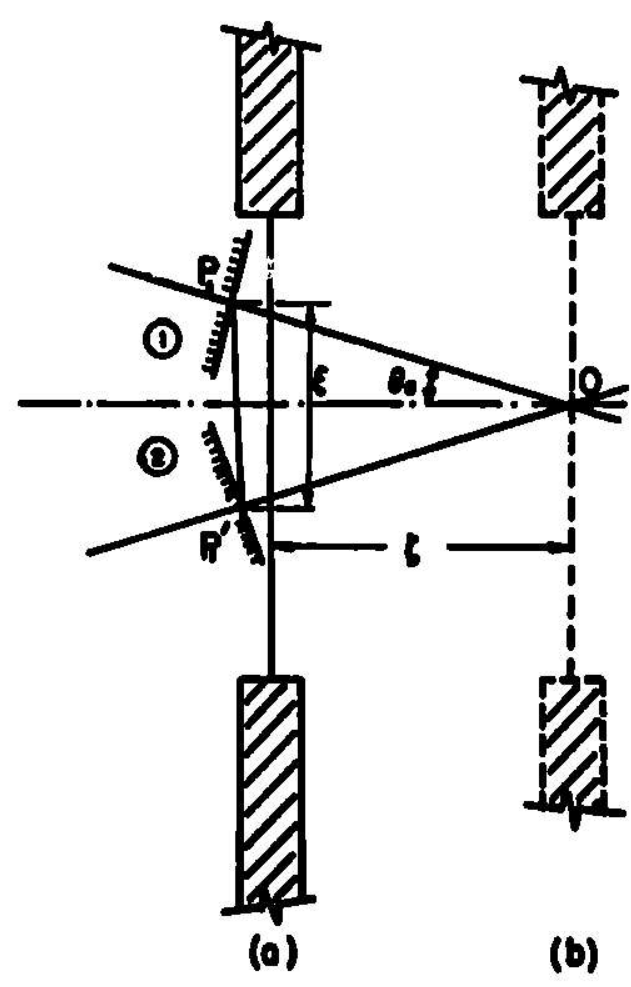

Big. 7

Wght-sensing Device for Measuring Fringe Contrest in Neightorhood of Localisation Polnt. ANL Neg. No. 306-77-49\%.
Monneret ${ }^{26}$ his shown that $C$ can be related to the real part of the autocorrelation function $\Gamma_{\mathbf{N}}$ of the diffracted waves in the considered plane. Let us suppose, as shown in Fig. 7, that we have a light-sensing device to measure the fringe contrast. The two interfering wave fronts 1 and 2 reach the sensing device with a shift 5 shown in Fig. 7, where $F$ is the distance in the plane of observation between two identical points $P_{1}$ and $P_{1}$. In Ref. 26, it is shown that

$$
C=\operatorname{Re} \Gamma_{N}\left(P_{1}-P_{1}^{\prime}\right)=\operatorname{Re} \Gamma_{N}(\xi) .
$$

The maximum contrast is reached when $\xi=0$, that is, when the ocanning aperture io located at point 0 , called the point of localization of the fringes.

Wo coneider that we are canning the real image of the hologram and that the typo of scanning device is euch that ite entrance pupil is the entrance pupll of the zone lene where the Information of a point is recorded 
in the hologram. Further, we assume that the localization surface is near the image of the object. Thus,

$$
C=\operatorname{sinc} \frac{k}{4}\left(\frac{1}{D}-\frac{1}{2}\right) a_{0}^{2}
$$

where $k=2 \pi / \lambda, D$ is the distance of the imaged point $P$ to the holographic plate, $z$ is the distance at which the reconstructed point is observed, and $a_{0}$ is the radius of the zone lens formed by the light coming from $P$ on the holographic plate. The value of $a_{0}$ depends on the aperture of the imaging system and on the distance $D$ between the object point and the hologram plate.

This derivation assumes that the surface of localization is close to the surface of the object. This condition is fulfilled when the real image of the hologram is covered by the interference fringes. Under this assumption, we can write

$$
\frac{1}{D}-\frac{1}{2}=\frac{6}{D^{2}} \text {, }
$$

where

$$
Z-D=C \text {. }
$$

and since we are ncar the focusing plane,

$$
\mathbf{Z D}=\mathbf{D}^{2} \text {. }
$$

Equation 39 can be written

$$
C=\operatorname{sinc} \frac{k}{4} \frac{6}{D^{2}} a_{0}^{2} .
$$

The angle between the homologous rays depends on the spatial frequency considered. If we take the lowest frequency, that is, the frequency corresponding to the maximum angular aperture of the system, then

$$
\theta_{a}=\frac{a_{0}}{D} \text {. }
$$

and from Fig. 7 we can also get

$$
\theta 6=\frac{5}{2} \text {. }
$$

Roplecing Eqs. 43 and 44 in Eq. 42, we finally get

$$
C=\operatorname{sinc} \frac{k}{8} \theta_{2} s \text {. }
$$


The first zero of the sinc function occurs for

$$
\frac{k}{8} \theta_{a} \xi_{c}=\pi
$$

or

$$
\xi_{c}=\frac{4 \lambda}{\theta_{a}},
$$

where, following Monneret, we call $\xi_{c}$ the radius of the correlation shift that leads to the disappearance of the fringes. Since $\theta_{a}$ is directly proportional to the magnification ratio, we can conclude that

$$
\xi_{c}=\frac{1}{m} .
$$

This means that the radius of correlation is inversely proportional to the magnification ratio. If $\mathrm{m}$ is large, the radius of correlation becomes very small. The observation of the fringes, even on a small a rea, becomes very difficult, unless we make $m$ less than one, thus increasing the value of $\xi_{c}$.

We can make the aperture of the observation system the controlling aperture, and thus, by reducing its angular aperture, we can improve the fringe contrast. Unfortunately, the speckle size depends also on the angular aperture of the observation system. If we reduce this aperture beyond certain limits, the speckle noise becomes extremely high.

Summarizing the discussion of this section: (a) To be able to detect small defects, we must resort to lens holography in order to enlarge the observed image. (b) The best results are obtained by using systems in which the light path is reversed and the image is recorded with an initial magnifica tion. (c) The phenomenon of fringe localization produces a very undesi rable effect. When magnification of the image is required, it degrades the fringe contrast.

D. Multiplication of Holographic Fringes to Increase Sensitivity in Detection of Displacements

\section{General Discussion}

In the preceding section we discussed the resolution of the holograms concerning point location. We must now consider the possibility of increating the sensitivity in the measurement of displacements. If we consider the meseuremente of displacemente perpendicular to the surface, for normal Illuminations and normal observation, Eq. 12 gives us the minimum displacement that can bo moseured, $\lambda / 2$. For a holium-neon laser, thie quantity is 
$0.3164 \mu \mathrm{m}$. A fringe-multiplication technique can be applied to further reduce this figure. The technique is based on the introduction of a system of fictitious fringes by rotating the holographic plate. The procedure can be applied to lensless holography or to lens holography.

Let us consider the application to lens holography. Figure 8 shows the holographic setup that can be used for fringe multiplication. The

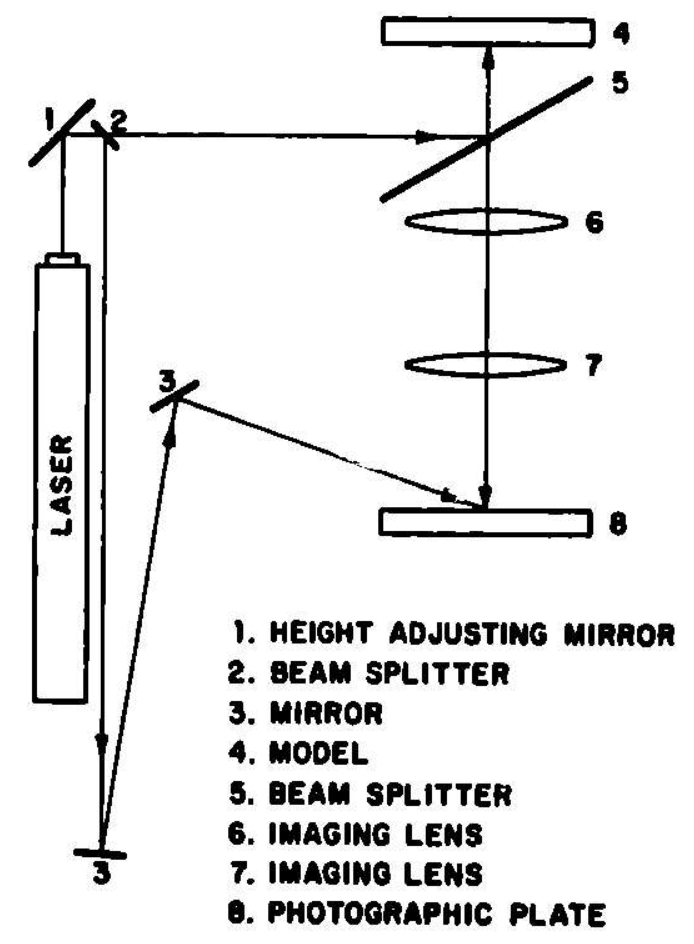

ligig. 8. Experintental Sctup for Fringe Multiplication model is imaged by the lens system on the holographic plate.

Let us assume that we apply the double-exposure method. A first exposure is made; then the plate is rotated at an angle $\beta$, and a second exposure is made. Once the hologram is developed and reconstructed as shown in Ref. 27, we can observe on the hologram a system of fringes parallel to the axis of rotation and with a fringe pitch given by

$$
{ }^{8} \mathrm{~m}=\frac{\lambda}{\beta\left(1-\cos \theta_{R}\right)} \text {. }
$$

where $\lambda$ is the wavelength of the utilized light, and $\theta_{R}$ the angle made by the reference beam and the normal to the holographic plate.

Let us assume that we use the setup of Fig. 8 to measure displacements normal to the surface of the model. The procedure is as follows. A reference system is needed to obtain the final fringe pattern. This reference system is obtained by rotating the holographic plate as previously explained. The second step consists of taking another double-exposure hologram with the plate rotated and the model loaded. Both the reference hologram and the hologram containing the load information are then multiplied. The multiplication can be achieved by putting the hologram in the filtering system of Fig. 9.

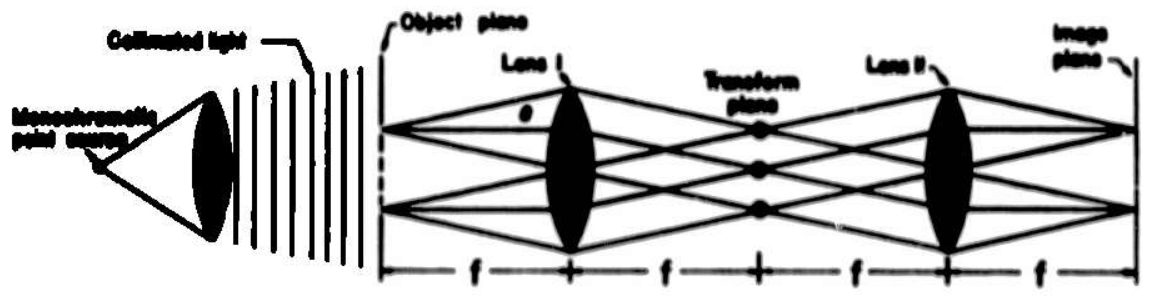

Plg. 9. Flltering System for Fringe Multipllcation. ANL Neg. No, 306-77-493. 
When subjected to the collimated illumination, the system of lines produced by the plate rotation produces the corresponding Fourier Spectrum in the focal plane of the filtering lens. If we filter the order +1 and -1 by introducing an opaque screen with two apertures corresponding to the location of the se orders, in the image plane we obtain the image of the object covered by twice as many lines as the original pattern. If, in general, we filter the order $-n$ and $+n$, the obtained fringes will be of frequency $2 n$ times the fundamental frequency.

Both the reference hologram and the hologram corresponding to the loaded state are multiplied. After multiplication, both a re superimposed to produce a moire pattern.

The two superimposed holograms are put in the same filtering system. The difiraction spots are observed in the focal plane of the filtering lens. If we allow one order to pass and if we observe the image of the object on the image plane, we will see it covered by $2 n$ times the number of original fringes. With this procedure, we have been able to obtain multiplications of X8. With a multiplication X8, the minimum displacement that can be measured is $0.03955 \mu \mathrm{m}$.

\section{Derivation of Equations Corresponding to Process of Fringe Multiplication}

After the films are developed, ${ }^{23}$ the nonlinearities of the film will produce high-order harmonics. The transmittance function corresponding to the initial or reference state is given by

$$
F(x)=F_{0}+\sum_{i=1}^{i=n} F_{i} \cos \frac{2 \pi n x}{p},
$$

where $p$ is the pitch of the fundamertal harmonic generated by the plate rotation and $n$ represents the additional orders produced by the film nonlinearity. Likewise, for the loaded specimen,

$$
F_{1}(x)=F_{0}+\sum_{i=1}^{i=n} F_{i} \cos \frac{2 \pi n x}{p(x)},
$$

where $p(x)$ indicates the variable pitch produced by the effect of the load added to the plate rotation.

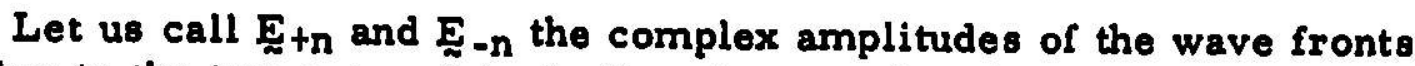
corresponding to the two symmetrical nth orders produced by the grating in the focal plane of the filtering system: 


$$
\begin{aligned}
& E_{+n}=E_{n} \exp (i 2 \pi n x / p) \\
& E_{-n}=E_{n} \exp (-i 2 \pi n x / p) .
\end{aligned}
$$

These two orders forn. the image of the model in the image plane. The amplitude collected by the photographic plate in the image plane is

$$
\mathbf{E}_{\mathbf{T}}=\left[\underset{\sim-\mathrm{n}}{\mathbf{E}_{-\mathrm{n}}}+\underset{\sim}{\mathbf{E}}\right]
$$

The intensity is given by

$$
\mathrm{I}(\mathbf{x})=\mathbf{E}_{\mathrm{T}} \cdot \mathbf{E}_{\mathrm{T}}^{*} \text {. }
$$

If we substitute Eqs. 52 and 53 in Eq. 54 and carry out the operations indicated in Eq. 55, the intensity needed by the photographic plate is

$$
I(x)=I_{0}+I_{1} \cos \frac{4 \pi n x}{p}
$$

where

$$
I_{0}=2 E_{n}^{2}
$$

and

$$
I_{i}=E_{n}^{2} \text {. }
$$

The transmittance of the developed film will be given by

$$
T(x)=T_{0}+\sum_{i=1}^{i=m} T_{i} \cos \frac{4 \pi n m x}{p}
$$

A similar expression can be obtained for the grating corresponding to the loaded case:

$$
T^{\prime}(x)=T_{0}+\sum_{i=1}^{i=m} T_{i} \cos \frac{4 \pi n m x}{p(\lambda)}
$$

In the reconstruction process, the two films are placed in a collimated beam. In the focal plane of the filtering system, a diffraction pattern is observed. If we consider, for example, the +1 order, we will have the components

$$
T_{+1}=T_{1} \exp (14 \pi n x / p)
$$


and

$$
\underset{\sim}{T+1}=T_{1} \exp [i 4 \pi m x / p(x)]
$$

If, in the filtering system, only these two components are allowed to pass, the intensity observed in the image plane will be

$$
I(x)=T_{+1}^{2}+\underset{\sim}{T} T_{+1}^{\prime}+2 \underset{\sim}{T}+1 T^{\prime}+1 \text {. }
$$

After simple transformations are obtained,

$$
\bar{I}(x)=\bar{I}_{0}+\bar{I}_{1} \cos 4 \pi n x\left(\frac{1}{p(x)}-\frac{1}{p}\right),
$$

where

$$
\bar{I}_{0}=2 A_{1}^{2}
$$

and

$$
\bar{I}_{1}=A_{1}^{2} \text {. }
$$

Equation 63 is the equation of the moire pattern produced by the reference and the loaded pattern.

We can write

$$
\frac{1}{p(x)}=\frac{1}{p}+\varphi(x)
$$

where $\varphi(x)$ represents the change of frequency produced by the loading. When

$$
\frac{1}{p(x)}-\frac{1}{p}=\varphi(x)
$$

Eq. 63 becomes

$$
\bar{I}(x)=\bar{I}_{0}+\bar{I}_{1} \cos 2 \pi 2 n \varphi(x) .
$$

Consequently, by the described process, 2n as many fringes are observed as in the fundamental pattern.

E. Experimental Verificationg

\section{Thermal Loading}

A number of holographic setups were tried, and fringe patterns were recorded. 
In the preliminary tests, thermal loadings were used. The twoexposure method was applied. An initial hologram was taken; then the blade was thermally loaded by applying a torch flame to the desired point. Immediately after the heat application, the second exposure was taken. Although good holograms were obtained (see Fig. 10), it was concluded that a mechanical loading would be a more convenient means to detect flaws. To check the actual effect of local heating, the technique described in Sec. B above for inplane displacements was app!ied. Figure 11 shows the pattern of displacements projected on a plane tangent to the upper crown of the blade.

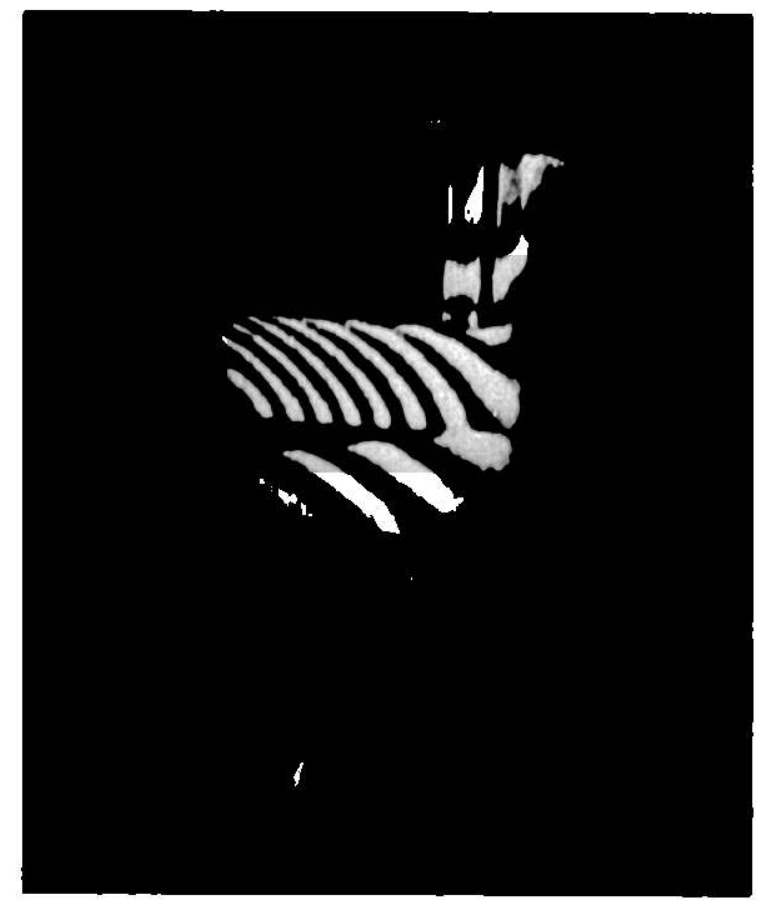

Fig. 10. Blade Subjected to Thermal Loid, Slowing Deflections Produced by lleating the Blade with a Forch. ANL Neg. No. 306-77-499.

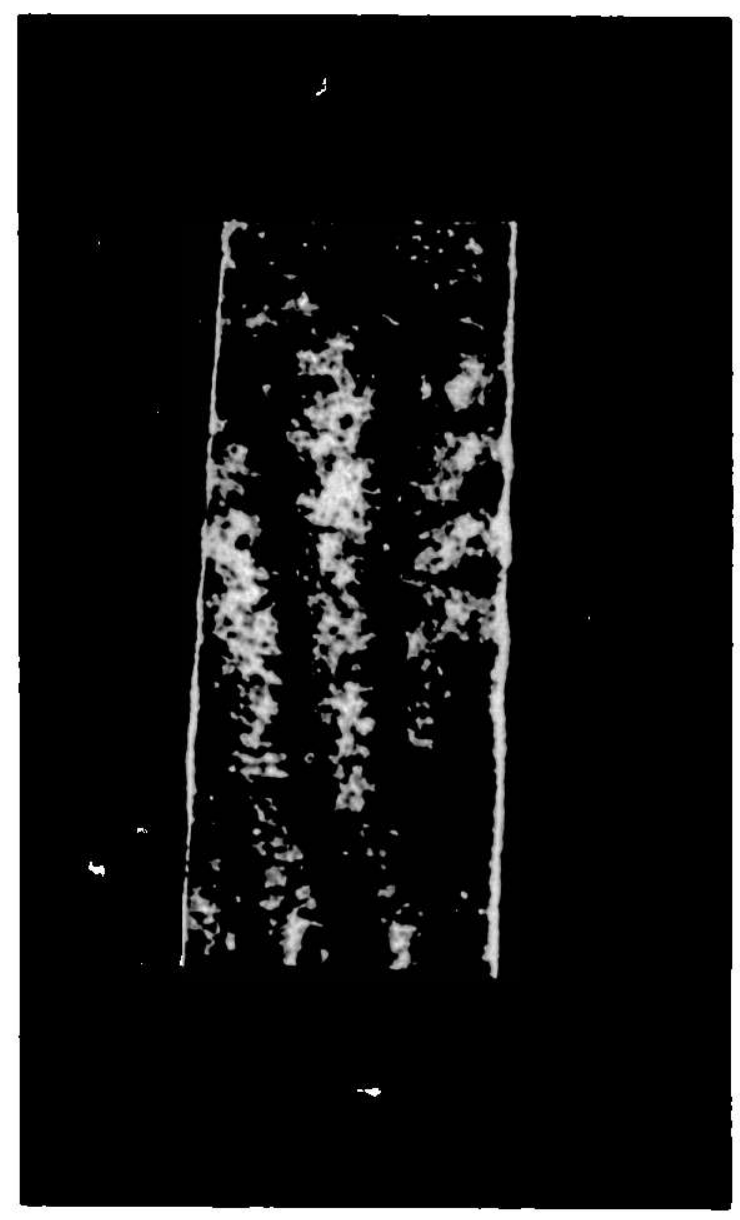

Fig. 11. In-plane bisplacement Pattern for Blade subjected to l'lermal lovad. ANI. Neg. No. 30li-77-500.

From the analysis of the data, it was concluded that the observed fringes correspond to the expansion of the blade due to the applied temperature. At the tip of the blade, near the region where the flame was applied, maximum strains of about $100 \times 10^{-6}$ were observed. The result is logical, since the heat conduction in the blade is very fast and the hologram cannot be taken while the torch is being applied. 


\section{Mechanical Loading}

In the next group of experiments, a mechanical load was applied. Since no blades with sizable cracks were at our disposal, cracks were generated by thermally shocking the blade. The blades were heated with a torch to the point of red glowing, and then water was poured on the heated region. Very tight cracks were obtained. The dye penetrants or microscopic observation did not reveal the presence of a typical crack. However, while cleaning for the application of the dye penetrant, we observed that, during the process of evaporation of the cleaning fluid, an outline of the crack could be observed (see Fig. 12).
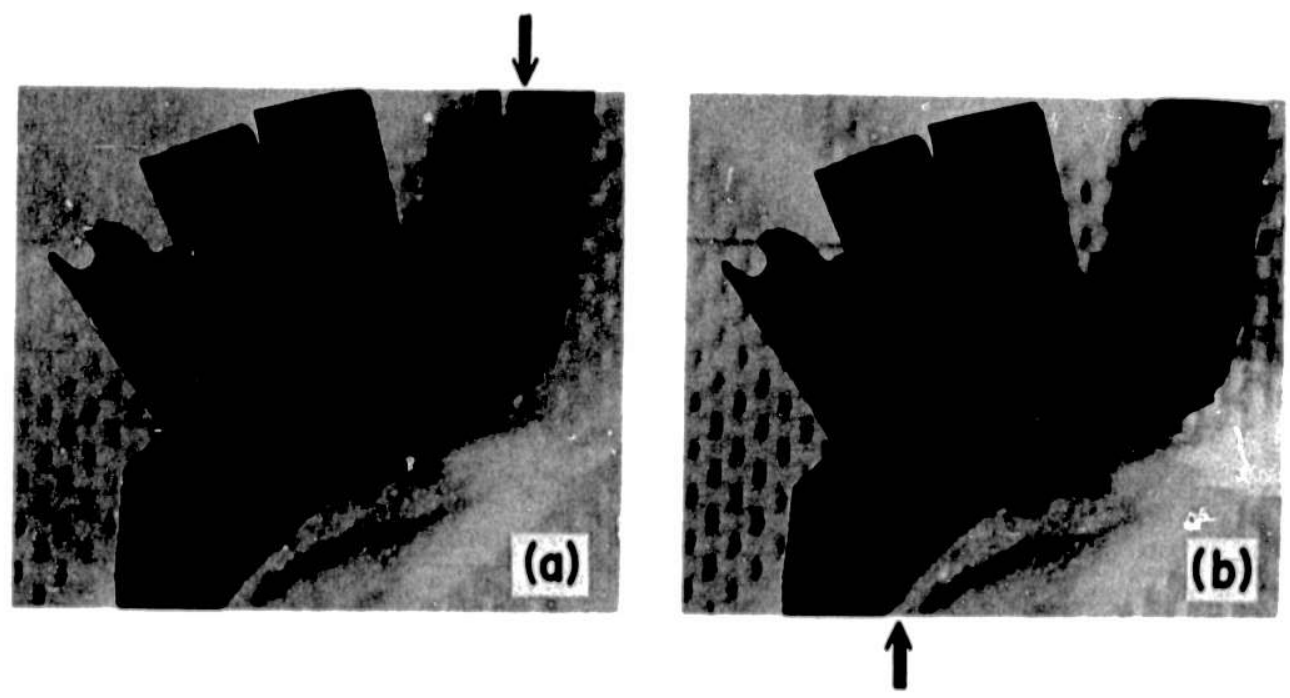

Fig. 12. Crack Detection by Evaporation of a Very Volatile Fluid. (a) Presence of crack indicated by volatile liquid tcchnique and (b) no crack revealed before volatile liquid applied.

The appearance of the crack outline can be explained ivy the fact that, in the region of the crack, some volume of liquid remains while the liquid in the rest of the surface has evaporated.

Figure 13 shows the holographic pattern corresponding to a blade similar to that shown in Fig. 12, but with a crack perpendicular to that indi cated. The blade was loaded with a load perpendicular to the blade plane. The load simultaneously applies bending and torsion to the blade; that is, modes I and III are activated at the crack. Most of the observed fringes are not generated by the applied stresses, but by the rigid body motion of the blade due to the applied load. The presence of the crack can be noticed by a diecontinuity in the fringe patterns.

The pattern was analyzed by plotting fringe orders along the sections indicated in Fig. 13. Figure 14 shows one of the plots. From the deflection curve, it is possible, by assuming that deflection is continuous, to obtain the field of displacements produced by the presence of the crack. Using 
graphical interpolation, we obtained the plot of Fig. 15. The graph shows the profile of the dimple produced by the presence of the crack. The dimple is a combination of modes I and III. We can see that, by the process of interpolation, displacements of the order of $1 / 20$ th of $\lambda$ have been measured.

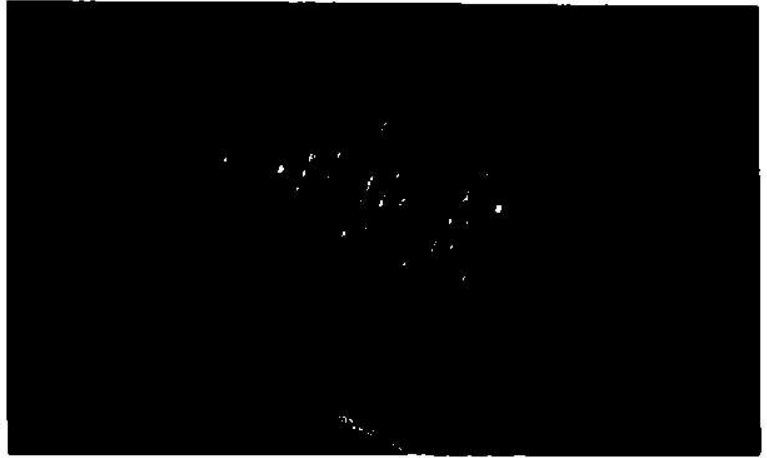

Fig. 13. Pattern of the $w$ Displacement for a Cracked Turbine Blade Loaded Perpendicular to Its Own Plane. ANL Neg. No. 306-77-505.

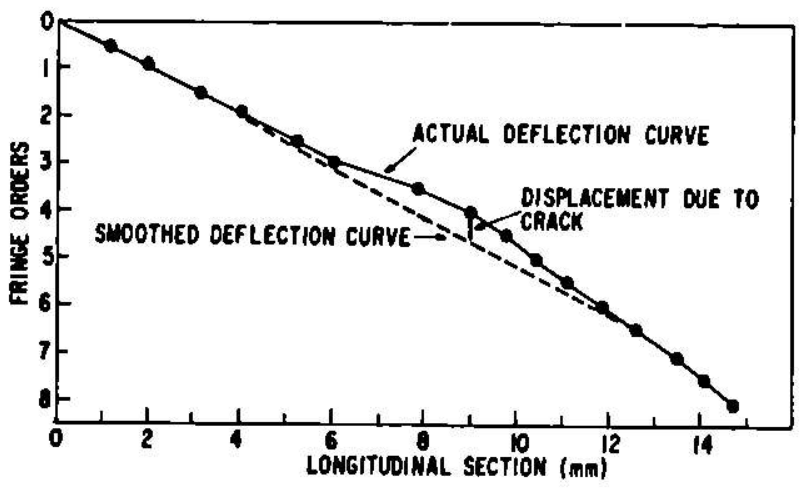

Fig. 14. Plot of Fringe Orders vs Position. By this plot, one obtains the contribution of the displacement field duc to the crack from the overall field.

eaver ancis mires
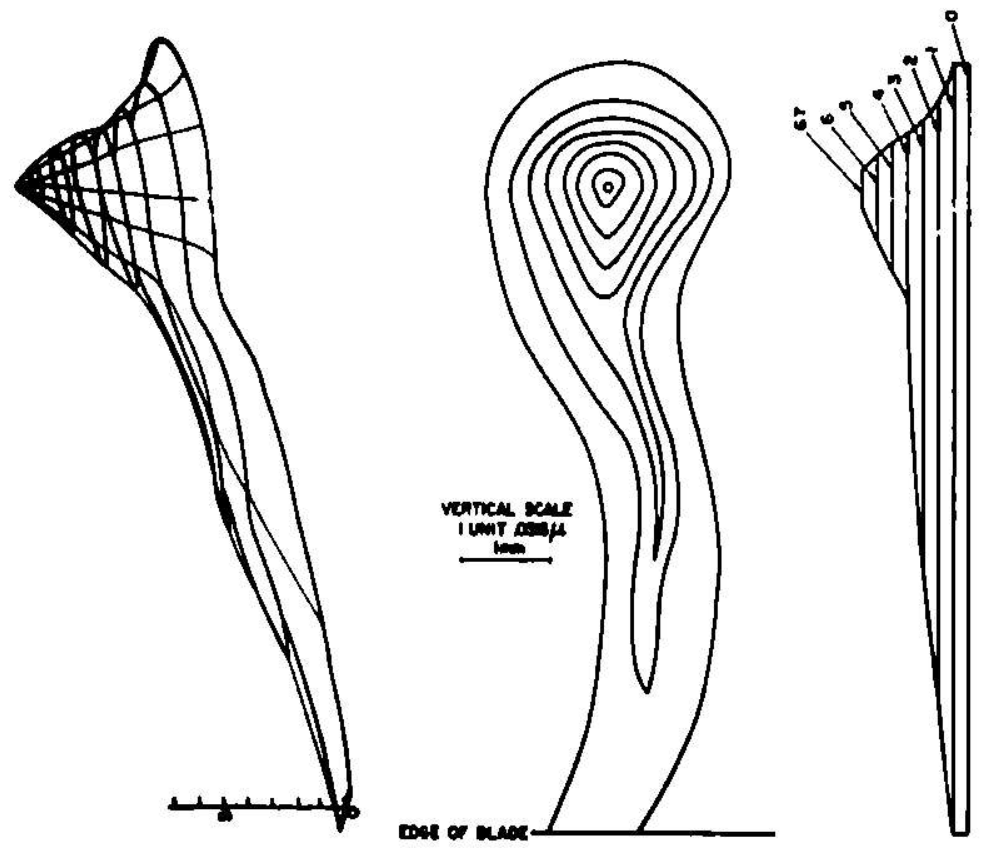

Fig. 15. Proflle of Dimple Produced by Presence of Crack on Blade of Fig. 12. ANL Neg. No. 306-77-494.

To have another comparison of the results obtained in Fig. 16, the theoretical fringe orders corresponding to mode I have been plotted along the line of angular coordinate $\theta=0$. The se theoretical values have been computed by means of the Irwin approximation outlined in Sec. B above to be able to compare the theoretical values with the experimental values, since we 


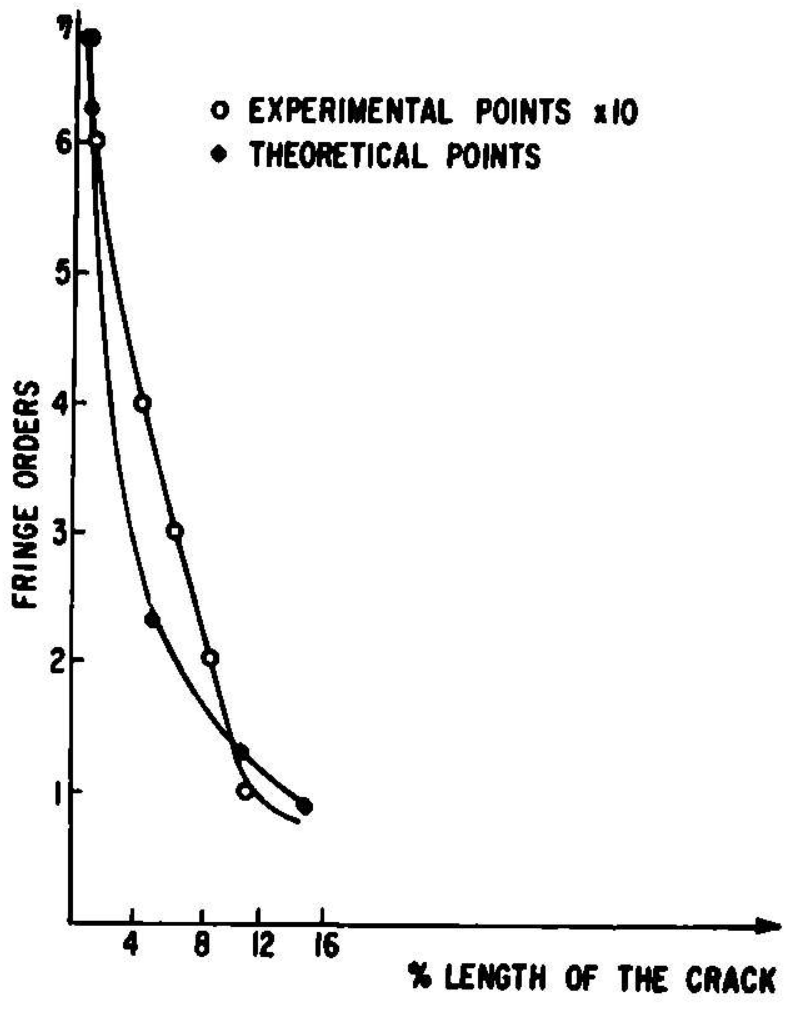

Fig. 16. Plot of Eringe Orders vs Position along Line of Angular Coordinate $\boldsymbol{O}=0$. Theoretical and experimental results. do not know the exact stress distri bution in the blade, only the shape can be considered. For this purpose, the experimental values have been multi plied X10. The two curves show simi lar shapes, indicating that the procedure is accurate enough to give a good picture of the displacement field near the tip of the crack. We can see also that the local changes of shape of the deflection curves indicate the presence of a flaw in the blade.

\section{Detection of Smaller Cracks}

The crack detected in Fig. 13 is $6.8 \mathrm{~mm}$ long. To detect cracks one order of magnitude smaller, we must modify the holographic system. According to the discussion in Sec.II.C, it is necessary to resort to magnification, and the best way is to magnify a real image produced by a reversal of the optical path. Since we wanted to capture the entire turbine rotor, the uptical system of Fig. 17 was used to obtain the hologram. The telecentric system produces a one-to-one image of the object in the vicinity of the holographic plate.

Fig. 17

Holographlc System Used for Obscrvation of Real Images with a Magnlfying System

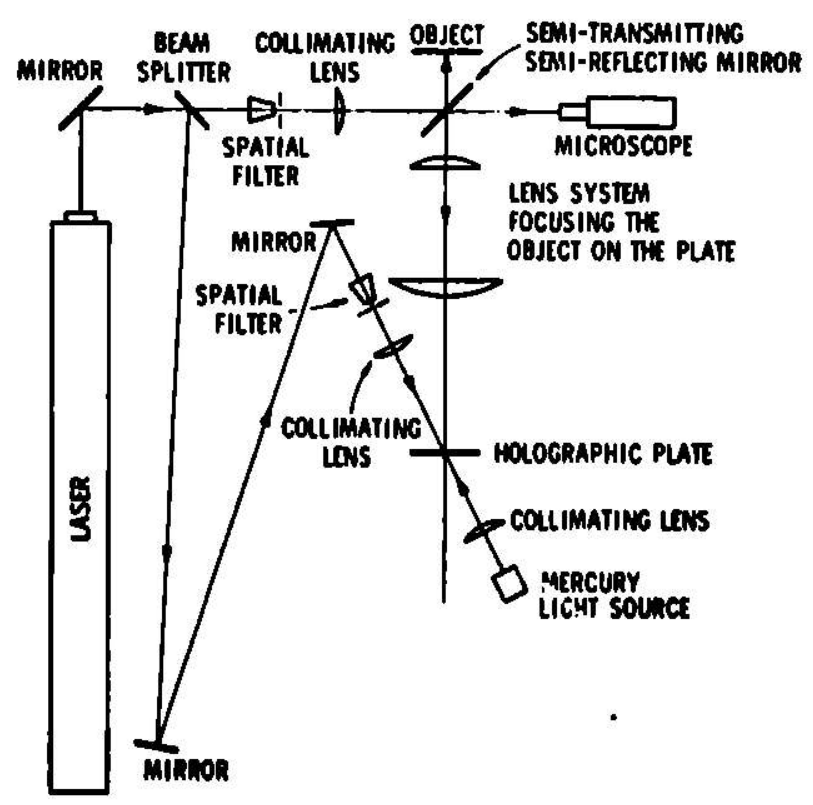


Furthermore, the teleceniric system has the property of yielding a constant magnification within a certain depth. Thus it eliminates the distor tion of the image produced by other lens systems. This distortion is due to the fact that the lateral magnification is the squa re of the transversal magnification.

To observe the effect of a crack in the displacement field produced by the applied loading, we carefully inspected a rotor with blades that had cracks on its roots. The minimum crack size that could be located was a crack $750 \mu \mathrm{m}$ long very close to a blade root.

A picture was taken of the real image reconstructed by reversal of the optical path, in the optical system of Fig. 17, through a magnifying sys tem yielding an X10 magnification. Figure 18 shows the corresponding picture. The presence of the crack is visible by the disturbance of the field of fringes. The fringes are mostly due to the rigid body r.sotion of the blade produced by the overall deformation of the rotor plus the supporting system, when the load is applied. The surface of localization of the fringes is away from the surface of the blade, and due to the effect explained in Sec. II.C, the surfaces of the blade and the fringes cannot be focused simultancously. The result is the lack of resolution of the picture due to poor focusing. However, as shown in Fig. 19, the dimple produced by the crack can be clearly detected from the curves of fringe orders versus position along the region of the crack tip.

The experience gained in the preceding experiments indicates that, as expected from the theoretical analysis, fringe localization is one of the serious obstacles to obtaining high-resolution pictures required for de tecting cracks of one order of magnitude smaller. Furthermore, as it has

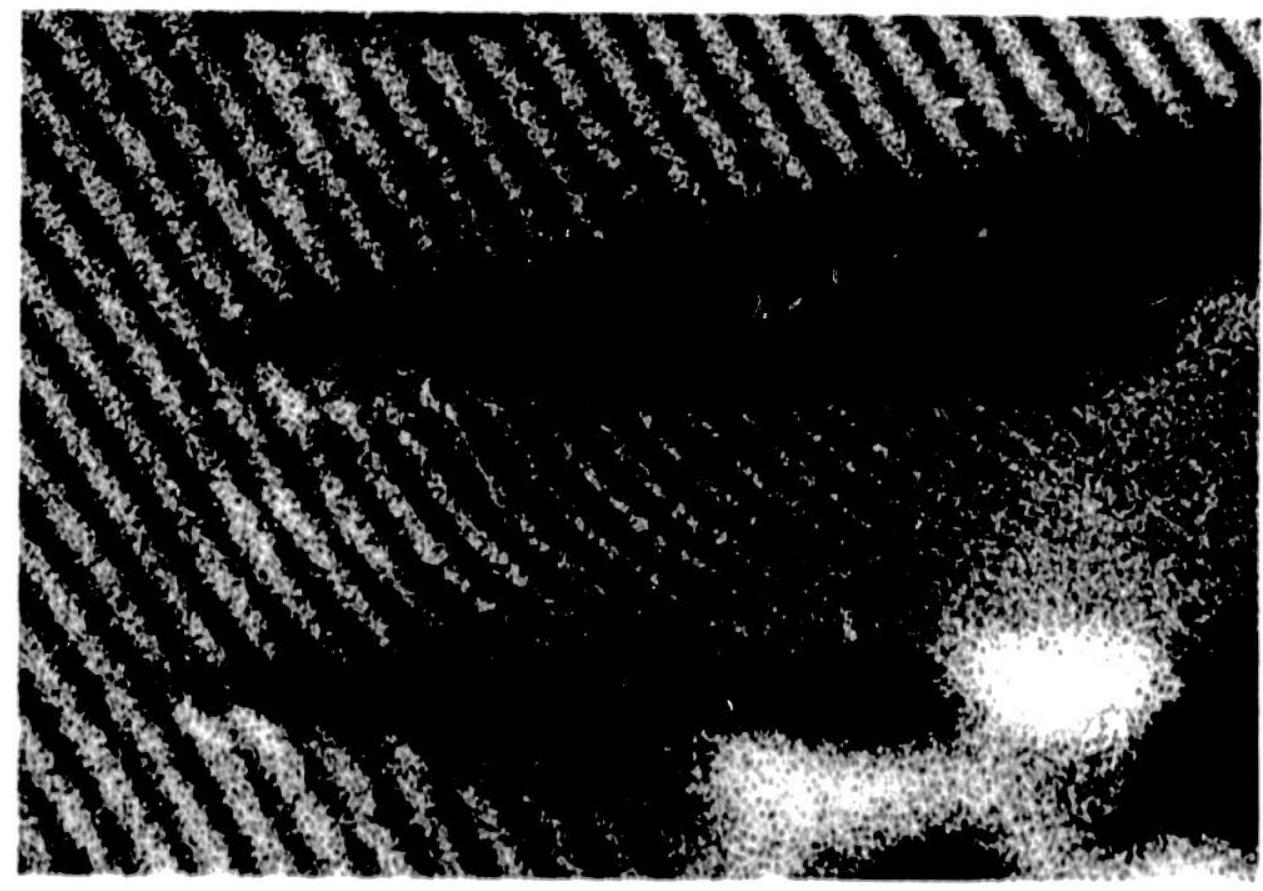

Fig. 18. Lack of Resulution of Holographic Reconstruction When Vlewed with X10 Magnification. ANL Neg. No, 30i-77-491. 


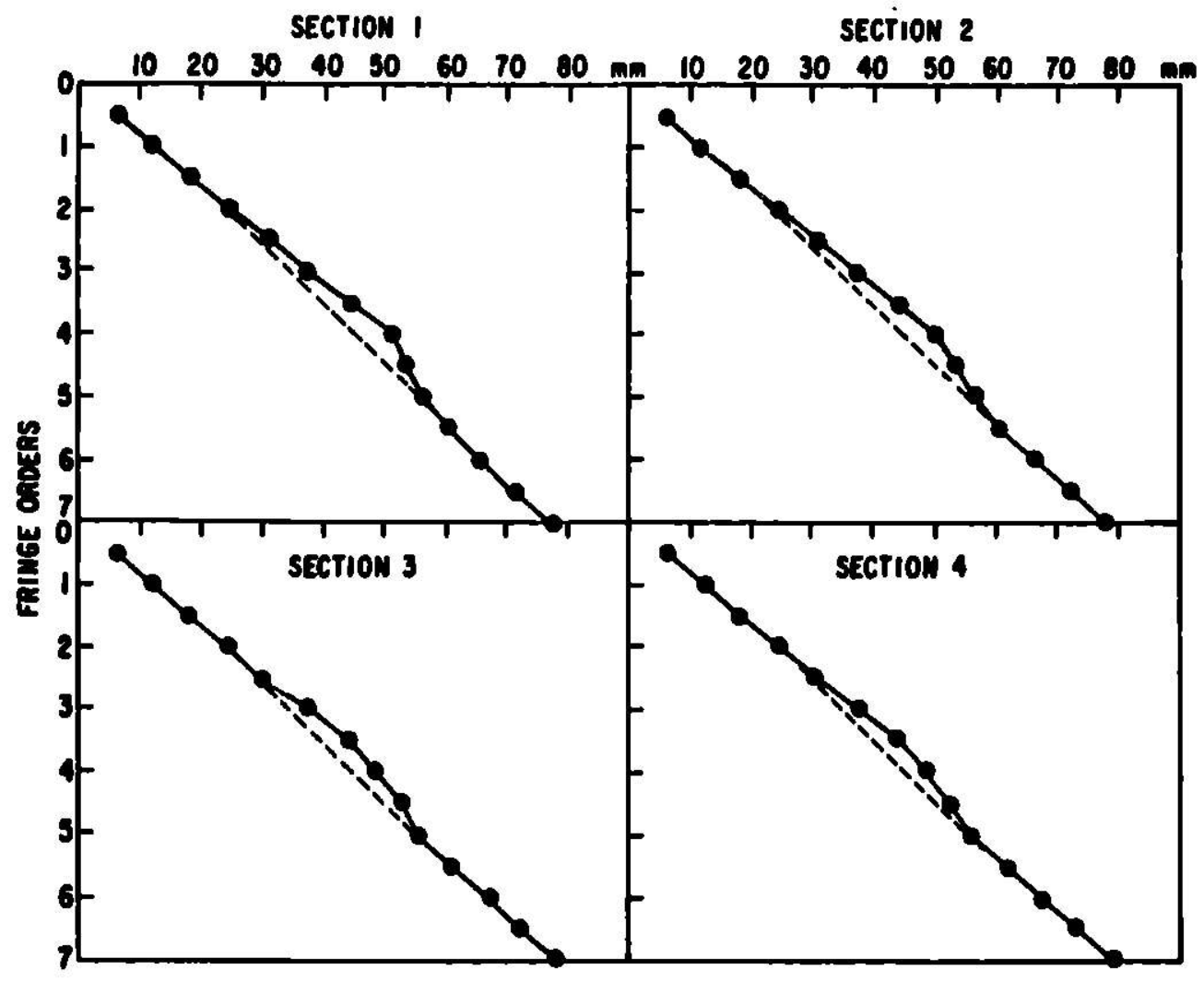

Fig. 19. Plot of Fringe Orders vs Position for Suveral Sections, Showing Presence of Dimple in Region of Rort of Crack

been the experience of previous researchers, the enlargement of the image captured by the hologran helps in the resolution of the obtained images. To check these two points, a new hologram was made with a new fixture to support the turbine rotor.

body motions.

Figure 20 shows the new support designed to minimize the rigid

Figure 21 shows a picture of the blade subjected to bending in its own plane. The rigid body motion has been minimized. A magnification of X20 was used producing a picture with good resolution.

F. Application of Fringe Multiplication; Crack Detection on Components Other than Blacles

Can a crack that is not in the observed surface be detected? To answer this question, a different test was porformed. A circular plate with a crack along a diameter was tested, as shown in Fig. 22. The crack was originated by the local effoct of the concentrated load, and the crack remained within the compression region of the plate. The condilions of this crack are different from those reviewed in Sec. II.B.1, since the loading is directly applied to the crack, whlle in the analysis presented in Soc. II.B.1, the load is alwaya romotely located with respect to the crack. 


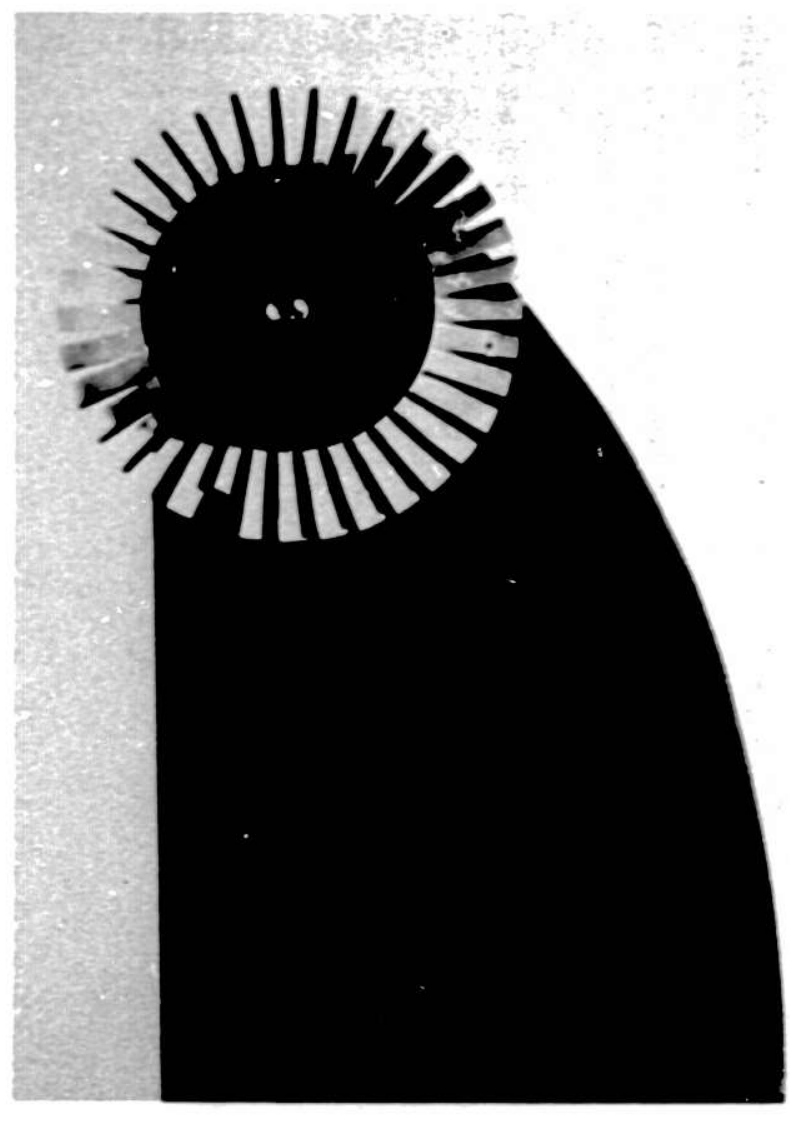

Fig. 20. Fixture for Testing Turbine Rotor

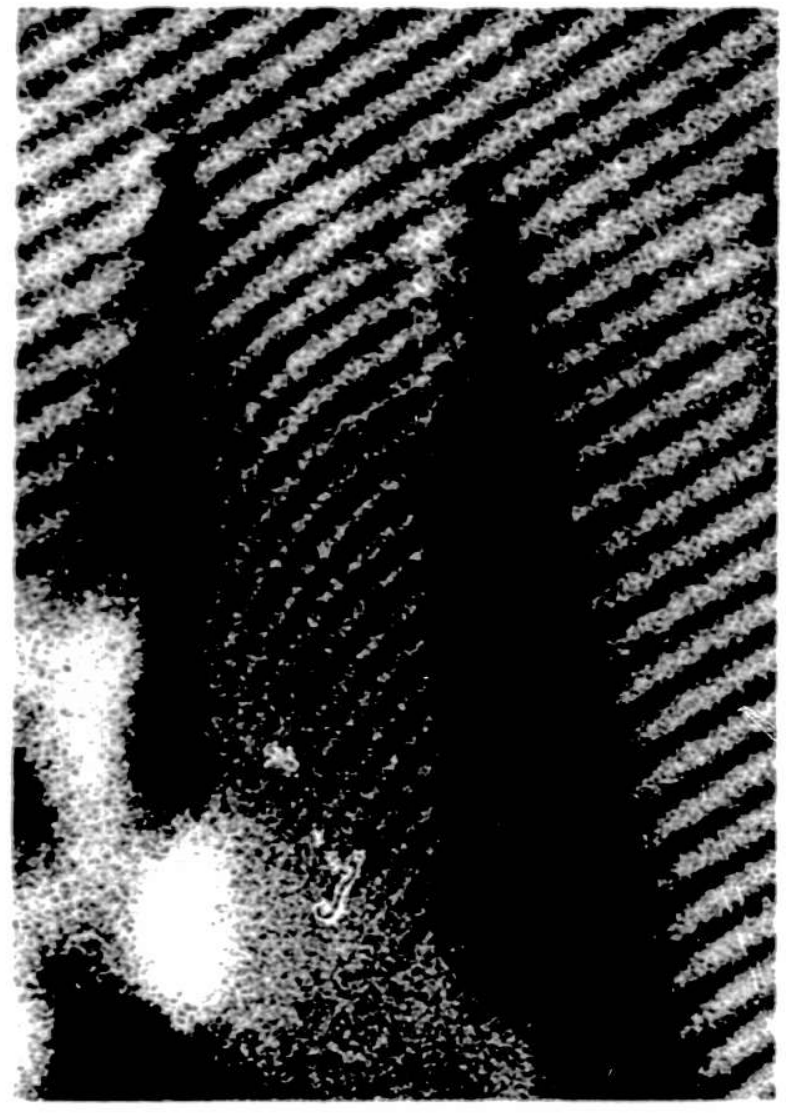

Fig. 21. Picture of Blade Loaded in Bending in Its Own Plane. Improved resolution. ANL Neg. No. 306-77-491.
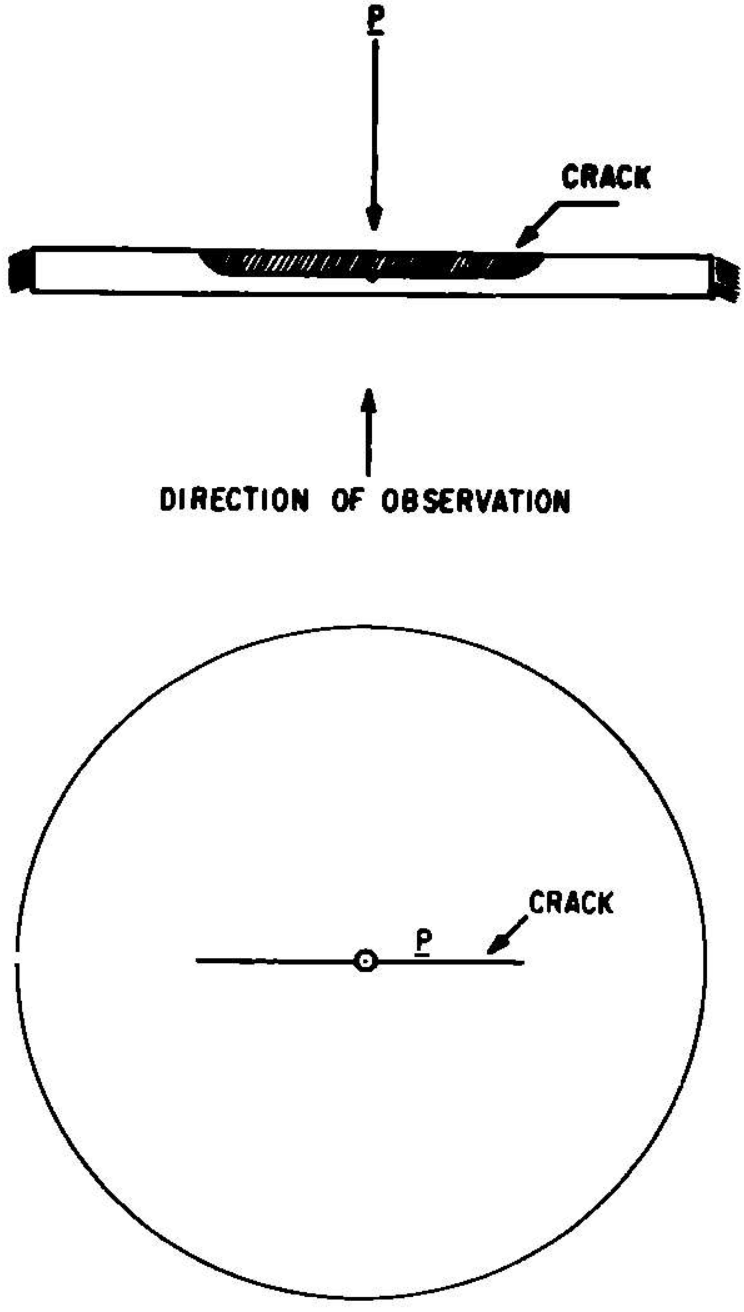

Fig. 22. Circular Plate Loaded with Concentrated Load 
In Fig. 23, we can see the deflections of the central region of the plate. Multiplications up to X8 have becn obtained. The presence of the crack is clearly seen as an edge where the deflection fringes show a discontinuity. Figure 23 shows that the multiplication of fringes is feasible and that the detection of cracks away from the observed surface is also possible, through discontinuities or other features that the presence of a flaw will produce in the fringes.

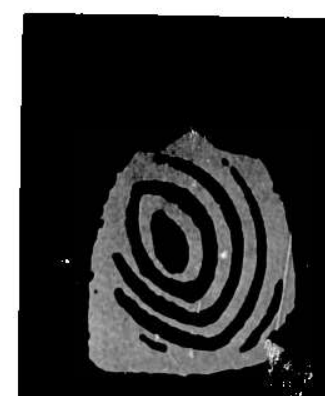

Xi

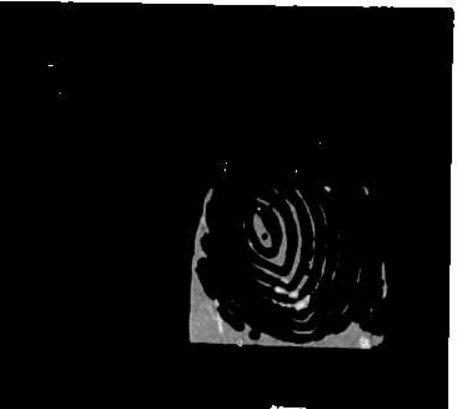

(6)

Fig. 23

Successive Multiplications of Pattern Corresponding to Deflection of Central Reyion of a Circular Plate Loaded with a Concentrated Load. The crack in the compress!on face shows as a discontinulty in the fringe pattern. ANL Neg. No. 306-77-504.

\section{G. Summary and Conclusions}

Several fundamental contributions to the area of flaw detection in NDT have been made in the present program.

1. The basis of flaw detections from the point of view of the stress fields prevailing in the neighborhood of a crack has been established.

2. The necessary requi rements for the optical system needed for the detection of cracks of about 100 um have been established.

3. A process has been developed for increasing the sensitivity of holographic interferometry.

4. The feasibility of crack detection in turbine blades has been illustrated.

The analysis of Figs, 13 and 18 indicates that the possibility of crack detection is enhanced by the presence of holographic fringes produced by the 
applied load on the part under analysis. In general, the pattern due to the presence of the crack will not be isolatedly observed, but will be mixed together with the displacement field of the part under observation. The field of the crack appears as a perturbation, and this leads to the technique shown in Figs. 14 and 19. With the interpolation technique applied in Figs 14 and 19, displacements of the order of $1 / 20$ th of $\lambda$ have been obtained At the same time, the presence of fringes in the field provides further reference points as far as the location of the flaw is concerned. To understand clearly the meaning of this statement, we have to go back to Fig. 4. The high orders generated by the presence of the crack are crowded together near the crack tip. The orders larger than one are inside a region that is about $12 \%$ of crack length.

For example, for the 750-um crack of Fig. 18, the region of orders greater than 1 is about $90 \mathrm{\mu m}$. With magnification of $\times 10$, this region is smaller than $1 \mathrm{~mm}$. However, due to the presence of the field of fringes, this region becomes easily detectable. That $i s$, not only has the sensitivity been enhanced in the detection of fringe orders, but a greater resolution can be obtained in the point location. This indicates that, to detect small flaws, the magnification required is less than the ones that one could assume as necessary on the basis of the isolated crack field.

The introduction of real images makes it feasible to use some advanced forms of observation that can greatly facilitate the visual inspection of patterns. The enlarging system can be placed on a traveling carriage, and the reconstructed real image can be projected onto a vidicon tube in a closed-circuit video system. The closed-circuit video system will permit additional magnification and an increase in brightness without a 1088 of contrast.

For example, X20 magnification can be given to the readout optical instrument, and $X 5$ to the video system, very easily reaching $X 100$ overall magnification. Zoom systems can be i.zcluded in both the optical system and the closed-video system. In this way, different ranges of magnification can be used to easily inspect the different parts of the turbine rotor and then to get closeups of those regions that need close inspection.

The most important factor in the quality of the fringe patterns, the phenomenon of fringe location, can be controlled by applying apecial techniques.

The application of holography to ceramic parts is not limited to the detection of flaws. By thermal expansion of the analyzed component, local inhomogendities can be determined. Another way to analyze the overall quality is to apply vibratione and observe the configuration of the vibration pattern. By comparison of high -quallty blades with blades containing defects, it may be feasible to obtain a vieual picture of the overall quality of the blade. High frequencles of vibra Hon, together with high fringe multipllcation and magnification, may make it feasi ble to obtain a high-resolution local description of the reglon under obeervation. The amplitudes of vibration of the different arese will reflect the local densities of the meterial. Thus, patterne of fringes may ohow the presence of volde and local inhomogenelties. 


\section{ACOUSTIC MICROSCOPY}

A. Experimental Procedure

The scanning laser acoustic microscope may provide a means for nondestructive evaluation of ceramic gas-turbine rotors. This preliminary effort concentrated on the characterization of turbine blades removed from blade rings as revealed through acoustic microscopy. This included empirically defining the normal structure, determining abnormal microstructures, and localizing specific defects.

Sonic microscopy uses elastic waves (acoustic) as means for producing images of internal structure in materials. Traditional methods for characterizing microstructure use a variety of instruments and techniques, such as optical and electron microscopy and X-microradiography. The common denominator of these methods is that the images are produced by interacting electromagnetic radiation with the specimen. In contrast, the acoustic microscope is an jmaging system based upon acoustic rather than electromagnetic waves. Thus, variations in the elastic properties are primarily responsible for structure visualized in acoustic micrographs.

The instrument used in these investigations is the Sonomicroscope 100 , which is operated at an ultrasonic frequency of about $100 \mathrm{MHz}$ (see Fig. 24).

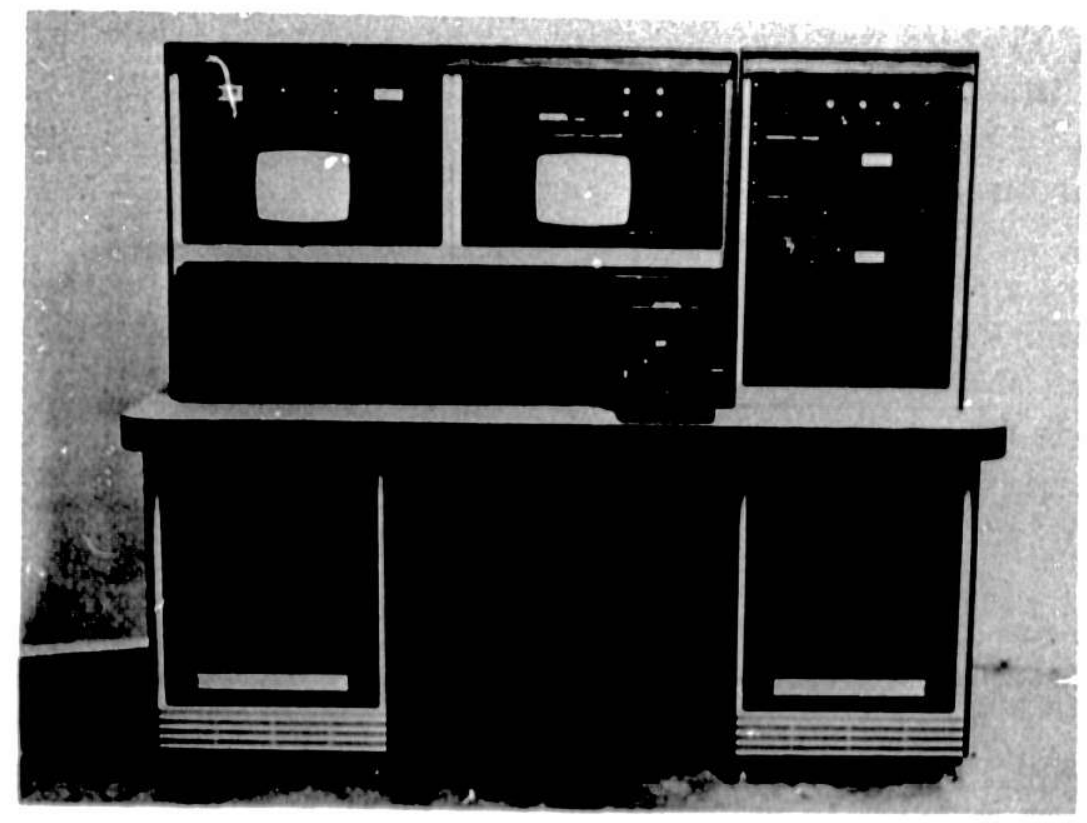

Fig. 24. Sonoscan 100 Acoustir Microscope. ANL Neg. No. 30G-77-489.

The ir radiation geometry used to produce the acoustic micrographs of samples studiel in this work is illustrated in Fig. 25. Ultrasonic energy is incident on the ample from below, at an angle of $10^{\circ}$. The transmitted acoustic energy imparts a slight oscillatory mechanical motion to the top surface of the 


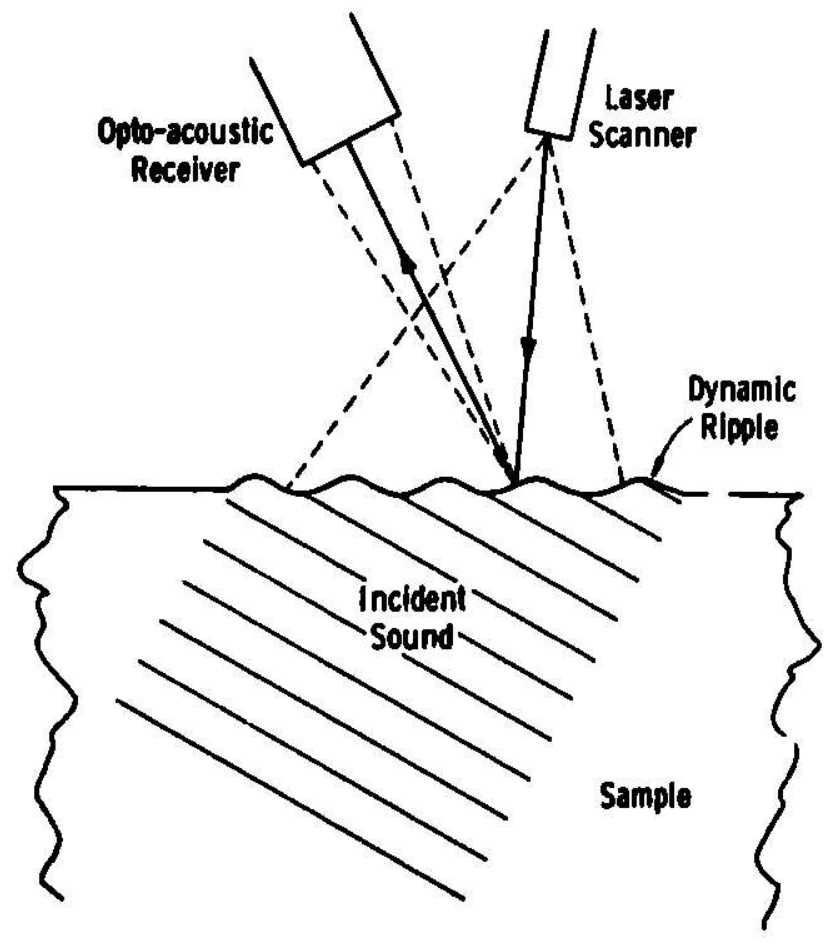

Fig. 25. Schematic Diagram Illustrating Detcction Scheme Used by Scanning Laser Acoustic Microscupc (SLAM) sample. These oscillations have the same frequency as the incident wave, but vary in amplitude depending on the acoustic attenuation and absorption properties of the underlying material. These disturbances are detected, point by point, by a rapidly scanning focused laser bean 140,000 image points per micrograph), which drives an opto-acoustic receiver. The acoustic image is then displayed on the TV monitor. Here the white regions correspond to areas of the sample with good acoustic-transmission properties, while the darker areas of the micrographs are regions of higher ultrasonic attenuation. If the sample has a good surface finish, an acoustic image can be obtained from the light specularly reflected directly from the surface. For SN blades, this is not the case. A mirrored coverslip is placed in acoustic contact with the top surface of the sample, and light reflected from the coverslip is used to form the acoustic imagc.

The acoustic energy is coupled to the sample through the acousticmicroscope stage. A glass cell, shown in Fig. 26a, is used. The transducer

Flg. 20

Scandard Stage Cells. (a) Glass cell and (b) llquld cell.

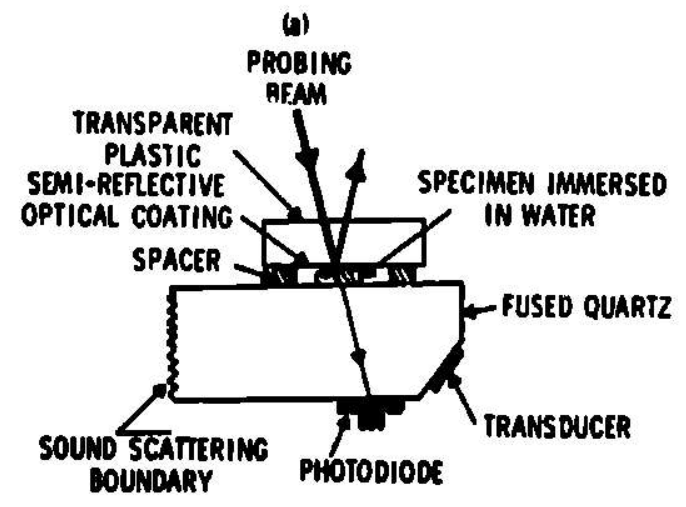

(b)

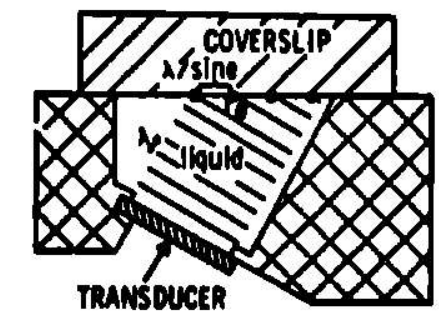


is bonded to a glass block, which transports the acoustic energy from the transducer to the sample. The liquid cell is shown in Fig. 26b. Here sound is conducted from the transducer to the sample by a liquid that fills the chamber. Microscope stages designed to moet specific needs, such as reflection-mode imaging, larger fields of view, and different sonification angle can also be fabricated. Figure 27 shows a schematic diagram of the entire system.

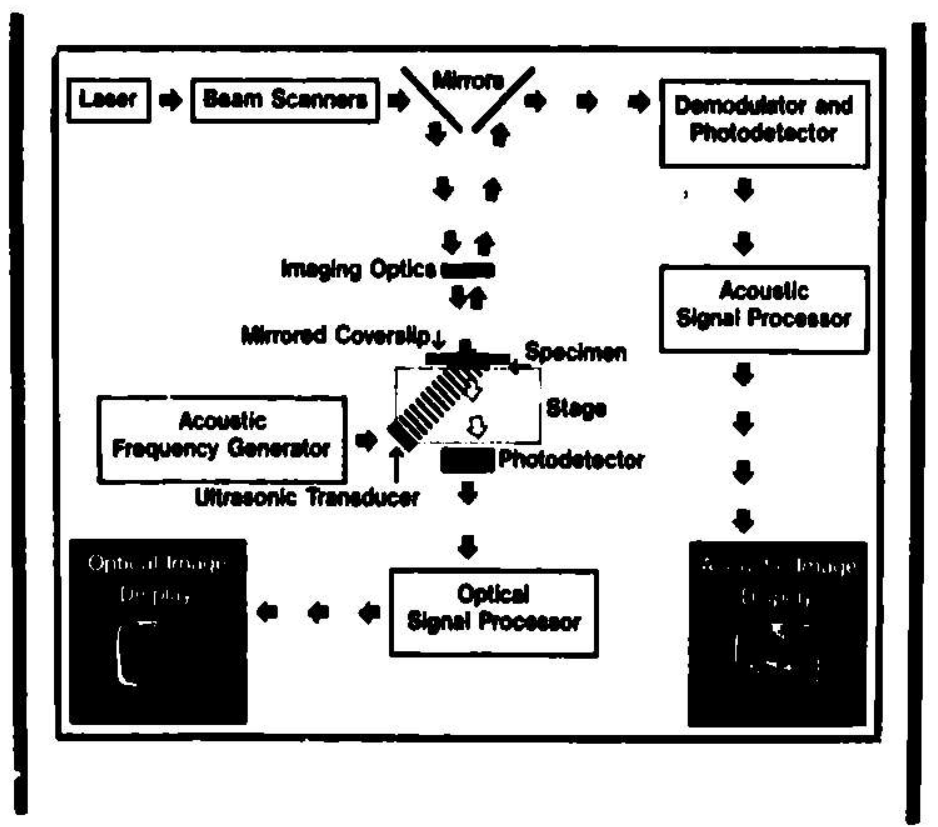

Fig. 27. Schematic Diagram of Acuustic Microscope stage. ANI. Neg. No. :306-77-498.

Data are presented in the form of photomicrographs.

There are two types of acoustic amplitude pictures. First are amplitude pictures made at a single ultrasonic frequency. These acoustic micrographs are generally characterized by a substantial amount of contrast and are often subject to coherent speckle. The amount of speckle is related to the degree of scattering in the specimen and provides some indication of both the mode of acoustic loss and the elastic microstructure of the material under investigation. The second type of amplitude picture is obtained by sweeping the frequency over a variable bandwidth around $100 \mathrm{MHz}$. This eliminates coherent speckle and reveals features often masked by the specklc. In this report, the singlefrequency amplitude pictures are designated by the abbreviation $A$; the frequency-modulation amplitude micrographs are designated by Am.

In addition to displaying the acoustic amplitude distribution throughout the field of view, the Sonomicroscope provides an acoustic interference mode of operation. Acoustic interferograms show a serics of alternating light and dark stripes. For acoustically homogencous samples, these bands (interference fringes) are parallel to one another and are equally spaced. For samples that 
are elastically inhomogeneous, the interference lines are distorted by localized variations in the sound velocity and/or sample thickness. All the interferograms included in this report are designated with the abbreviation 1 , and are oriented so that a fringe shift to the left corresponds to an area of lower ultrasonic velocity and shifts to the right indicate regions of higher sonic velocity. Because many of the samples investigated have controlled thicknesses, the character of the interferograms is determined solely by localized variations in the velocity of sound. These variations are related to either variations in the bulk density or elastic modulus of the sample constituents.

The switching to any of the visualization modes is accomplished electronically. Thus, no repositioning of the sample is required.

This study of reaction-sintered $\mathrm{Si}_{3} \mathrm{~N}_{4}$ gas turbines involved the investigation of 10 blades after being removed from blade rings.

A first step toward localization and identification of important defects is to establish a definition of the normal structure. This was accomplished cmpirically in this study where the "normal" structure is operationally defined as that which appears most often in actual rotor material. There are advantages of working directly with the "real" turbines. First, the data obtained are directly applicable to the nondestructive testing of the intact blades. Second. the elastic properties may depend on the details of the fabricetion process; thus, duplication of the microstructure observed in the blades may be difficult in test specimens with simple geometries. By analyzing the blades directly, we study the properties of materials that have been part of the manufacturing cycle. Lastly, difficulties encountered in testing a blade with its complex geometry provide insight into the fixtures required for the nordestructive testing of the entire turbine.
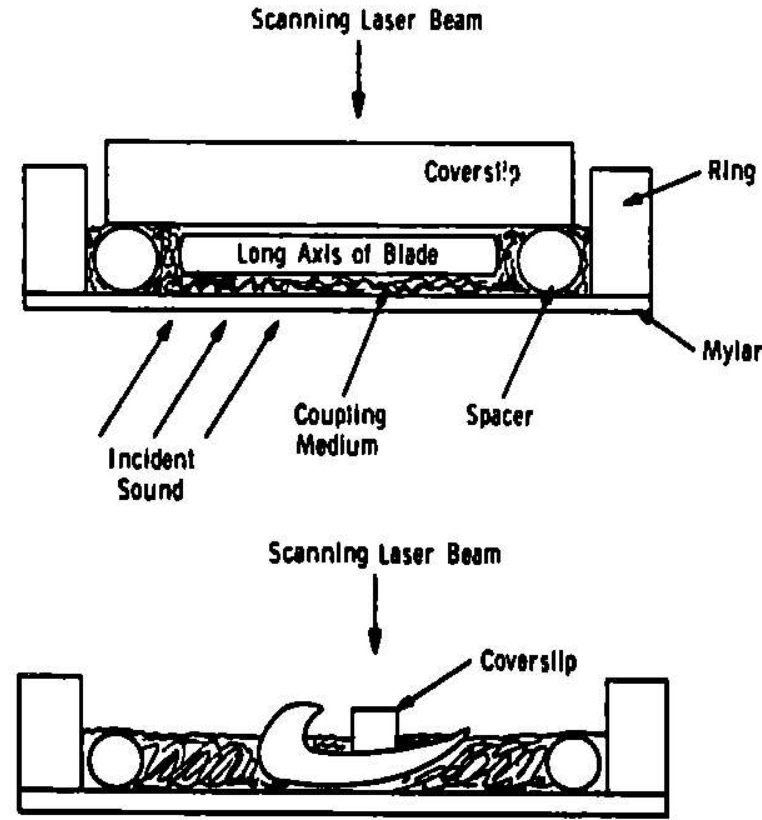

Fig. 28. Schematle Dlagram of Sample Configuration
B. Results

1. Sample Preparation and Scanning Procedure

Analysis has been carried out on 10 ceramic gas-turbine blades which were removed from a ring by applying static pressure. Although no modification of the Sonomicroscope 100 was required for this study, a scanning procedurc was developed that permitted the rapid and systematic scan of a number of blades. This procedure is outlined bricfly below.

Two orthogonal views of the sample configuration are shown in Fig. 28. The blades were placed in a 
sample holder which consisted of a stainless steel ring $[2 \mathrm{in.}(50 \mathrm{~mm})$ in

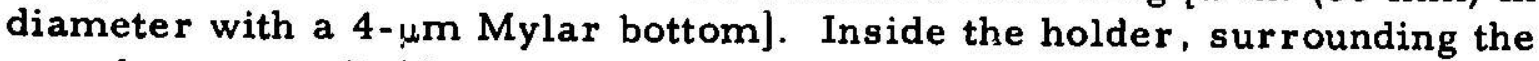
sample, was a pliable spacer ring. The coupling medium, water, filled the holder to the level of the spacer ring. The coverslip was placed in close contact with the sample and was such that it rested on the spacer ring. The coverslips fabricated for this study were 2 in. ( $50 \mathrm{~mm}$ ) long and about $3 \mathrm{~mm}$ wide. The length was such that the coverslip rested on the spacer ring, which was pliable. Thus, it could be pressed firmly in contact with the top surface of the blade (Fig. 28a). The width of the coverslip ( $3 \mathrm{~mm}$ ) was made thinner than normal so that the contact with the sample was nearly planar (see Fig. $28 \mathrm{~b}$ ).

The blades were scanned by first placing the coverslip in one position and translating the sample holder parallel to the long axis of the blade (to the left in Fig. 28a). After each long axis scan, the coverslip was indexed (e.g., moved to the left in Fig. 28b), and another longitudinal scan was made.

\section{Documentation}

All blades analyzed in this study came from blade ring 3261 and are labeled numerically on the convex surface. Of the 10 blades scanned, specific areas of six different blades were photodocumented and the mic rographs are presented in this report. (See Figs. 29-42.)
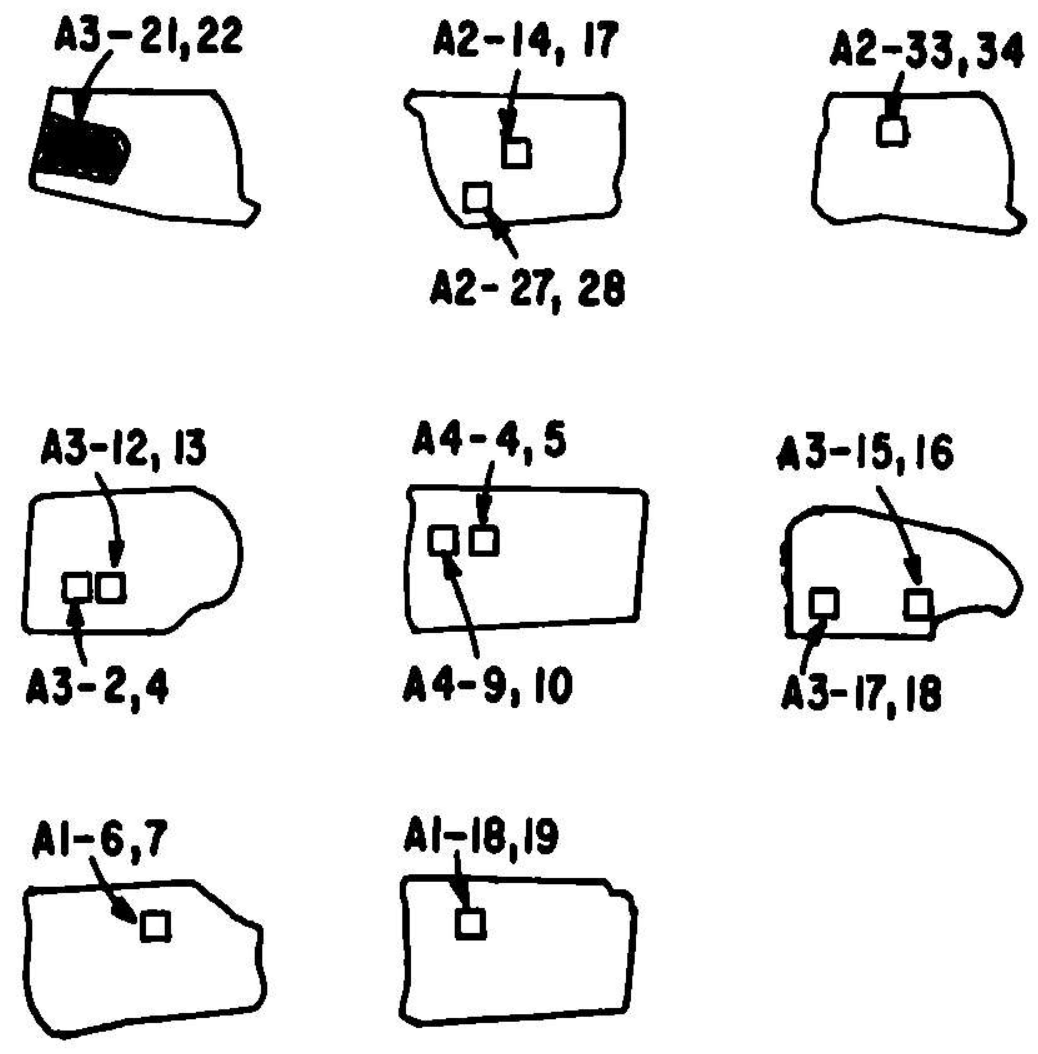

Fig. 29. Schematic Dlagram of Blades Examined. Areas shown represent Figs, 30 and 31-42. 


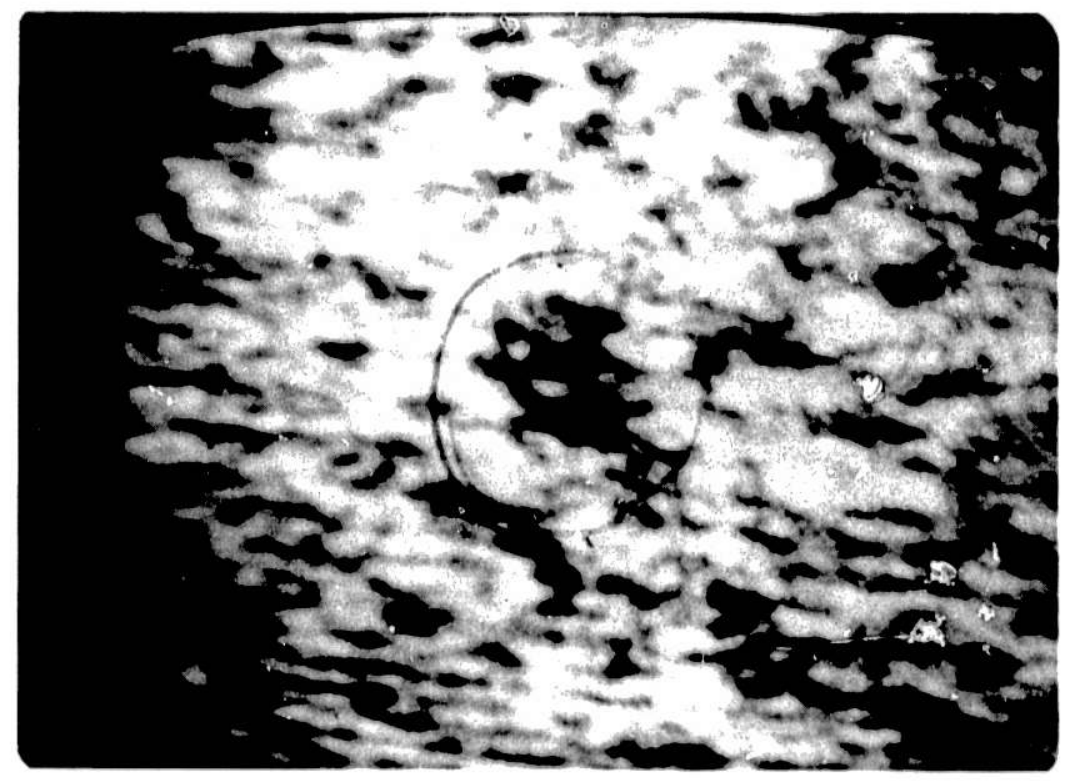

A3-21

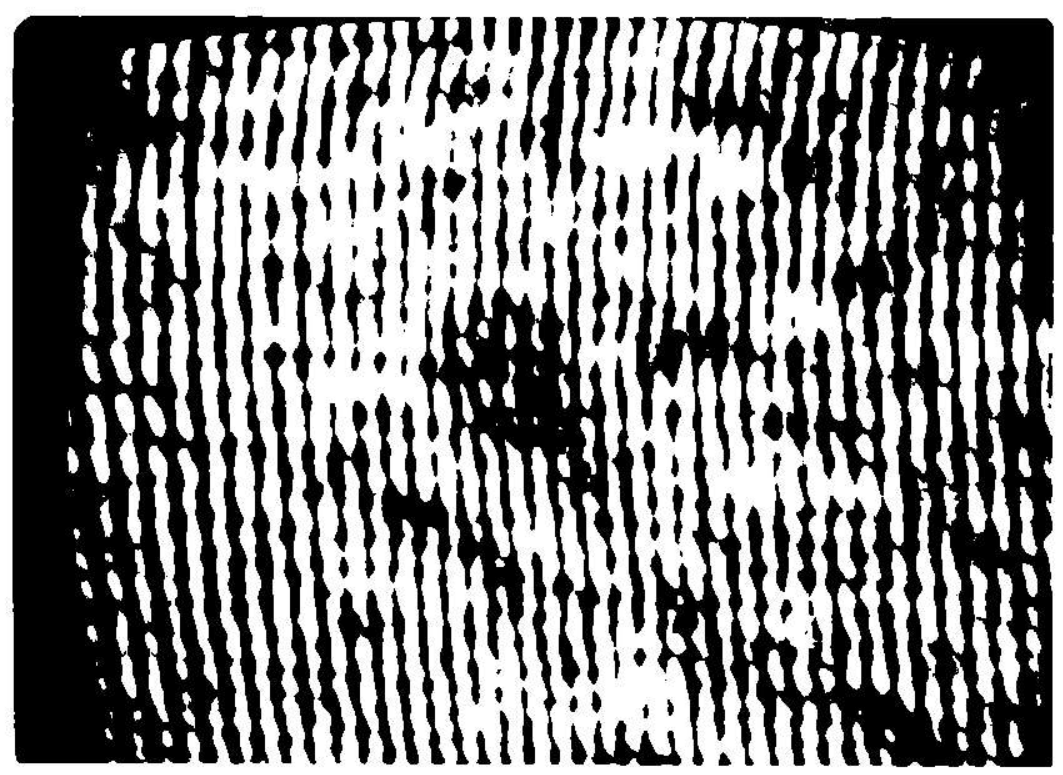

A.3-22

Fig. 30. Am and I of Defect (iluster (eireled) (Olserved in Flatter Portions of Blade 28. The elastic microstructure surrounding the cireled region is typical of that encountered throughout most of the blacle. The exact location of these micrographs is uncertain, but is within the hatched lxoundaries marked on the blade. 

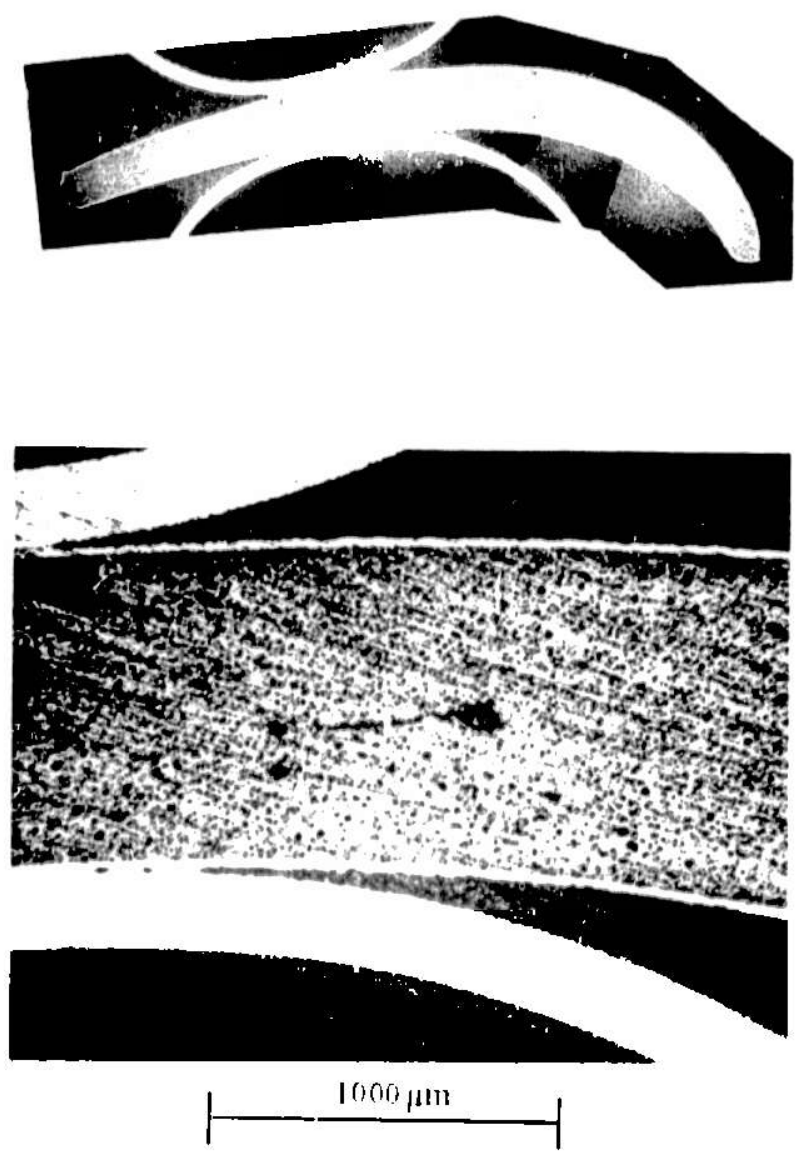

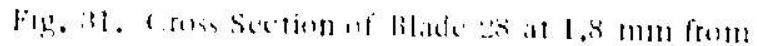

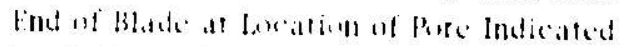
by Rabluteraly) and in cienctal Regton al

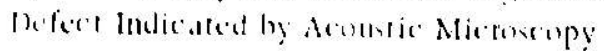



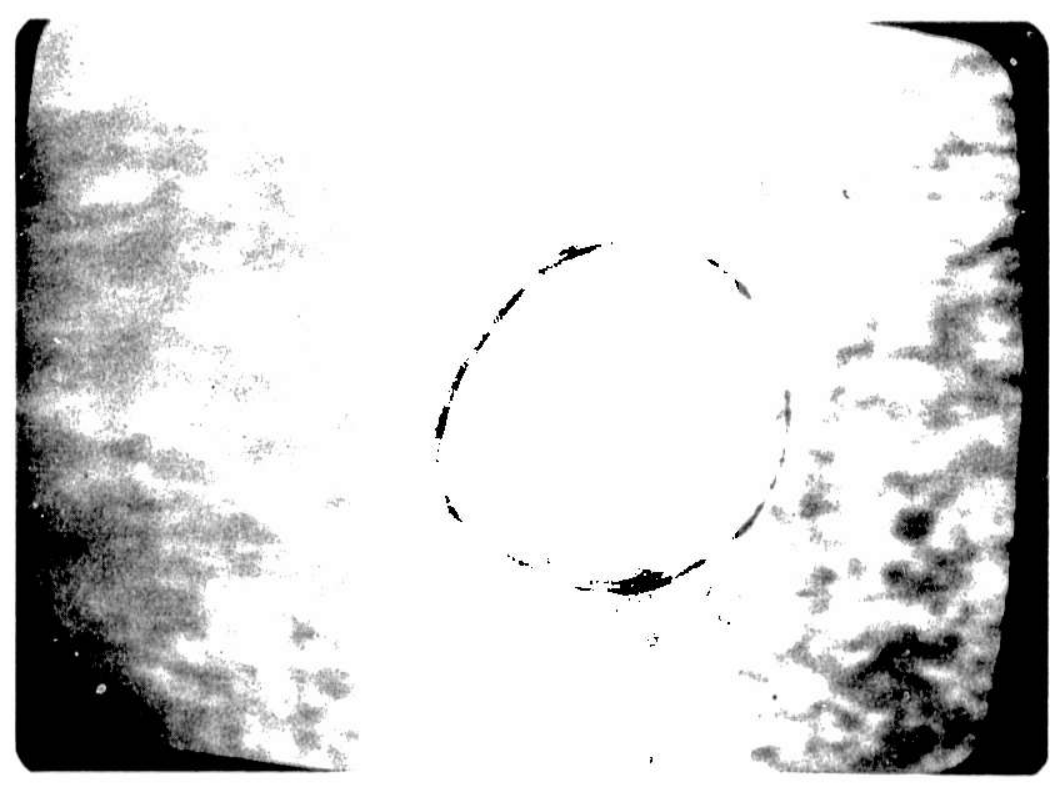

$\therefore-17$

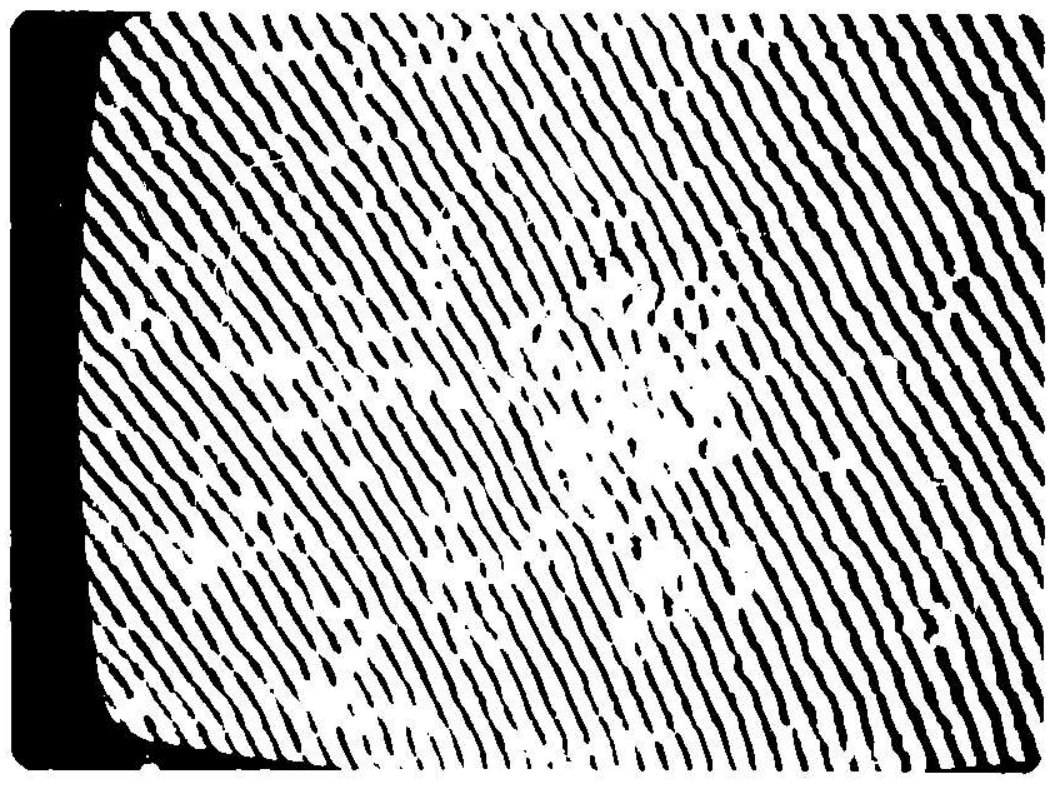

$$
\therefore-1 \cdot 1
$$

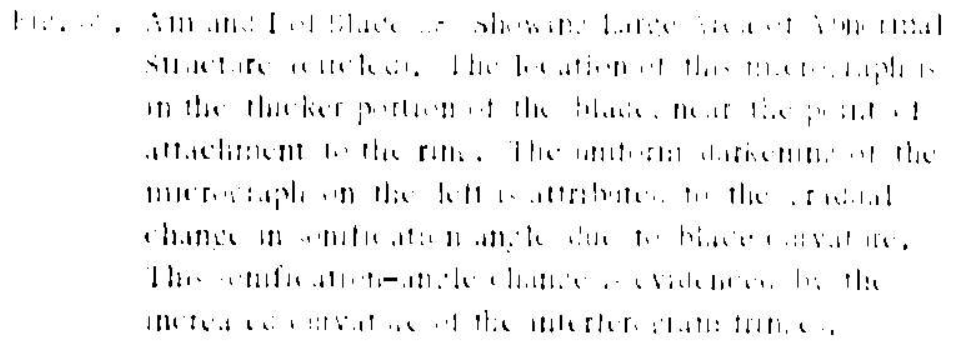



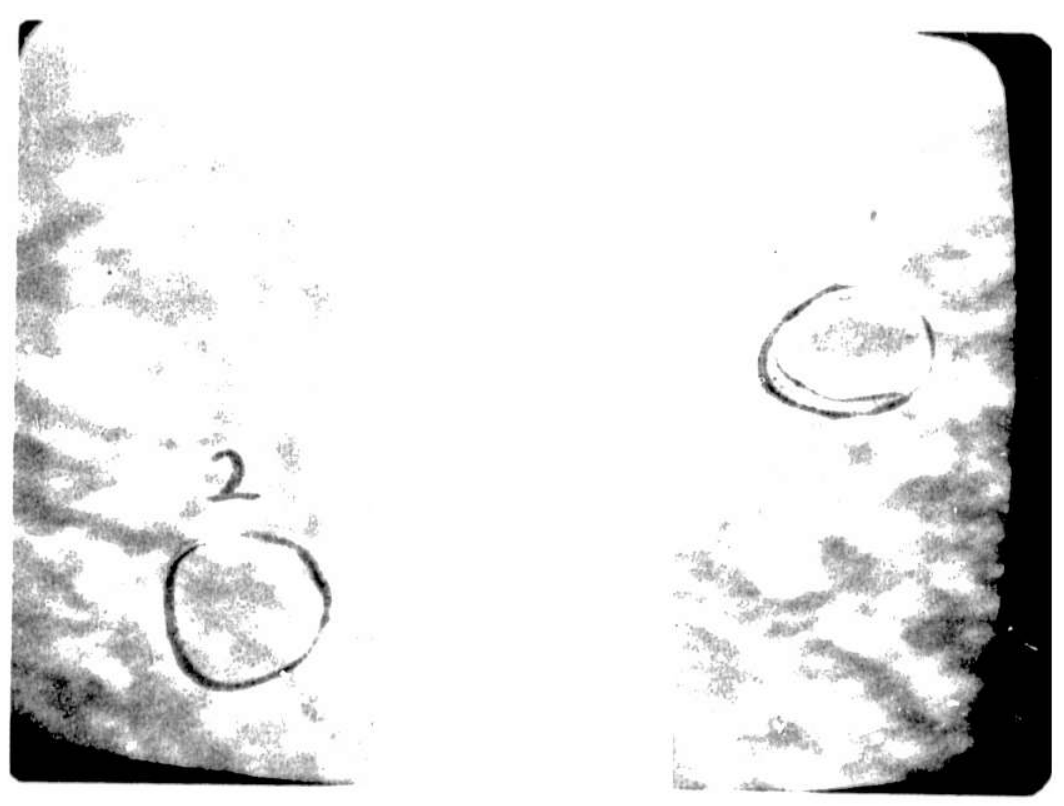

$A:-27$

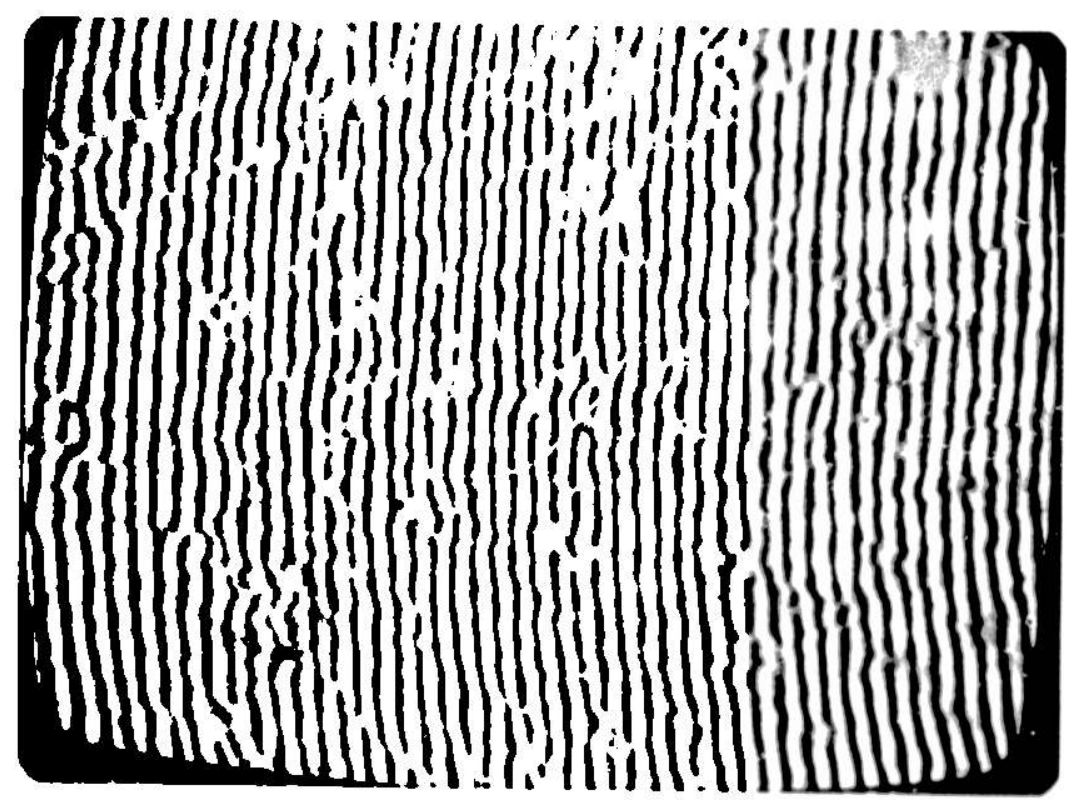

A2-28

Fig. 33. Am and I obtained on ciervedmest partion of Blade: 2 . The overall attenuation is greitter than that sen in the thinner

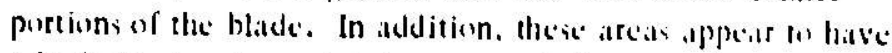
a highter percentitge of darker areats, ind'icattive of a licatized increase in porosity conecentration. Twe typers of acomstically dark areas con be seen. Areal, where the interferenes lines vary amoothly, maly correspond to large suburfice voisl. In area :- the interferogram line's are jaghesed, which maly be indicative of a high concentration of small vords. 

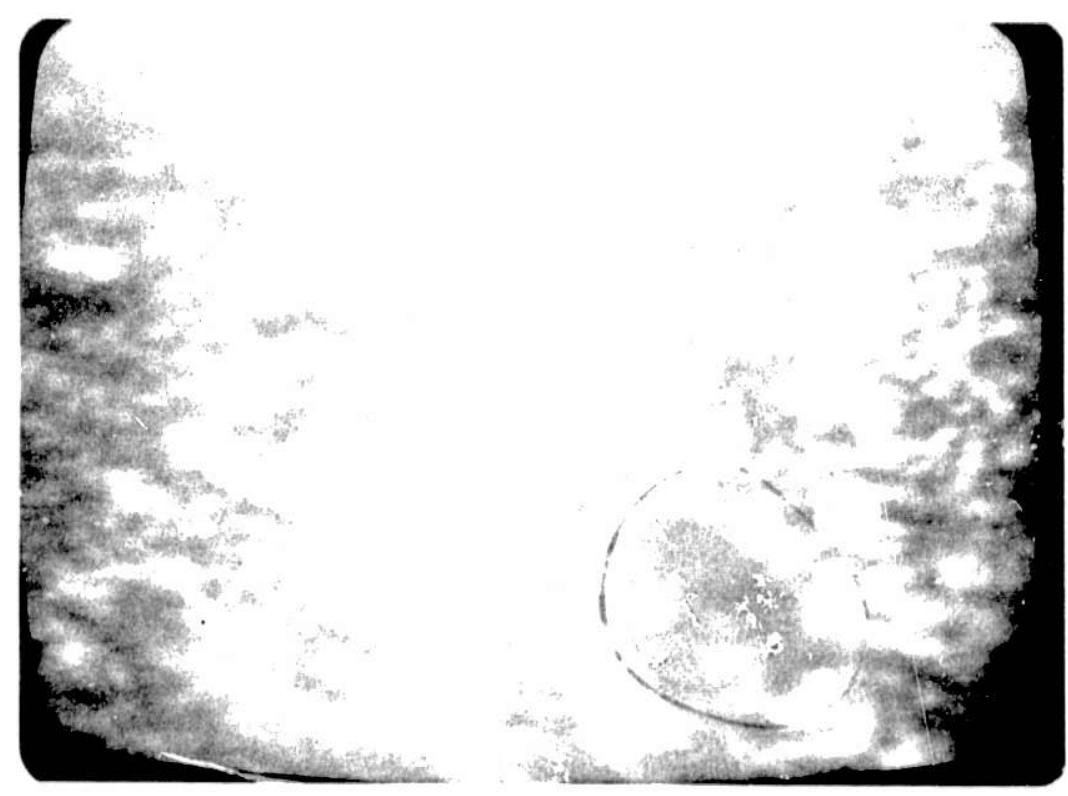

A2-13

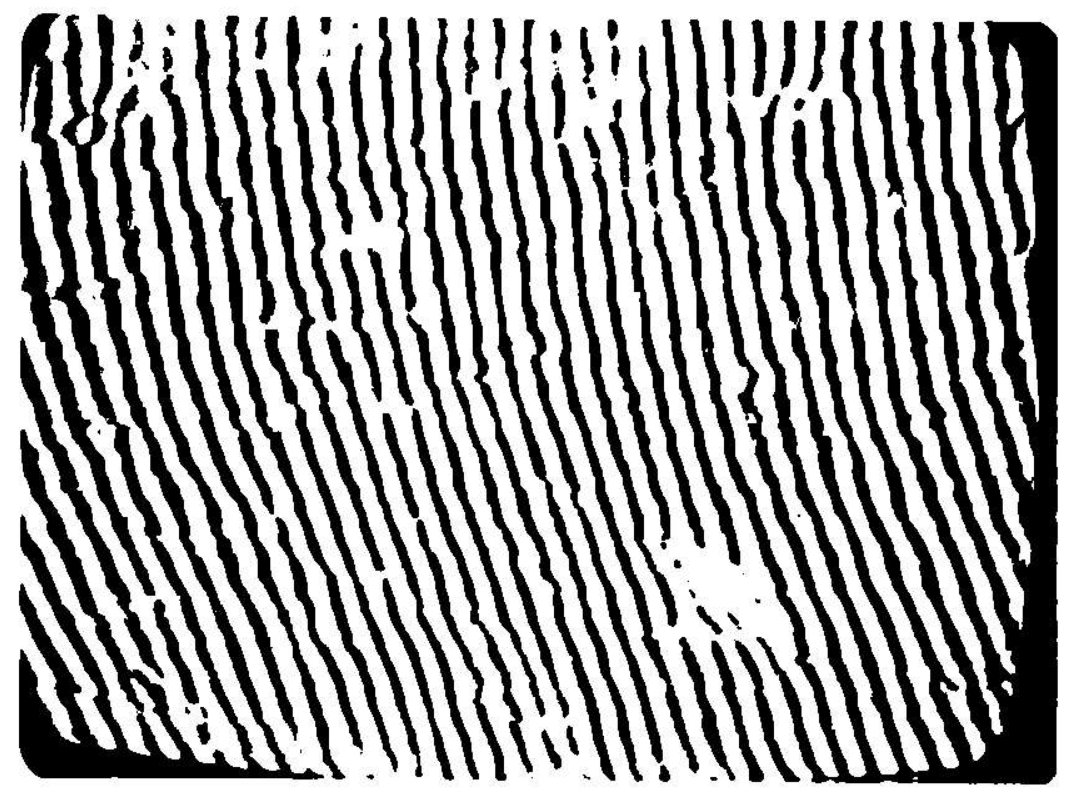

A:I-:i.4

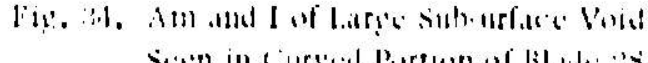

scon in tursid Pertun of lilak :s 


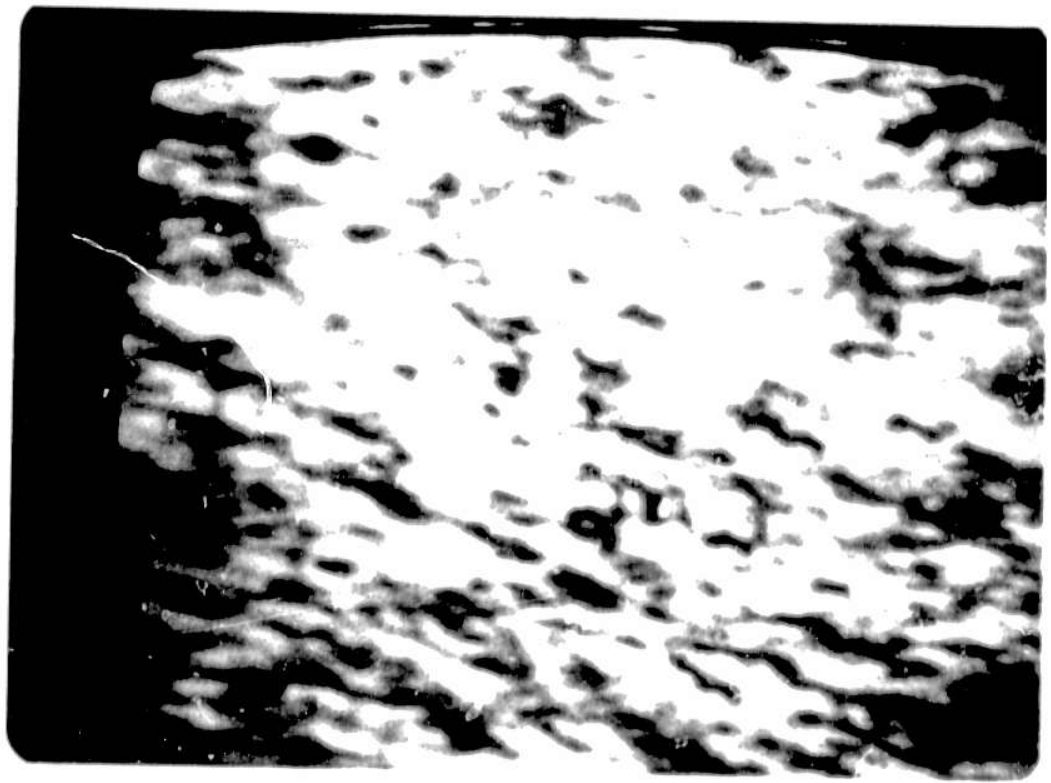

$\therefore-1$.

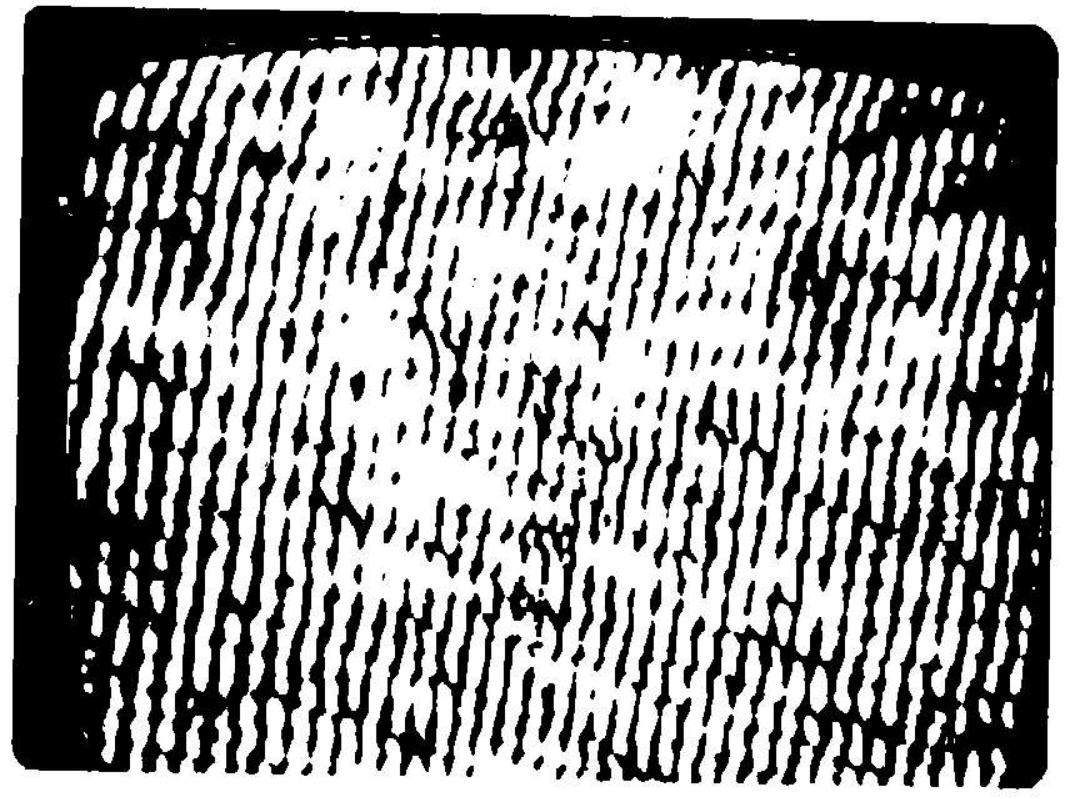

$A-1:$

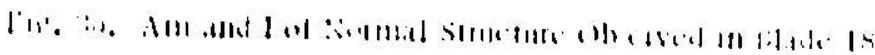



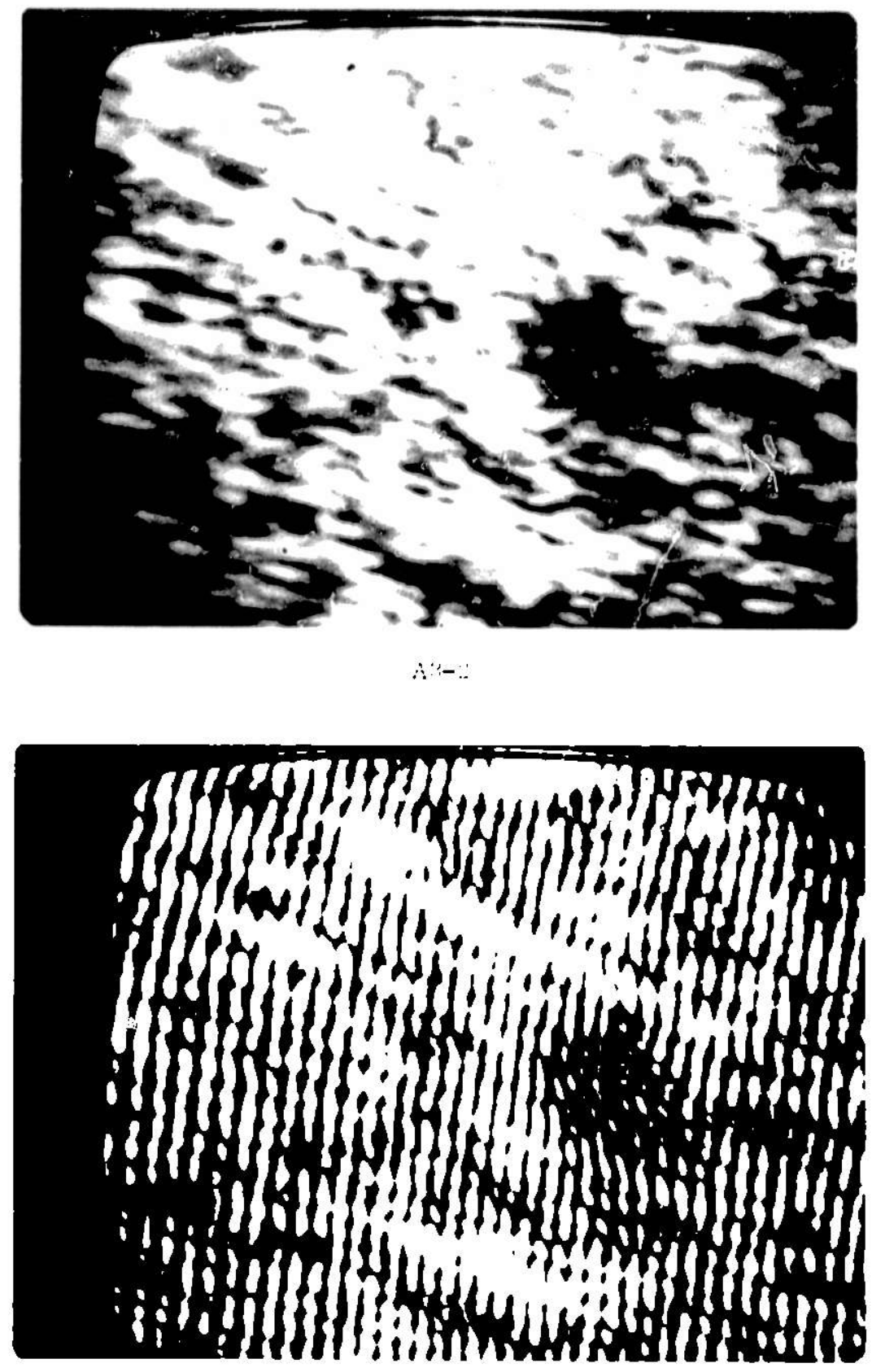

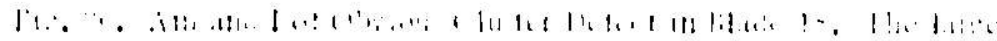

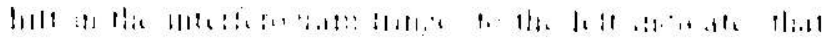

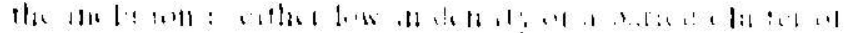

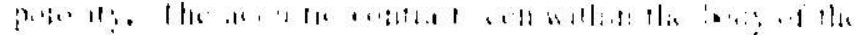

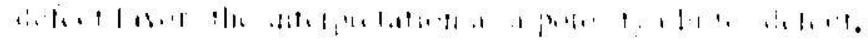




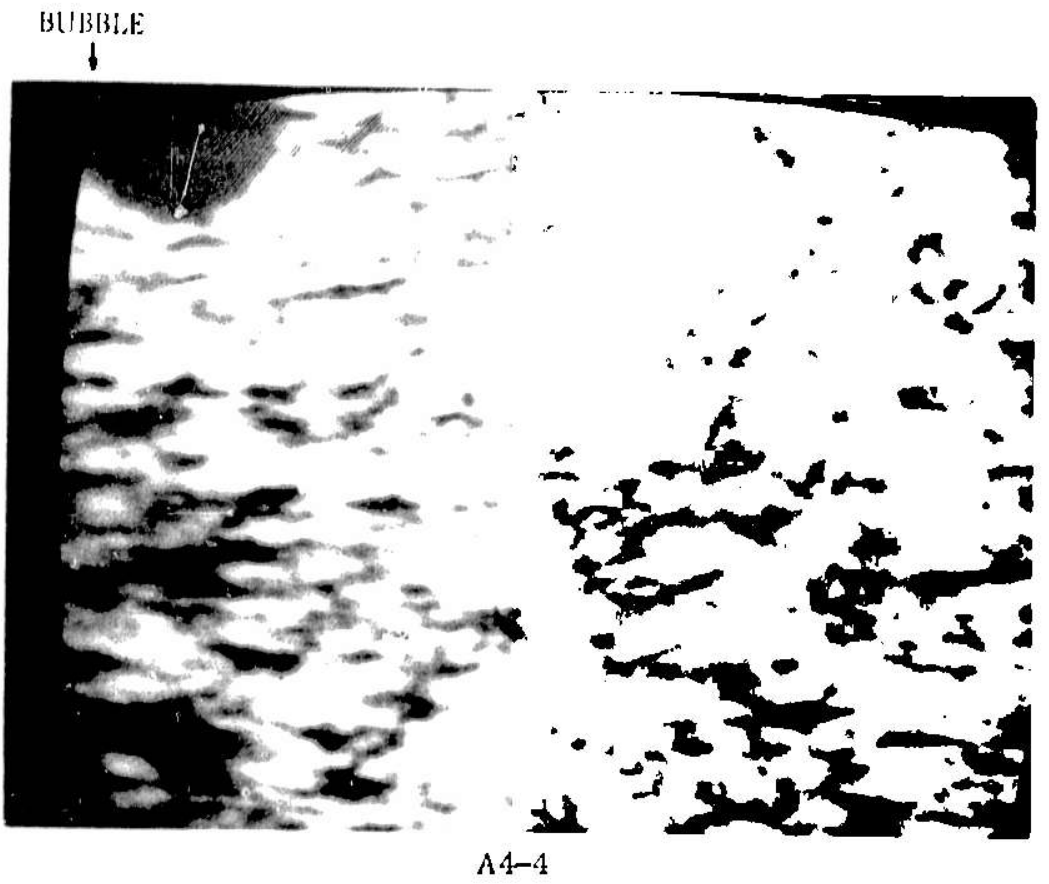

BUBBLEE

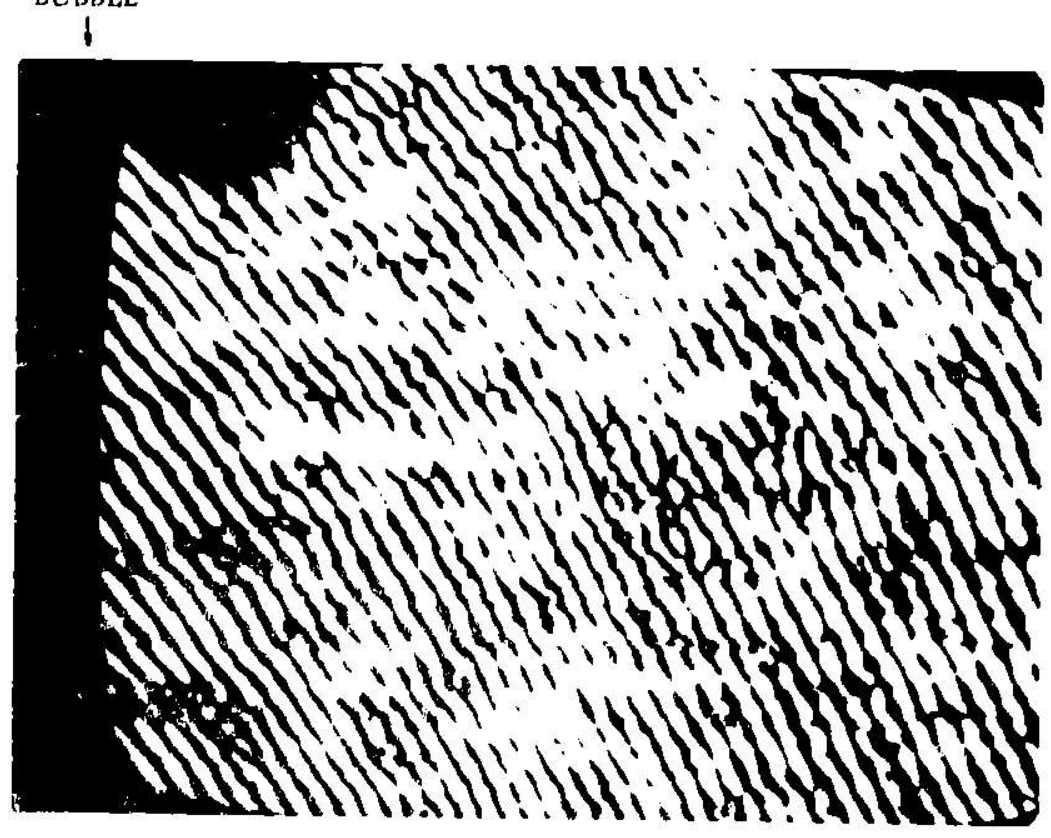

$A \cdot 1-i)$

Fig. 37. Am anc' 1 of interesting siructure in Ha.ke 1.1. The circled area thows two acoustically bright grains associated with an area of dissupted interferegram lines. Tlle st un: velocity in the bright regions does not appear en differ iubstantially irom that of the surrounding "notmal" material. The: ampintale picture show a mumber of interesting folamentlike structures within the circled reglion. 

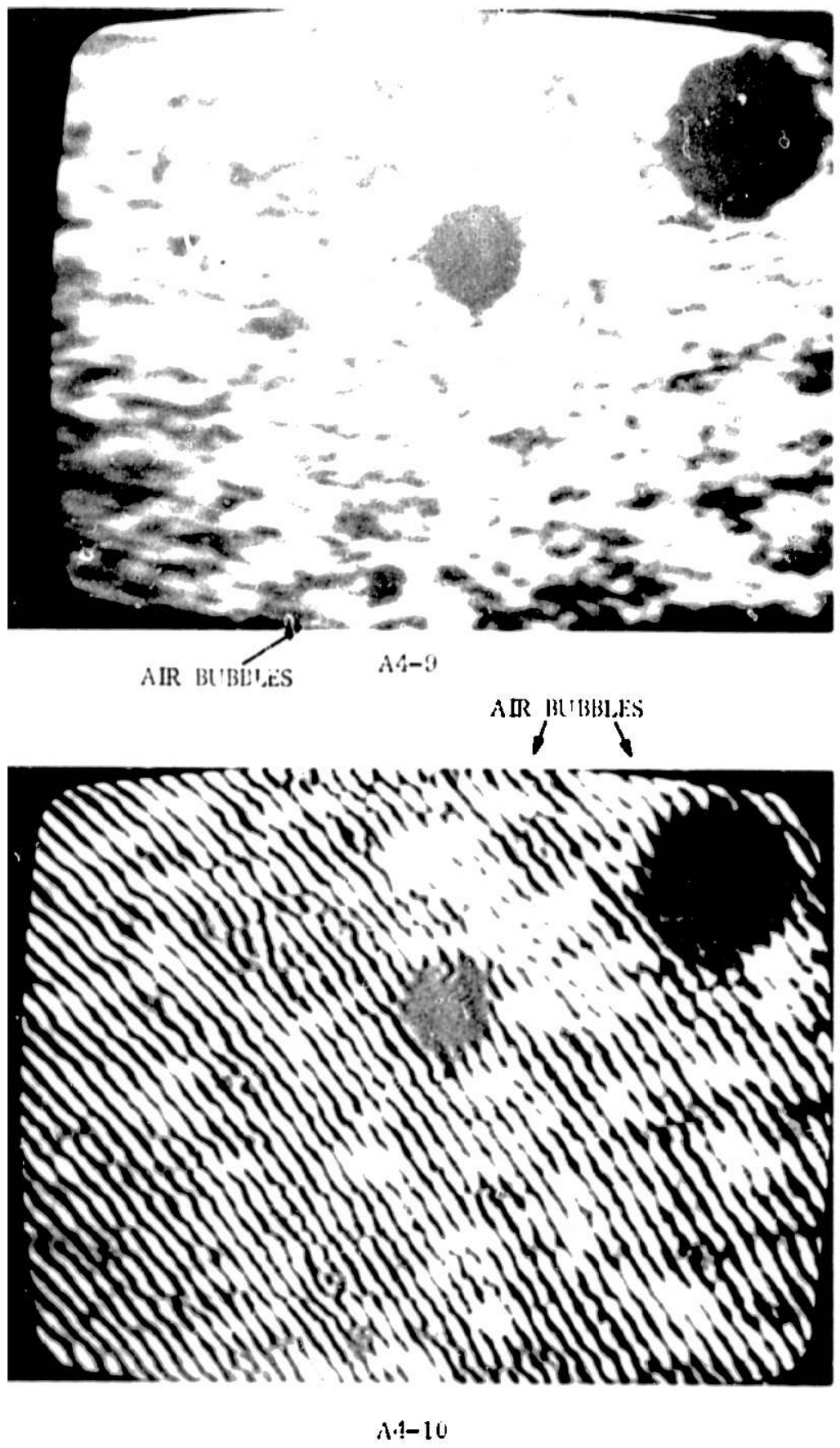

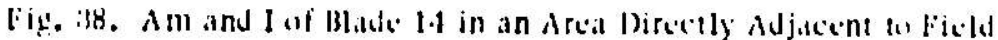

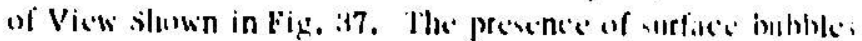

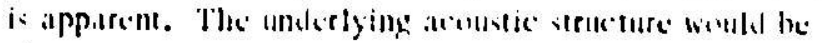
clasied a ispical ur " normal." 


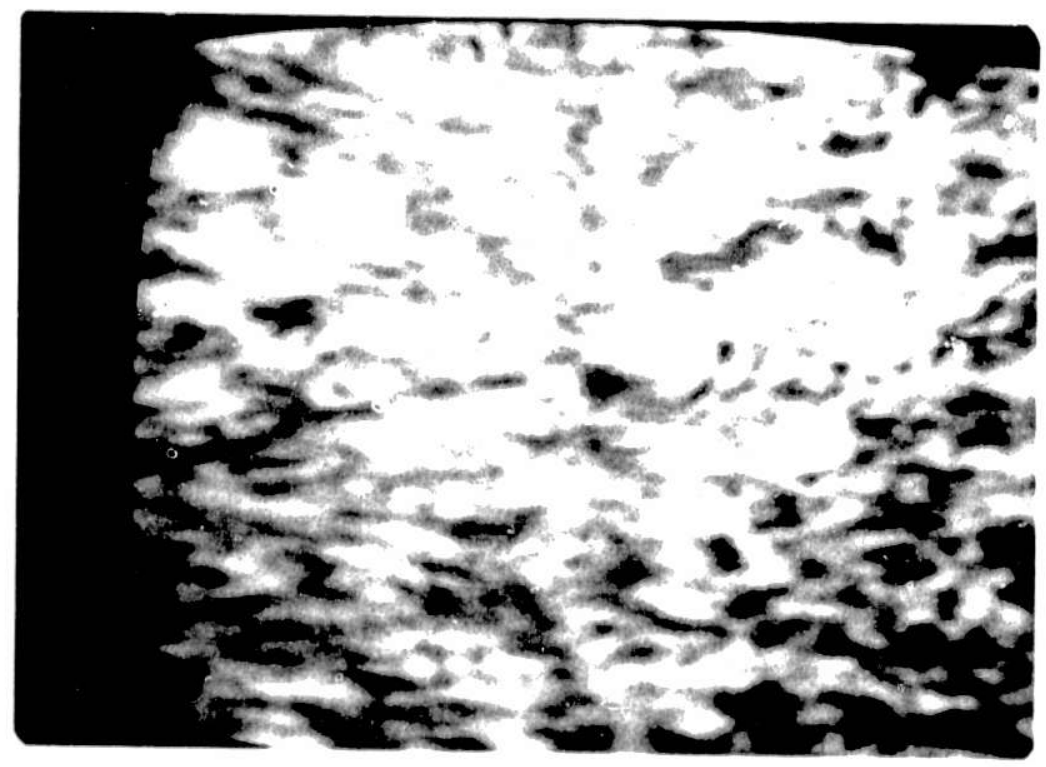

$A:-17$

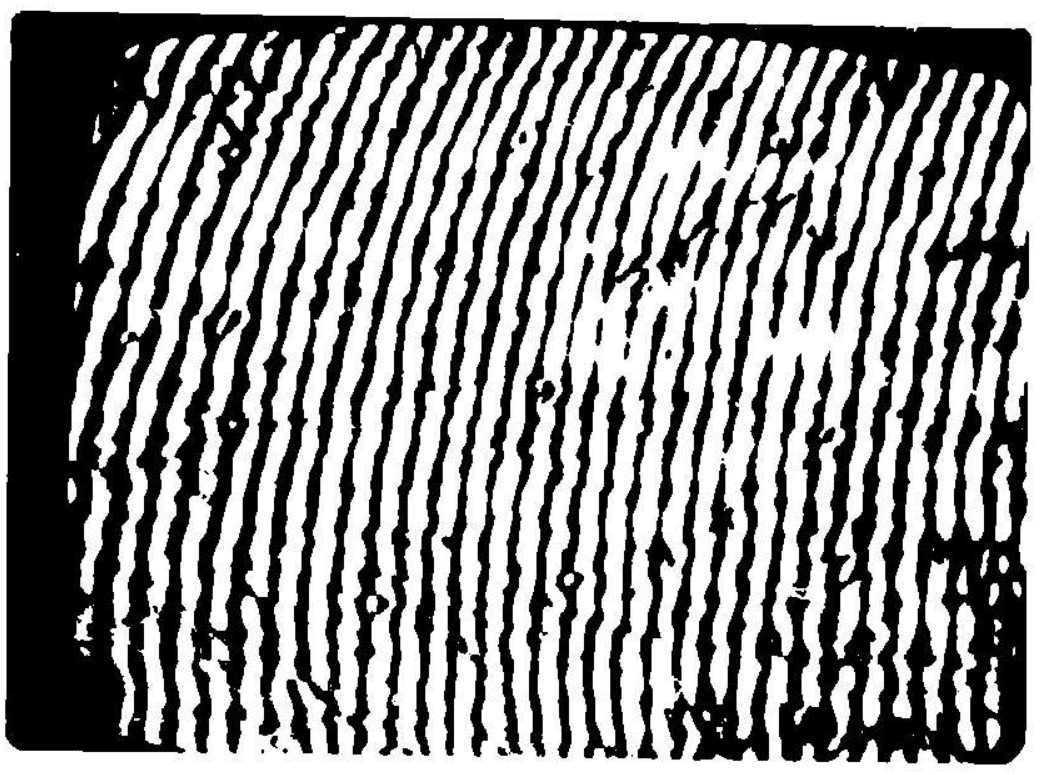

A:3-18

Fig. 39. Am and I of Normal Strueture (bserved in Blitde di 


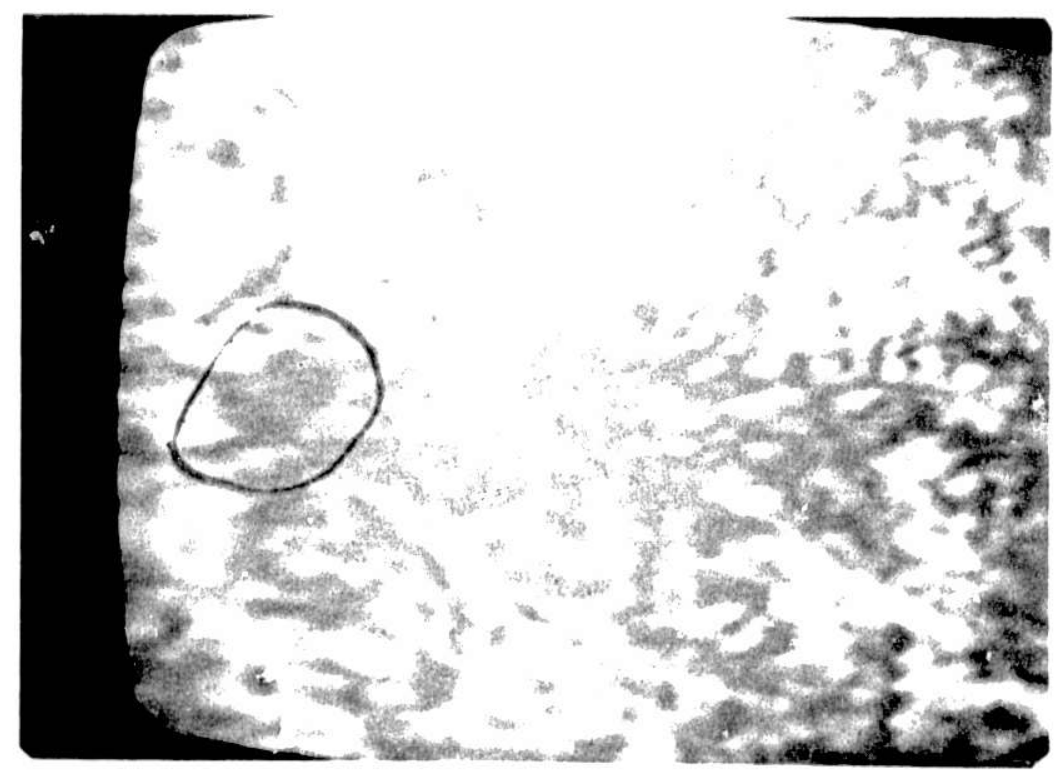

A.3-15

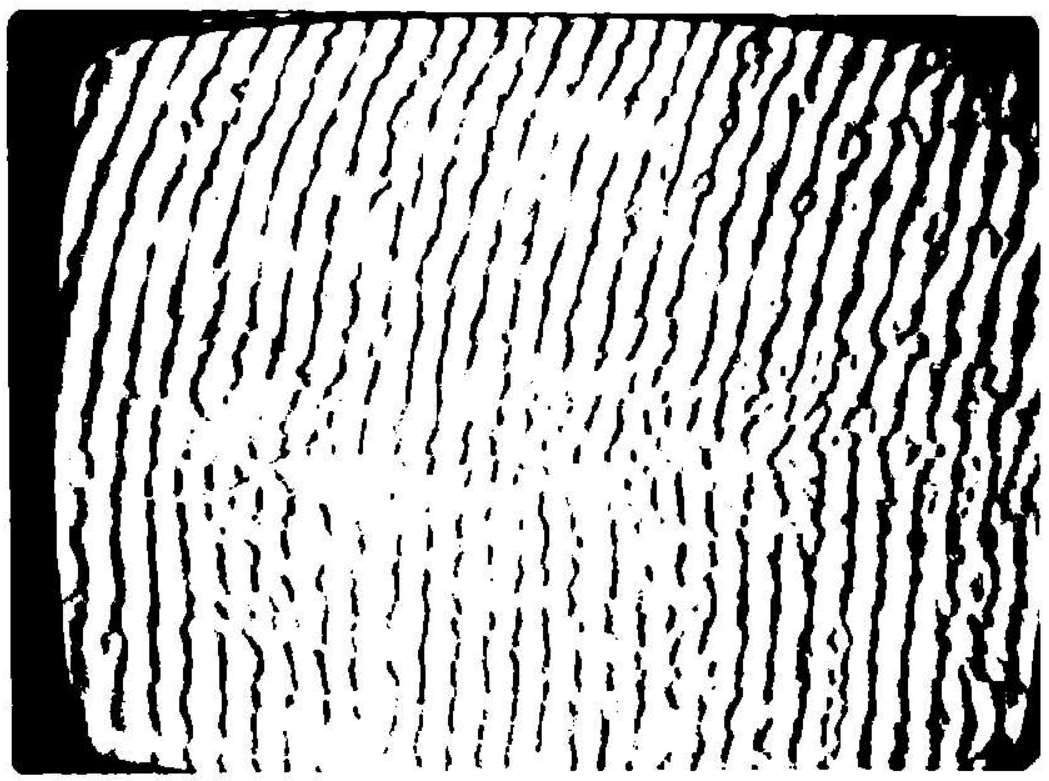

A3-16

Fig. 40. Ant and $I$ of lixterted Area of Darkening (Observed in Blade Li. The change in contrast (darkening) is more gradual than that

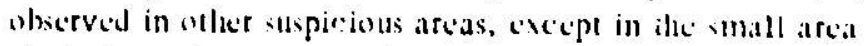
circled. A change in sonification angle acress the fickld of view may la responsible for part of the ittereascd low in this e'vtended darkened repion. 


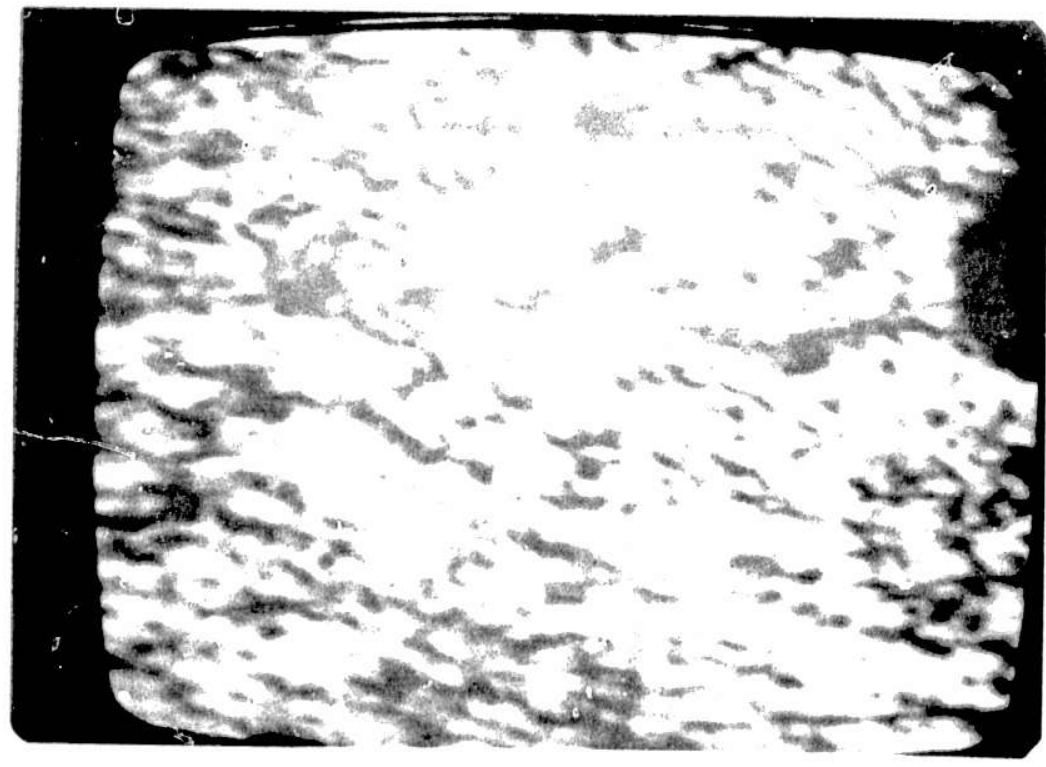

A 1-6

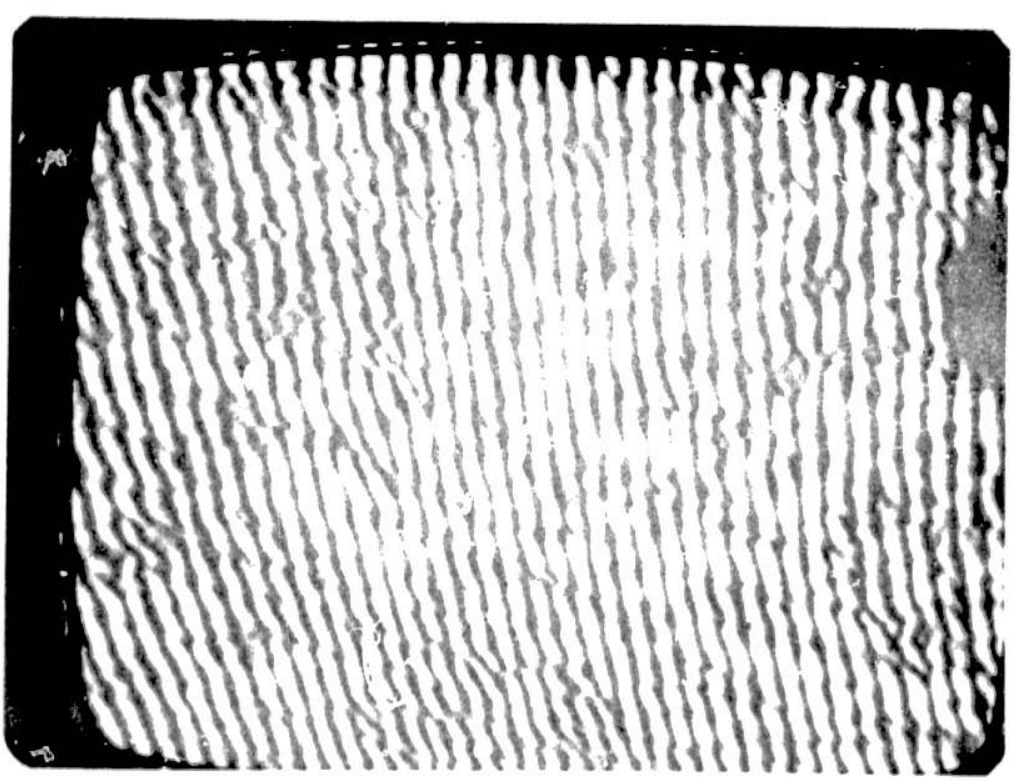

A1-7

Fig. 11. Am and $l$ of Normal Structure Observed in [3]ate 1 is 

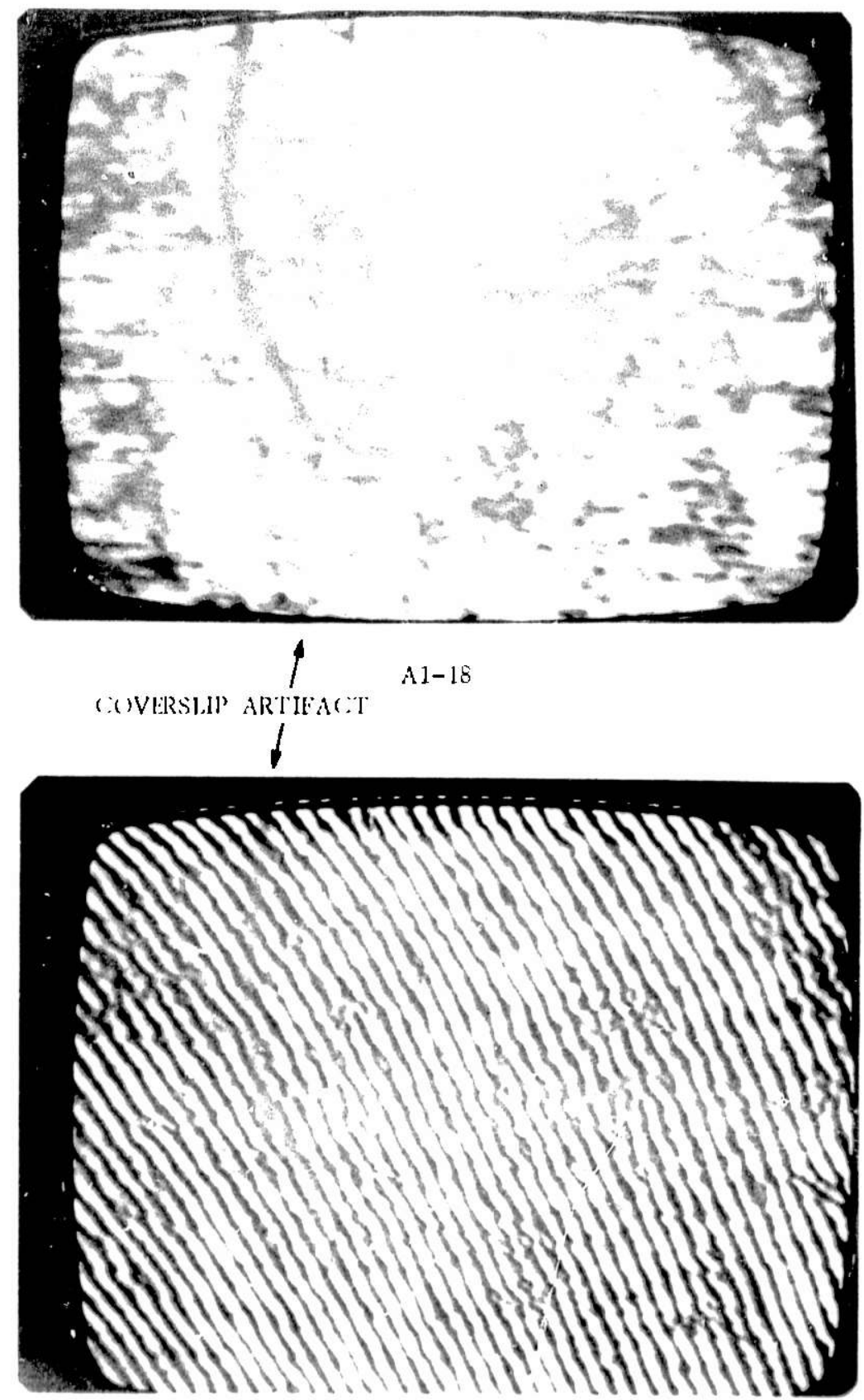

$(1-10$

Fig. 42. Am and I of Blade :36. The large dark area (circled) and Jark lines running horizontally across the field of view arc coverslip scriltelies.

The connection between the field of view shown in the micrographs and its location on the sample is made in the following way. First, on the concave surface of each blade, a rectangular box is marked (in pencil) indicating the approximate location of the acoustic image. The actual raster size (size of the micrographs) is 4.3 by $3 \mathrm{~mm}$. Howcver, the areas marked on the sample are somewhat larger and represent the uncertainty in the raster location. Second, additional documentation and orientation information is provided 
by a sketch of the blade that accompanies the micrographs. Operationally, the sketches are made by placing the blade on the page and tracing its outline. The approximate location of the raster is then drawn within the boundaries sketch. This drawing serves two purposes:

a. Tracings are made in the same orientation that was used to obtain the micrographs. (The perspective is that of looking down along the scanning laser beam.)

b. In samples where more than one region was photographed, several rasters are marked on the blade. The tracing makes the connection between the various micrographs and their location on the blade.

\section{Defect Confirmation}

After acoustic scans suggested abnormally sized defects in blades 18 and 28 , radiographs of these blades were made. A Siefert $150-k \mathrm{~V}$ $\mathrm{X}$-ray machine was used at $80 \mathrm{kV}$ and $4 \mathrm{~mA}$. The source focal spot was $0.4 \mathrm{~mm}$, and the distance to the film (Kodak SR) was $1 \mathrm{~m}$. The blade in contact with the film was $X$-rayed with the curved side down as well as up, and two exposure times were used (240 and $180 \mathrm{~s}$ ). The close proximity of the blade to the film made the resolution higher than can be achieved with ordinary radiographic techniques used for the blade ring. The flaw in blade 18 determined by acoustic mic roscopy is about $700 \times 450 \mu \mathrm{m}$. All X rays of blade 18 revealed a porelike defect in the same location as determined by the acoustic microscope. No other defects were seen on the X-ray film for blade 18 . By $\mathrm{X}$-radiography, the anomaly was found to be $530 \times 350 \mu \mathrm{m}$ in general agreement with the acoustic measurement.

$X$ rays of blade 28 revealed one porelike defect in one of four radiographs. This was in the general area where an anomaly was detected by the acoustic microscope. A search for this flaw at the location suggested by the one radiograph revealed a laminar type defect with a pore at its edge (Fig. 31). The small size of the pore $(\sim 100 \mu \mathrm{m})$ explains the difficulty in detecting it by radiography and suggests a limit of resolution for conventional $\mathrm{X}$-ray methods.

The advantage of detecting laminar flaws by acoustic microscopy is clearly demonstrated in this example where such a flaw could not be seen by radiography techniques. In addition, the size of the delamination, about $500 \times 100 \mu \mathrm{m}$, is comparable with the $550 \times 300-\mu \mathrm{m}$ size indicated by the acoustic microscope. The cross section of blade 28 indicates the general porosity of the reaction-sintered blades. Pores on the order of $10^{\prime} \mathrm{s}$ of microns can be seen. These are not revealed by radiographs. However, the acoustic microscopy does reveal anomalies of 50-100 $\mu \mathrm{m}$ and with the same general frequency as seen on the micrograph. 


\section{Summary}

This preliminary study using acoustic microscopy techniques has indicated that:

1. Reaction-bonded $\mathrm{Si}_{3} \mathrm{~N}_{4}$ material which comprises the rotor blade ring is sufficiently transparent acoustically to be investigated at $100 \mathrm{MHz}$. The thickest area of the blade available for this study was $3 \mathrm{~mm}$, which was easily penetrated at $100 \mathrm{MHz}$. It should be feasible to image samples that might be as much as a factor of two thicker (e.g., $6 \mathrm{~mm}$ ).

2. Surface finish presents no problem. Geometry, though complex, could be circumvented by proper scanning procedure and permit direct imaging of entire blade surface area.

3. Subsurface defects or flaws can be distinguished from the normal or typical structure. For example, abnormal structures, which probably correspond to localized clusters of porosity were found in blades 28 and 18 . The pressure of a large pore in blade 28 was confirmed by $\mathrm{X}$-radiography. The general porosity indicated in blade 18 was confirmed by micros opy.

4. No major elastic microstructure changes were observeri as a function position on the blade. The typical or normal structure remiained similar as the blade was scanned from one end to the other. There was an overall increase in attenuation on the thicker portions, which was $\epsilon$..pected. In the curved, thick portions of blade 28 , the results suggest that there may be a slight increase in the mean size and/or concentration of the porosity compared to the thinner portions.

5. Results demonstrate feasibility and establish a data base for the acoustic microscopic examination of intact ceramic turbines. 


\section{DYE-ENHANCED RADIOGRAPHY}

\section{A. Discussion}

The objective of dye-enhanced radiography is to fill surface defects with a substance (doping agent) that will absorb penetrating radiation more effectively then the base material. Thus, whereas normal radiographs may not reveal surface defects such as cracks with the dye present, these flaws may become detectable. This idea has been successfully used with neutron radiography. ${ }^{29}$ Gadolinium nitrate is mixed with acetone and a wetting agent to form the penetrant. Used with metal parts, the dye can reveai cracks, even if the neutron beam is not parallel to the crack plane. Thus a surface crack may be mapped out from its shadow. Since gadolinium has a massabsorption coefficient for neutrons three orders of magnitude greater than iron, for example, the technique is particularly useful. Although neutronradiography techniques can be used for ceramics, the main effort here has been to find a doping agent with sufficient contrast so that conventional $\mathrm{X}$ rays could be used effectively. This seemed feasible because of the nature of silicon nitride (low atomic number and low density).

The absorption of a parallel narrow beam of monochromatic $X$ rays in a plane-parallel layer of homogeneous isotropic material can be described by

$$
I=I_{0} \exp (-\mu t)
$$

where $I_{0}$ is the incident intensity, $I$ the emerging intensity, $\mu$ the total linear absorption coefficient, and $t$ the material thickness in centimeters. The mass-absorption coefficient $(\mu / \rho)$ is generally used, as the intensity reduction is determined by the quantity of matter traversed. The quantity $\mu / \rho$ is almost independent of the physical state of the material and is additive with respect to the elements composing it:

$$
\mu / \rho=\sum_{\mathbf{i}} g_{\mathbf{i}}(\mu / \rho)_{i},
$$

where $g_{i}$ is the mass fraction contributed by the element $i$ with mass absorption $(\mu / p)_{i}$. Thus,

$$
I=I_{0} \exp \left(\frac{-\mu}{\rho} \rho t\right) .
$$

The mass-absorption coefficient is dependent on wavelength. For silver nitrate $\left(\mathrm{AgNO}_{3}\right)$ at $0.3 \AA$,

$$
\mu / \rho(0.3 \AA)=10.5 \mathrm{~cm}^{2} / \mathrm{g} \text {. }
$$


For fully dense silicon nitride $\left(\mathrm{Si}_{3} \mathrm{~N}_{4}\right)$,

$$
\mu / \rho(0.3 \AA)=0.5 \mathrm{~cm}^{2} / \mathrm{g} \text {. }
$$

The ratio of mass-absorption coefficients is about the same, even for shorter wavelengths. Thus the silver nitrate absorbs $\mathrm{X}$ rays 20 times more strongly Sian silicon nitride. For less than fully dense silicon nitride, the contrast is even greater. Surface flaws not visible by ordinary X rays may be observid by a dye-enhanced technique.

B. Results

Many commercially available medical enhancing agents were tried including Hypaque-M 90\% and Hypaque- Na 50\%, Cholografin Meglunine (iodine $52 \%$, sodium $18.2 \%$ ), and Gastrografin (sodium $10 \%$, iodine $30 \%$ ). A dye consisting of lead oxide mixed with alcohol was tried.

The most successful doping agent, however, was silver nitrate solution formed from equal parts by weight of silver nitrate and water plus a small amount of photo flow for a wetting agent. The procedure for generating the dye-enhanced radiographs is as follows (see Fig. 43).
a. Clean ceramic rotor in an ultrasonic bath
b. Place rotor in hot $\left(80-90^{\circ} \mathrm{C}\right)$ silver nitrate solution
c. Remove rotor and $X$ ray using conventional techniques
d. Clean part in ultrasonic bath.

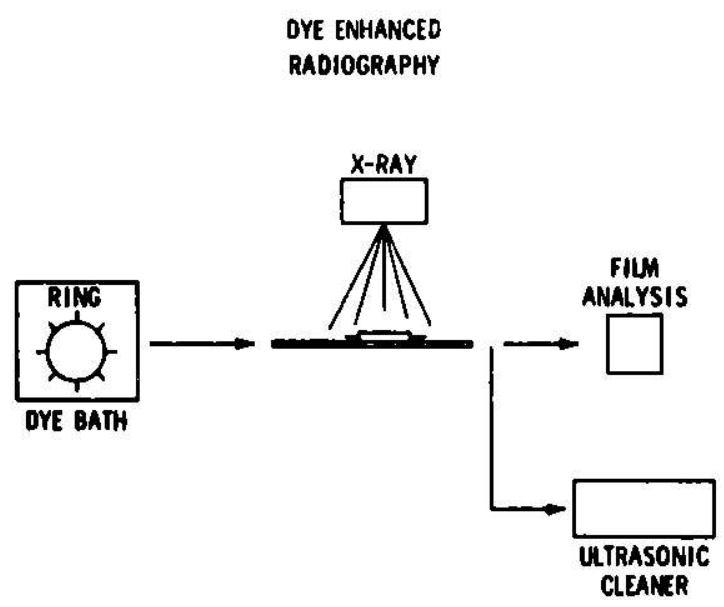

Fig. 43. Schematic Diagram of Dye-enhanced Radiography Technique for Sllicon Nitride Rotors
An $80-V$ X-ray machine with a film-toobject distance of $100 \mathrm{~cm}$ was used. Type SR Kodak film was employed.

In an example to demonstrate the enhancement technique, a layer of silver nitrate nominally $0.05 \mathrm{~mm}$ thick was placed on a $3.8-\mathrm{mm}$-thick flat plate of hot-pressed silicon nitride. Although the silver nitrate represents an increase in thickness of only $1.3 \%$, the film density increased by almost $10 \%$.

This technique has also resulted in indications that appear to be cracks in certain regions of several rotor blades. Normal $X$ rays, conventional dye penetrants

or observations under a 30-power microscope do not reveal flaws in these regions. An example of one indication from the root area of a blade is shown in Fig. 44, where the magnification is $20 \mathrm{X}$. This anomaly reveals itself more clearly in the actual $X$ ray. 


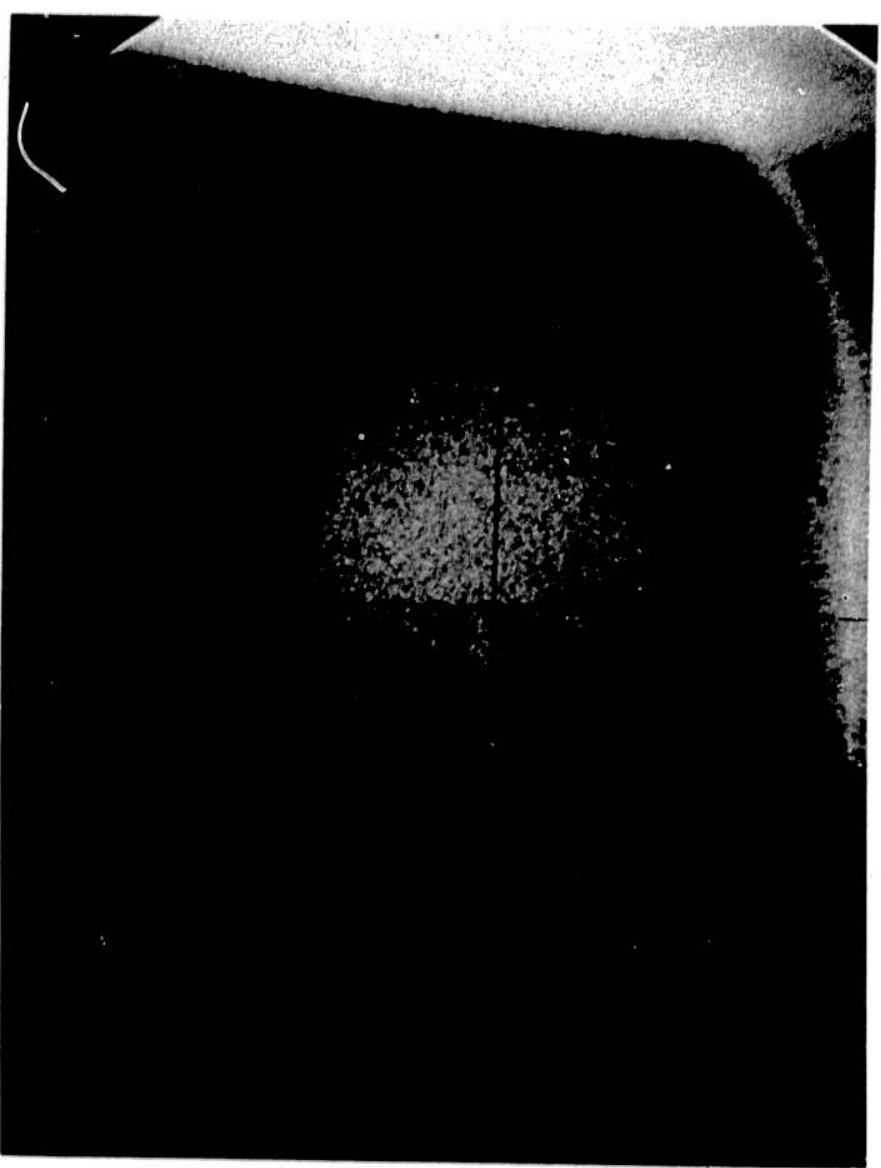

Fig. 44

Anomily Revealed in l3lade-root Region of SN Rotor. Matg. 20X. ANL Neg. No. $306,77-502$.

Another ring had weak linear indications near the tip of a blade.

Figure 45 shows a drawing of the linear anomaly revealed by the dye-enhanced radiography technique. Again, othertechniques did not indicate a defective blade. Figure 45 shows two branches of what appears to be a crack. The blade was removed from the blade ring for sectioning and polishing. The blade was potted in "Koldmount," but plated with nickel before insertion in the mold. This was done to preserve the blade edge during grinding and polishing.

Figure 46 shows an $80 \mathrm{X}$ micrograph of the blade cross section at the plane indicated in Fig. 45. A porosity string about $100 \mu \mathrm{m}$ decp intersecting the surface and a crack below the surface (about $100 \mu \mathrm{m}$ deep) are clearly indicated. The subsurface crack is further magnificd by the use of a scanning electron microscope (SEM) Figure 47 shows the SEM results.

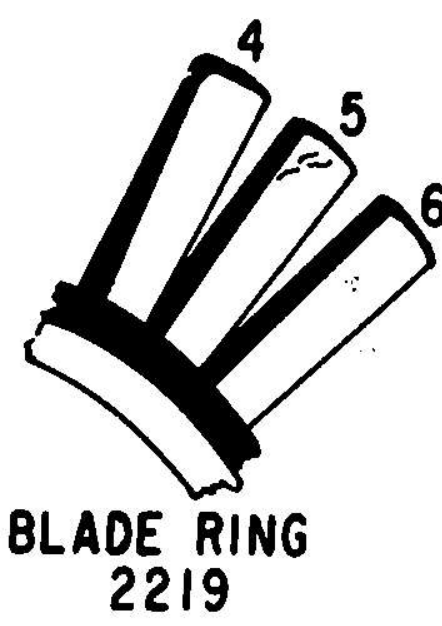

Fig. 45. Sketsh of Indications Revealed by Dye-enlanced Radiography l'ecluniques for Blade Ring 

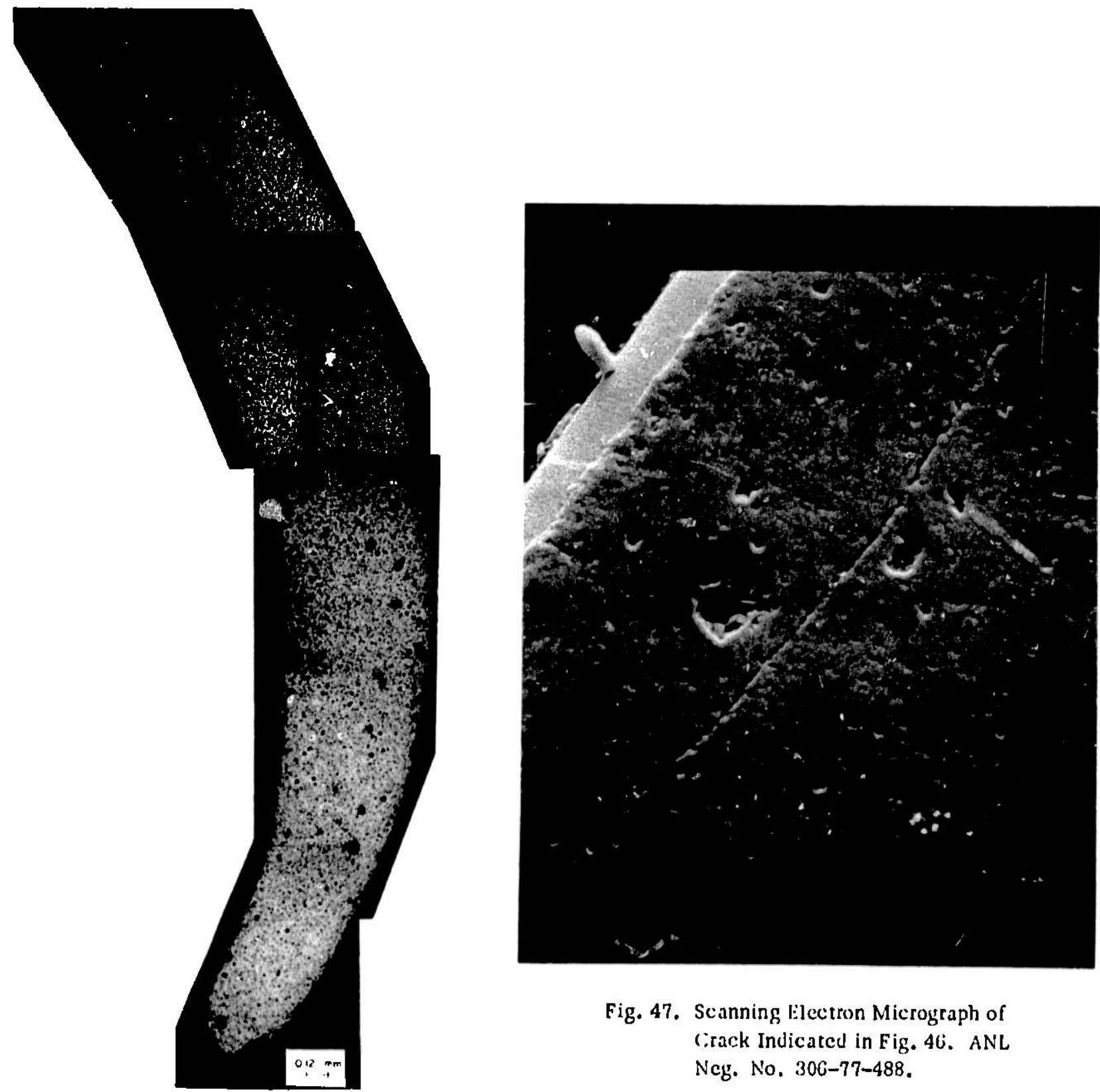

Fig. 47. Scanning liectron Micrograph of crack Indicated in Fig. 46. ANL Neg. No. 306-77-488.

Fig. 46. Micrograph of Blade Shown in Fig. 45. The plane of this Micrograph is indicated in Fig. 45. Two cracklike flaws are indicated. Mag. $80 X$. ANL Neg. No. 306-77-503.

The two cracklike flaws revealed by the micrographs are consistent with the location of the dye-enhanced radiograph indications. The subsurface crack indication is assumed to penetrate the surface in the region closer to the blade tip, where the radiograph has a cracklike indication.

\section{Summary}

This initial effort has shown that dye-enhanced radiography can be extremely useful for detecting critically sized $(100-\mu \mathrm{m})$ surface flaws in 
structural ceramics where conventional $X$ rays, dye penetrants, and visual methods are unsuccessful. Because of its nature, dye-enhanced radiography is readily adaptable to complex component shapes and is a relatively inexpensive and rapid nondestructive-evaluation technique.

\section{ACOUSTIC EMISSION}

A. Discussion

In the application of acoustic-emission (AE) technology toward flaw detection in structural ceramics, the objective is in general to detect the presence of elastic waves generated from the initiation and/or propagation of flaws or from a change in flaw population. Considerable literature has been published on this subject. ${ }^{30-33}$ For the specific application of silicon nitride (SN) rotors, thermal and mechanical stresses were used to propagate existing cracks or, in some detectable way, change the flaw population. Acousticemission data have been accumulated with commercially available equipment. A schematic of the equipment used is shown in Fig. 48.

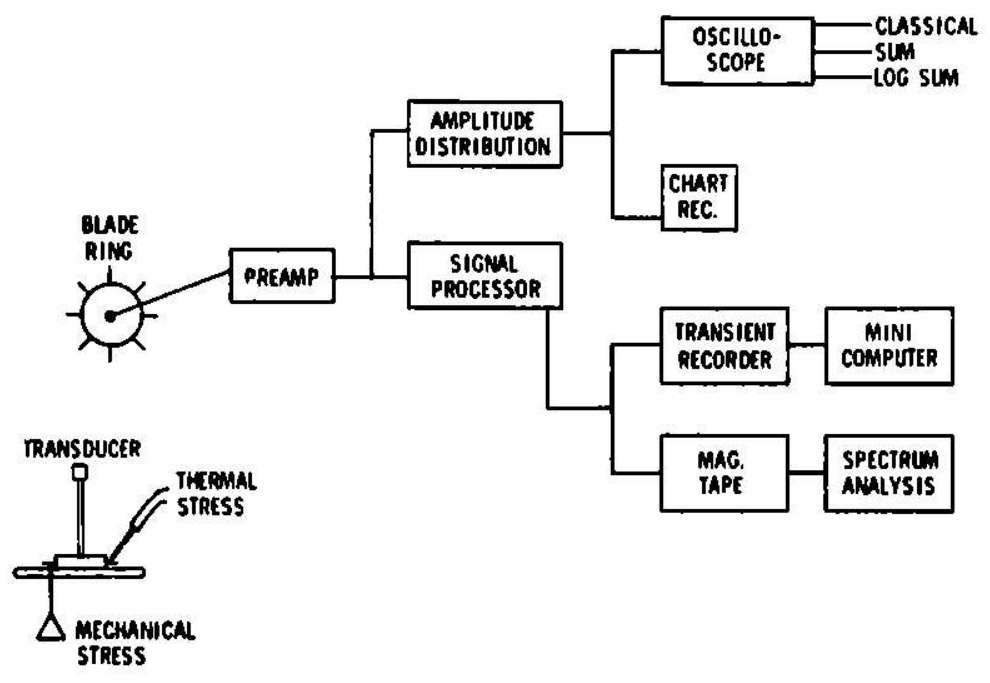

Fig. 48. Schematic Diagram of Experimental Apparatus for Acoustic-emission (AE) Experiments
An Acoustic Emission T'echnology Model 201 signal processor and Model 203 amplitude-distribution analyzer (ADA) were used along with a Biomation 8100 transient recorder Tektronix 7904 oscilloscope and 7L.5 spectrum analyzer. This electronic equipment allows single $\mathrm{AE}$ events to be captured and analyzed (transient recorder, oscilloscope, and spectrum analyzer) or distributed according to amplitude (using the ADA). Total AE activity can be recorded by using the root mean square or the total

counts output of the signal processor. The number of counts is the number of times the radio-frequency (rf) output level exceeds a preset threshold level. The system also can record data on magnetic tape, and data from the transient recorded can be inputted to a NOVA 2 minicomputer for storage and analysis.

Most AE data were generated by thermally stressing an individual blade with a butane torch. Signals are generated because of flaw propagation, 
initiation, or frictional motion of defect surfaces. A constant flame length plus constant heating time ensured reasonably reproducible thermal stressing. Mechanical loading of the blades to stress them was difficult and beyond the scope of this effort. Unwanted spurious signals are generated from the sample loading and mask the AE signals from flaws. Thus, mechanical-loading experiments were terminated, and all AE data presented are the result of thermal stressing.

Figure 49 shows the apparatus used to acquire the AE data. The blade ring tested was placed on a reaction-sintered SN stand (attached to the stand

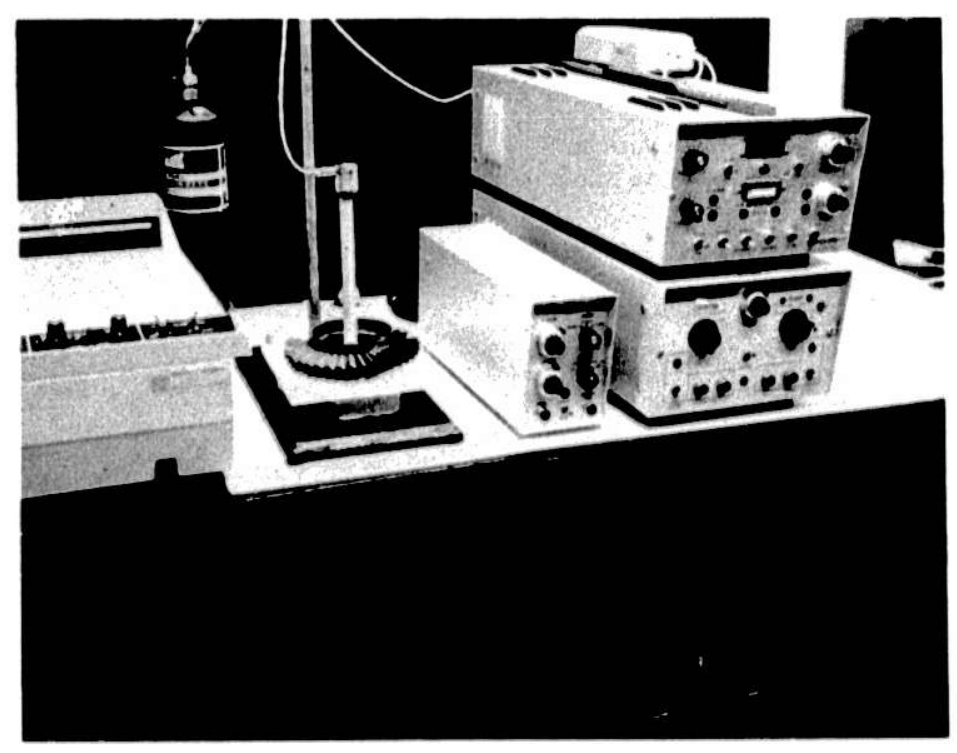

Fig. 49. Photograph at: $;$ Rotor, SN Stand, Amplitudedistribution Analyzer, and Signal Processor for Acoustic-emission (AL) lixperiments. ANL Neg. No. 306-77-497. with a shear wave couplant) with an SN wavesuide. The transducer $(175 \mathrm{kHz}$ ) was epoxied to the top of the waveguide. As a result, signals generated because of differential th ermal contraction between the stand and blade ring were virtually nonexistent.

B. Results

In these tests, an individual blade was heated for about $20 \mathrm{~s}$, reaching about $900^{\circ} \mathrm{C}$ (determined by a pyrometer). About $50 \%$ of the blade starting from the blade tip was red hot. Most of the blade ring, however, was only slightly warm to the touch during the data-acquisition period.

During the heat-up and cool-down cycle, AE signals were detectable for about 1 min. The most significant AE data, and that reported here, are total counts and the amplitude distribution.

Figure 49 shows the apparatus used. If the center of the blade ring is not cut out, the stand is inverted and the rotor is placed on top. The ability of AE monitoring to distinguish between flawed and flaw-free blades is demonstrated in Fig. 50, which shows the amplitude-distribution curve for heating and cooling cycles of blades 16 and 20 of ring 1957. Blade 16 had a crack about $13 \mathrm{~mm}$ long extending from the blade tip to the center of the blade (see Fig. 51). This crack was introduced to the specimen by thermal shock (heat blade to $900^{\circ} \mathrm{C}$; quench in water). Blade 20 had no known flaws.

The ADA divides the signal amplitude dynamic range of $60 \mathrm{~dB}$ into 50 channels. Channel 0 is set at $10 \mathrm{~s} \mathrm{~V}$ and channel 50 at $10 \mathrm{~V}$. These 
channels store signals received from the preamplifier, which has a gain of $40 \mathrm{~dB}$. The number of events per channel (classical) or the cumulative sum from a partic ' 2 r channel through all higher channels can be displayed.

Total Ring Down Counts

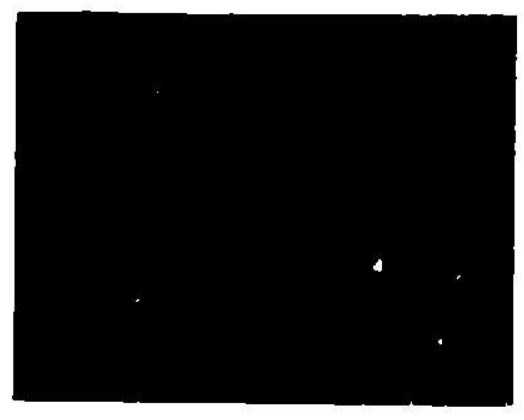

280

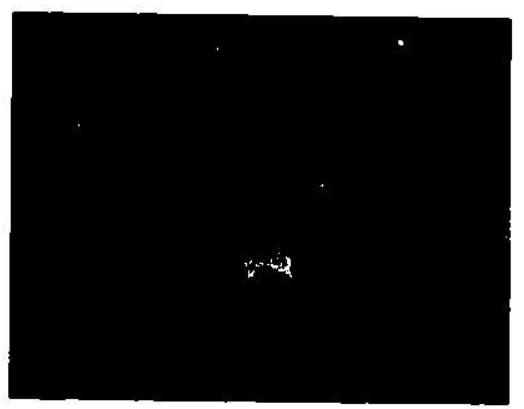

Fig. 50

A mplitude-distribution-data Cumulative $1.2 g$ and Total Counts for Thermal Stressing of Blades 16 and 20 of Ring 1957. ANL Neg. No. 306-77-482.

\section{0}

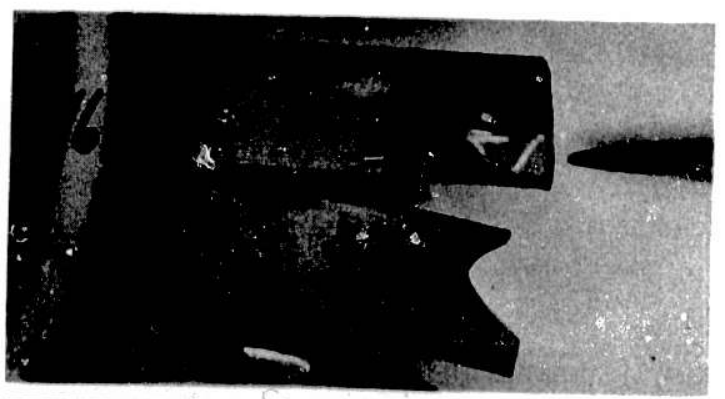

blade 16

Eig. 51

Blades 16 and 20 of Blade Ring 1957. ANL Neg. No. $306-77-490$.

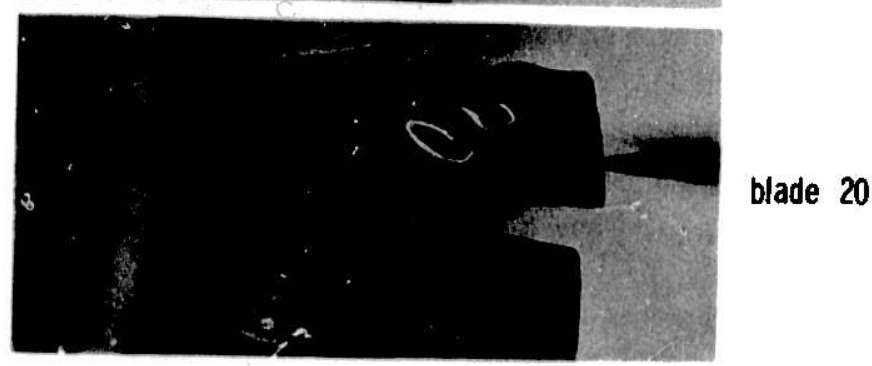

Figure 50 shows the log of the cumulative display for channels 1-18. The cracked blade has a significant amount of data through the first 13 channels and a "total count" of 280 . Blade 20 shows no counts and some data (probably spurious signal) from the cumulative log plot. The ability to identify this size and type of a flaw is clearly demonstrated. However, the ability to detect known cracks (up to $1 \mathrm{~mm}$ long) at the blade root has not yet been clearly demonstrated in similar tests. 
No reproducible difference in $A E$ data was noticed between blades with and without root cracks. Perliaps this problem can be resolved by the use of "quiet" mechanical-loading fixtures which can apply larger stresses at the blade root than have been generated in the thermal-stress experiments. In addition, testing has shown that $\mathrm{AE}$ data do not necessarily correlate with results of acoustic impact testing.

Interpretation of $\mathrm{AE}$ data is rather complex. Figure 52 shows amplitudedistribution data (classical display) and total counts for five blades of ring 2319. Blade 23, while showing a high total count, has only two events indicated. Blade 31 , which has a very low total count, has many

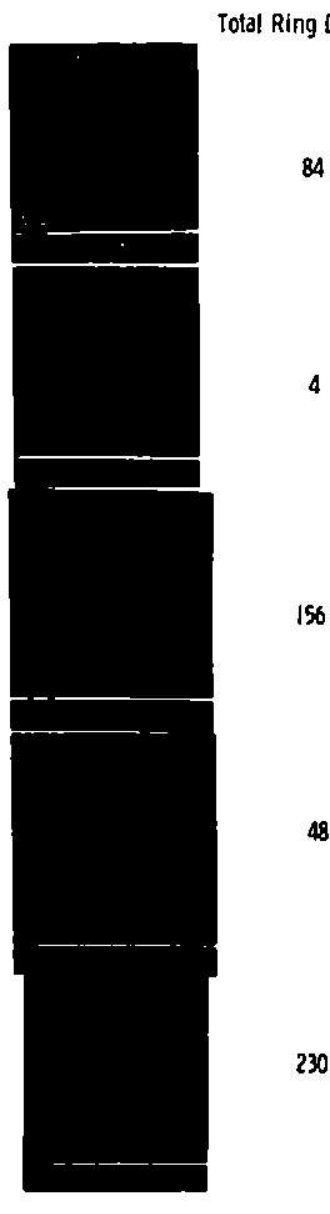

Fig. 52

Acoustic-emission Amplitudedistribution Data and Total Counts for Five Blades of Blade Ring 2319. ANL Neg. No. 306-77-485. events displayed in the ADA display. The loweramplitude events have fewer counts associated with them. Since blade 23 has higher-amplitude events than blade 31 , the data are at least internally consistent. Blade 26 (which is chipped at the blade tip) shows no AE activity, whereas in acoustic impact testing, this blade is shown to be particularly poor.

\section{Summary}

Acoustic-emission data, while potentially useful, are difficult to interpret and apply to ceramic rotors. A great deal of information in AE data may pertain to the condition of the components tested. At this time, in order to use AE data to detect critically sized flaws in a finished ceramic rotor, considerable study will be required to correlate the data with the presence of flaws and their size.

\section{ACOUSTIC-IMPACT TESTING}

In acoustic-impact testing (shown schematically in Fig. 53), a component is excited by striking it. The subsequent ringing, involving a time-varying combination of damping and frequency content, may indicate the quality of the component and may suggest the presence or absence of anomalies. This technique depends heavily on reproducible impacting and quantitative analysis. If the specimen geometry and contraints are constant during component testing, a shift in the resonant frequencies may indicate a

density or elastic-modulus change as well as the presence of a flaw (e.g., crack). The technique is difficult to apply for detection of small defects, as tolerable variations in fabrication may cause impact-response changes comparable to those caused by the defects. 


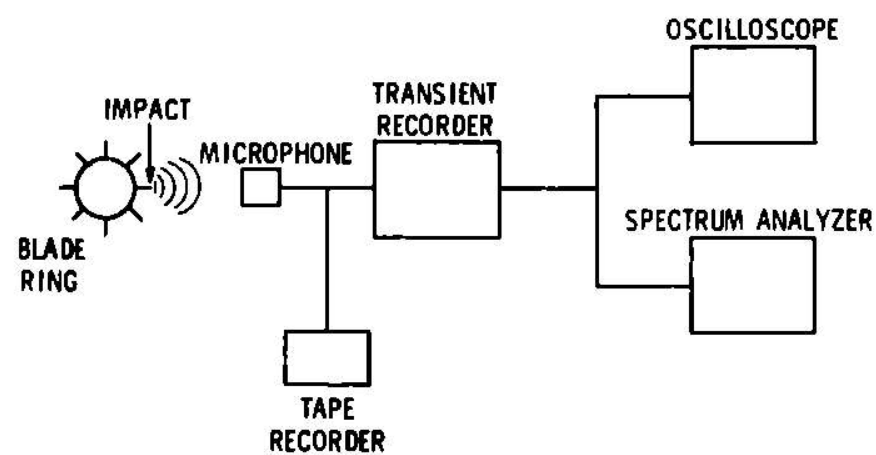

Fig. 53. Schematic Diagram of Acousticimpact-testing Technique
More complete discussions of acoustic-impact testing appear in Refs. 34-36. In the paper by Lloyd et al. ${ }^{36}$ the quality of ceramic plates is shown to be related to measurements of filtered response decay.

\section{A. Plocedure}

In this study, the audible spectrum of a ringing ceramic rotor blade is interpreted to in.

dicate the blade quality. For the current testing, a convenient method was found to excite the vibrational modes of the single rotor blade. This is shown schematically in Fig. 53. A mechanical-pencil lead was broken at the edge of a blade, causing it to ring. This simple, inexpensive technique was found to be reasonably reproducible and is discussed in Ref. 37.

A tape recorder, a Biomation 8100 Transient Recorder, and a Tektronix 7904 oscilloscope with a 7 L5 Spectrum Analyzer were used to obtain the data for acoustic-impact testing. The sampling $r$ ate of the transient recorder was $10 \mu \mathrm{s}$. This allowed $20 \mathrm{~ms}$ of data to be recorded. The data are played back through the spectrum analyzer in $1 \mathrm{~ms}$. Thus, the actual frequency is 20 times less than indicated on the oscilloscope trace. The frequency range of interest was $1-20 \mathrm{kHz}$. The $\mathrm{rf}$ trace is shown simultaneously with the spectral data given in Fig. 54.

Fig. 54

Frequency Spectra of Blades 16 and 20 of Blade Ring 1957. Indicating Variation in Blade Quality. Blade 16 has a tight radial crack from the blade tip to about midway between the blade tip and blade root. ANL Neg. No. 306-77-484.

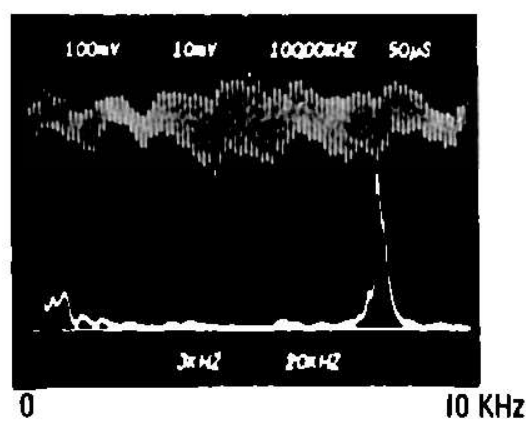

blade 20

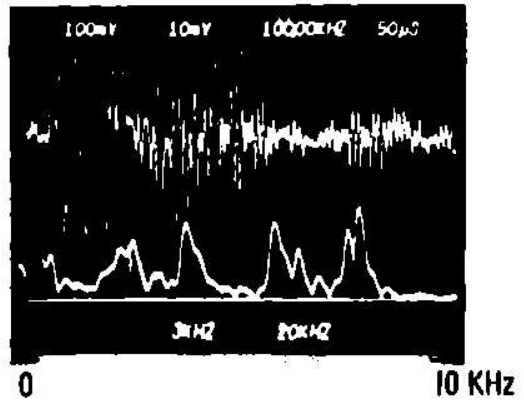

blade 16

(cracked) 
B. Results

Figure 51 shows blades 16 and 20. Blade 16 has a tight radial crack from the blade tip to midway between the blade and root. Blade 20 has no
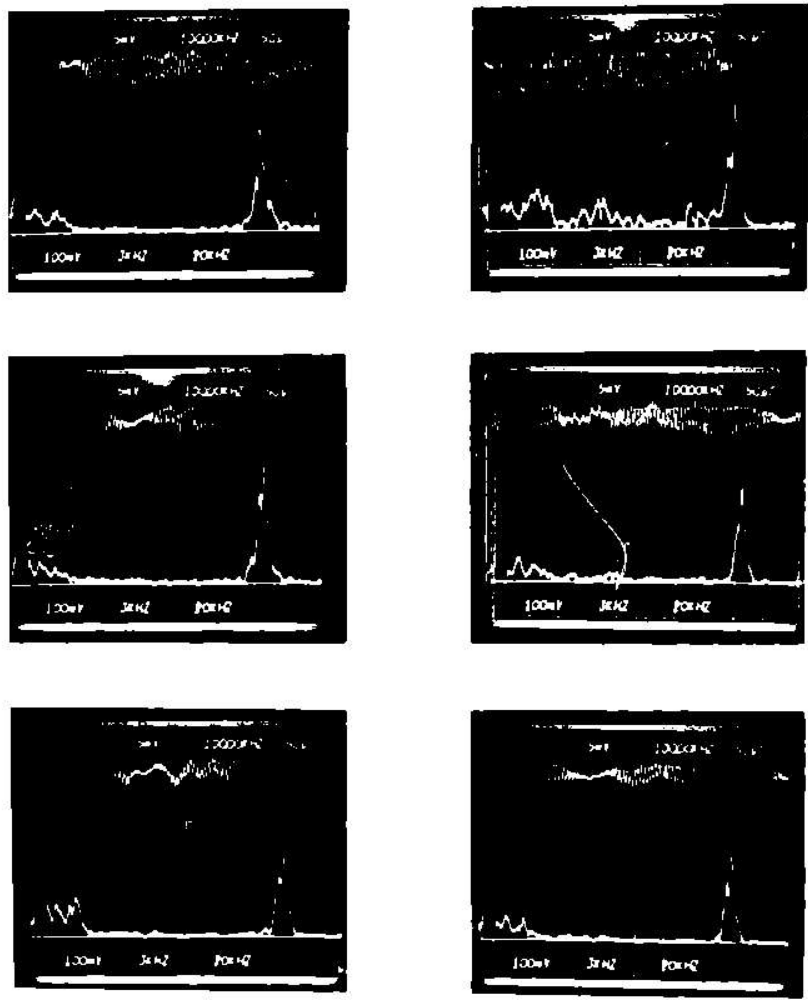

Fig. 55. Six Consecutive Impacts (Using pencil-lead technique) and Resulting Frequency Spectrum from Blacle 12 of Blade Ring 2319. ANL Neg. No. 306-77-486. obvious flaws. A relatively pure signal at about $8 \mathrm{kHz}$ is observed for the clean blade, whereas many frequency components are observed for the cracked blade in the range 1-10 kHz (Fig. 54).

\section{Representative data from} five other blades of ring 2319 have been taken. The intact blades have relatively pure spectra, whereas the broken blades do not. The fact that one spectrum from a broken blade is relatively clean, is surprising. A broader peak than normal does indicate more damping however. In addition, some blades have small (0.5-1-mm-long) cracks at the root of the blade. A comparison of these and evidently defect-free blades showed no reproducible difference in frequency spectra. The lack of sensitivity, except for some types of cracks, is clearly evident. The reproducibility of the spectra produced by impact testing is shown in Fig. 55.

In principle, the frequency-spectra data in the acoustic-impact testing can be calculated from a theoretical model that assumes a resonance frequency for the rotor blade in a cantilever mode of vibration. ${ }^{38}$ The equation used is

$$
f=\frac{A}{2 \pi} \sqrt{\frac{E b^{2}}{12 \rho l^{4}}},
$$

where

$$
\begin{aligned}
& E=300 \times 10^{10} \text { dynes } / \mathrm{cm}^{2} \text { (modulus of elasticity), } \\
& p=2.7 \mathrm{~g} / \mathrm{cm}^{3} \text { (blade density), } \\
& \mathrm{b}=0.2 \mathrm{~cm} \text { (average thickness of taper), } \\
& l=2.5 \mathrm{~cm} \text { (length) }
\end{aligned}
$$


and
$A=11.7$ (geometric factor for fundamental mode with thickness tapered from $3 b$ to $b)$.

The result is

$$
f_{\text {calc }}=9.1 \mathrm{kHz} \text {. }
$$

The calculated resonance frequency of $9.1 \mathrm{kHz}$ is close to that of the observed frequency of $8 \mathrm{kHz}$.

C. Summary

The data obtained here indicate that, although acoustic-impact testing may be useful as a quick and inexpensive test for indicating the overall quality of the rotor blades, it may not be sensitive enough to detect the small flaws that may lead to failure. More sophisticated techniques for exciting the blades (improving reproducibility of impact) could lead to an analys is in which small frequency shifts or components can be related to defects. At present, these shifts cannot be related to small defects.

\section{POSSIBILITY OF FLAW DETECTION BY MEASUREMENT OF VIBRATIONAL DAMPING}

This section considers the feasibility of measuring vibrational damping and relates the data to the presence of flaws or component quality. ${ }^{39}$

\section{A. Impacting Individual Blades}

For small amplitudes of vibration, any fairly rigid body vibrates as a harmonic oscillator. Consider a body of mass $\mathrm{m}$ and stiffness (restoring force) $k$ displaced from equilibrium in the $x$ direction an amount $x_{0}$ and then released (see Fig. 56).

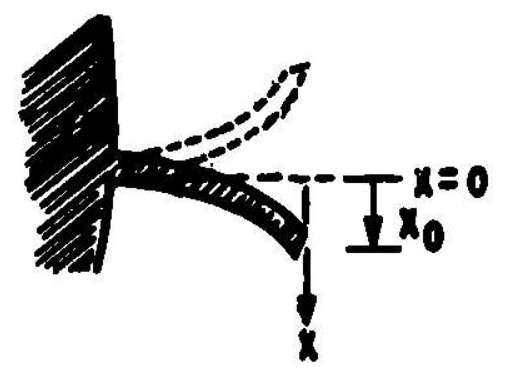

Fig. 56

Scliematic Diagram for Blade Vibration
The equation of motion is

$$
m \ddot{x}=-k_{0} \mathbf{x}
$$

The body will vibrate forever at the natural frequency

$$
\omega_{0}=\sqrt{\frac{k_{0}}{m}}=2 \pi f_{0} .
$$

Note that the frequency of vibration is directly related to the stiffness or modulus of the system. 
If the vibratory motion is damped by flaws and external and/or internal friction and if the damping is not severe, then it is usually assumed that (1) all three dissipative phenomena can be lumped into a damping parameter $R$ and (2) the energy dissipated is directly proportional to the velocity of the body $\dot{x}$ (viscous damping). Thus, the equation of the viscously dampedharmonic oscillator in free decay is

$$
m \ddot{x}=-k x-R \dot{x} .
$$

The solution of the equation indicates that $x$, the instantaneous amplitude of vibration of the oscillator, will decay exponentially with time (see Fig. 57).

That is,

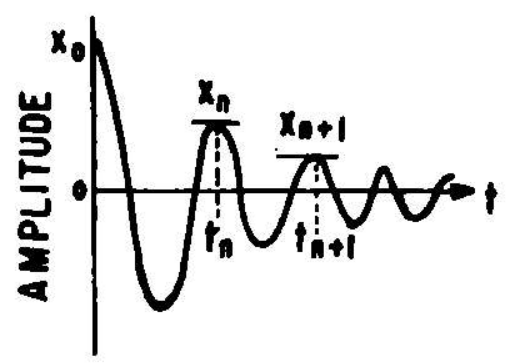

Fig. 57. Damped Oscillation for Blade

$$
x=x_{0} \exp \left(-\frac{R}{2 m} t\right) \cos \left(\omega_{1} t+\varphi\right)
$$

where

and

$\varphi$ is a phase angle (constant of integration)

$\omega_{1}$ is the natural frequency of a damped, undriven oscillator.

It can be shown that

$$
\omega_{1}=\sqrt{\omega_{0}^{2}-\frac{\mathrm{R}^{2}}{4 \mathrm{~m}^{2}}} \equiv \sqrt{\frac{\mathrm{k}_{1}}{\mathrm{~m}}}=2 \pi f_{1} .
$$

Note that $\omega_{1}<\omega_{0}$; the damped oscillator vibrates at a lower frequency than the undamped one. Hence a valid measure of damping in a system is the decrease in natural frequency.

Note also that $k_{1}<k_{0}$; the damped system has a lower stiffness than the undamped one. This phenomenon is referred to as the "modulus defect," which always accompanies flaws or internal friction. Thus,

$$
\mathrm{M}=\text { modulus defect }=\frac{\mathrm{M}_{\text {undamped }}-\mathrm{M}_{\text {damped }}}{\mathrm{M}_{\text {undamped }}},
$$

where

$$
\mathrm{M}=\text { any modulus. }
$$

Consider $x_{n}$, the amplitude of vibration at time $t_{n}$, and $x_{n+1}$, the amplitude of vibration one period later. Then, 


$$
\frac{x_{n}}{x_{n+1}}=\frac{\exp \left[(-R / 2 m) t_{n}\right] \cos \left(\omega_{1} t_{n}+\varphi\right)}{\exp \left[(-R / 2 m)\left(t_{n}+\tau_{1}\right)\right] \cos \left[\omega_{1}\left(t_{n}+\tau\right)+\varphi\right]},
$$

where

$$
\tau_{1}=\text { period }=1 / f_{1} \text {. }
$$

The cosine terms cancel, since they differ by one period, and the $t_{n}$ in the exponents cancel, so that

$$
\frac{x_{n}}{x_{n+1}}=\exp \frac{R_{T_{1}}}{2 m}=e^{8}
$$

and

$$
\begin{aligned}
\ln \frac{x_{n}}{x_{n+1}}=8 \equiv \frac{R_{T_{1}}}{2 m} & \equiv \text { logarithmic decrement } \\
& \equiv \text { damping. }
\end{aligned}
$$

Note that the ratio of two successive amplitudes defines a quantity $\delta$, also called the "damping," which is directly proportional to the dissipative ability of the system $R$.

It can be shown that

$$
\begin{aligned}
\sigma & =\frac{\Delta W}{2 W}=\frac{\text { energy lost in one cycle of vibration }}{2 \text { xaverage vibrational energy per cycle }} \\
& =\frac{R \tau_{1}}{2 \mathrm{~m}} .
\end{aligned}
$$

Note also that damping, period, frequency, and modulus are all interconnected. Measurement of one provides a measurement of the others.

B. Resonance of Entire Assembly

The body behavis : a damped, driven harmonic oscillator when driven at various frequencies nea. $t$ - ' quency of resonance. Its equation of motion is

$$
\mathbf{m} \ddot{\mathbf{x}}+R \dot{\mathbf{x}}+\mathbf{k x}=F_{0} \cos \omega t
$$

where $F_{0} \cos w t$ is the oscillatory drive function. The response of the body is as shown in Fig. 58. The response or amplitude of vibration is at a maximum for $\omega=\omega_{\text {resonance }}=\omega_{2}$; 


$$
\omega_{2}=\sqrt{\omega_{0}^{2}-\frac{R^{2}}{2 m^{2}}}=\sqrt{\frac{k_{2}}{m}} .
$$

Note that, since damping exists and $R$ is finite,

$$
\omega_{2}<\omega_{1}<\omega_{0}
$$

and

$$
\mathrm{k}_{2}<\mathrm{k}_{1}<\mathrm{k}_{0}
$$

so once more the modulus defect is $\left(k_{0}-k_{2}\right) / k_{0}$.

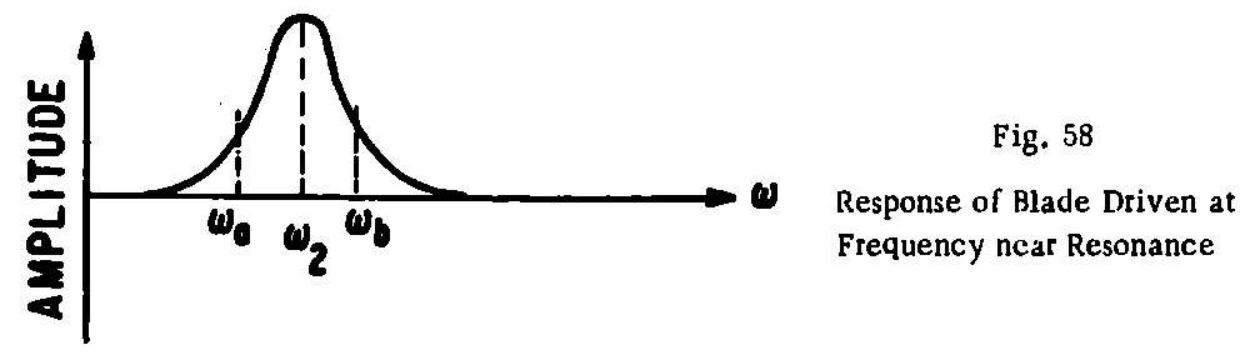

The damping of the body can be shown to be defined by $\Delta \omega=\omega_{b}-\omega_{a}$, the width of the resonance response curve at half maximum. We can also show that

$$
\delta=\frac{\pi \Delta \omega}{\omega_{2}}=\frac{\pi \Delta f}{f_{2}}=\frac{R_{T_{2}}}{2 m},
$$

where

$$
\tau_{2}=1 / f_{2} .
$$

Note the similarity of this expression for 0 to that of Eq. 79 for the damped, undriven oscillator.

If the body is driven at resonance $\left(w_{2}\right)$ and then the applied oscillatory driving force is removed, the vibration will decay in a manner similar to the discharge of a capacitor (see Fig. 59). The decay is $e^{-\alpha t}$, and the decay constant $\tau_{d}$ is the time for decay to $e^{-1}$ of the resonance. In this case, it can be shown that

$$
\delta=\frac{1}{f_{2} \tau d}=\frac{\alpha}{f_{2}}=\frac{\tau_{2}}{\tau_{d}} .
$$

Here, the damping is characterized by $\alpha=\tau^{-1}$ and by $f_{2}$; both quantities are easily measured. Moreover, the modulus defect $n$ is still characterized by $f_{2}<f_{0}$. 


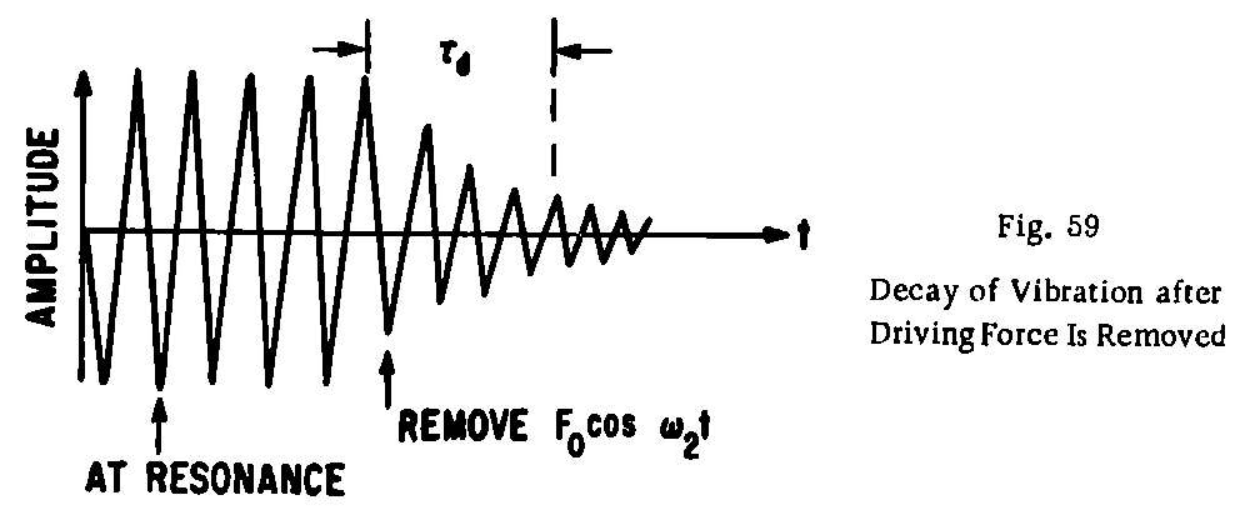

In the case in which a body is initially at rest and then forced into resonance by application of "burst" of $F_{0} \cos \omega_{2} t$, the body behaves as a capac.itor being charged, as shown in Fig. 60 , where ${ }^{\top} \mathrm{b}=$ buildup time constan't $=$ time to build to $1-\mathrm{e}^{-1}$ of maximum amplitude.

Fig. 60

Response of Body Initially at Rest,

Then Forced into Resonance

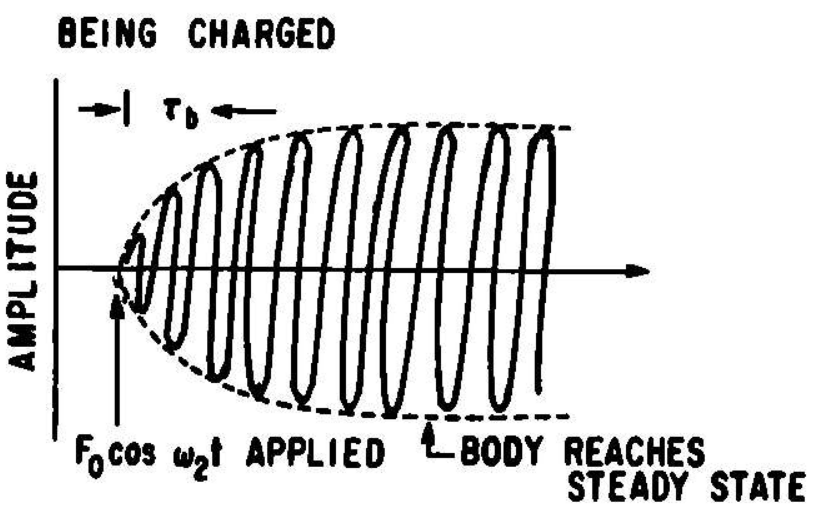

It can be shown that

$$
\delta=\frac{1}{f_{2} \tau_{b}} .
$$

Thus, the damping is characterized by the buildup time constant $\tau_{b}$ and $f_{2}$, both quantities easily measured. The modulus defect $N$ is characterized by $f_{2}$.

In all three resonance cases (Eqs. 73-75), and in the plucked case, $\delta=\Delta W / 2 W$.

\section{Summary of Measurement Procedures}

\section{Free Decay from Impact} frequency $w_{1}$.

Measure ratio of two successive amplitudes $\left(x_{n} / x_{n+1}\right)$ and natural

$$
6=\ln \frac{x_{n}}{x_{n+1}} ; \omega_{1}=\frac{2 \pi}{\tau_{1}} .
$$


If the blade has a flaw, vibrations will decay faster and with a lower value of $f_{1}$. In Sec. D below, the magnitude of those effects is estimated

2. Driven Body near Resonance

maximum:

Measure the width of the resonance response curve at half

$$
\delta=\frac{\pi \Delta \omega}{\omega_{2}} ; \quad \omega_{2}=\frac{2 \pi}{T_{2}}=2 \pi f_{2} .
$$

If the assembly has flaw(s), it will show a broader resonance peak and a lower value of $f_{2}$ than a "perfect" assembly.

3. Driven-body Decay from Resonance

Measure the decay from resonance:

$$
\delta=\frac{1}{f_{2} T_{d}} ; \quad \omega_{2}=\frac{2 \pi}{T_{2}}=2 \pi f_{2} .
$$

If the assembly has flaws, vibrations will decay faster and with a lower value of $f_{2}$ than a "perfect" assembly.

4. Buildup of Body to Resonance

Measure buildup characteristic time $\tau_{b}$ and $f_{2}$ :

$\delta=\frac{1}{f_{2} \tau_{b}} ; \quad \omega_{2}=\frac{2 \pi}{\tau_{2}}=2 \pi f_{2}$.

If the assembly has flaws, it will build up faster and have a lower resonance frequency than a perfect assembly.

D. Estimation of Magnitude of Effect

Materials typically show $\delta$ in the range of $10^{-2}$ to $10^{-5}$. Typical metals show 6 of $10^{-3}$ to $10^{-4}$, and high-quality, flaw-free ceramics show 8 of $10^{-5}$.

Consider an age-hardened aluminum alloy 2024-T6. At $f_{2}=81,175 \mathrm{~Hz}$, it displays a value of $\delta=1.4 \times 10^{-4}$, corresponding to a resonance response peak width $\Delta f=4.0 \mathrm{~Hz}$.

With a slight change in processing, the exact same specimen shows $f_{2}=$ $81,185 \mathrm{~Hz}$ and $\delta=2.0 \times 10^{-4}$, corresponding to a peak width $\Delta f=4.2 \mathrm{~Hz}$.

Thus, minute changes in the internal structure of material, smaller than microcracks, produce changes in 6 of $1-1000 \%$. These changes may be 
easily measured in specimens of simple geometry. As $\delta$ decreases, $f_{2}$ must decrease by way of the modulus defect phenomenon. Changes in $f_{2}$ of the order of one part in $10^{3}$ or $10^{4}$ occur and are easily measured.

\section{E. Conclusion}

In principle, measurements of damping and resonance or natural frequency capable of detecting microflaws in the turbine blade assembly.

The major difficulties to be overcome are establishing a suspension system for the assembly and a driving technique. Furthermore, the ability to obtain reproducible data on the same specimen must be established. In addition, variation in measurements between specimens, not due to the presence of critical flaws, may make data interpretation difficult.

\section{SUMMARY}

Several nondestructive-evaluation techniques were examined for their effectiveness in examining silicon nitride gas-turbine rotors. Preliminary experimental results were obtained from holographic interferometry, acoustic microscopy, dye-enhanced radiography, acoustic emission, and acousticimpact-testing techniques. Internal friction measurements were considered from a theoretical point of view as a way to evaluate ceramic rotors.

Holographic-interferometry techniques were shown to be capable of detecting surface cracks as small as $750 \mu \mathrm{m}$ at the blade root. With improved techniques, cracks as small as $100 \mu \mathrm{m}$ long should be observable. Acousticmicroscopy techniques were shown to be capable of detecting subsurface defects in rotor blades as small as $100 \mu \mathrm{m}$. In one example, the detection of a $400-\mu \mathrm{m}$ flaw was confirmed by radiography. In another example, a flaw detected by acoustic microscopy was confirmed by metallography. The acoustic images were shown to be indicative of the general extent of porosity as there was a fair correlation between micrographs of two blade cross sections and the acoustic images. Flaws smaller than $100 \mu \mathrm{m}$ apparently can be observed.

Dye-enhanced radiography techniques were used to find surface cracks that were apparently only $100 \mu \mathrm{m}$ deep. This capability was established by comparing a micrograph from a blade with the dye-enhanced radiography results. Acoustic emission and acoustic-impact-testing techniques will require more effort to determine if they can reliably detect critically sized flaws $(100 \mu \mathrm{m})$ in silicon nitride rotors. These techniques could be useful, however, as a rapid test for the overall component quality at various stages in the fabrication procedure. 
The use of internal friction measurements as a way to monitor rotor quality was considered from a theoretical point of view. Although potentially small defects can be detected, the rotor geometry and variable acoustic properties between rotors may prevent effective use of this technique. Table II summarizes these methods in terms of their adaptability and effectiveness.

TABLE II. NDE Techniques for Silicon Nitride Rotors

\begin{tabular}{|c|c|c|c|c|c|}
\hline \multirow[b]{2}{*}{ Method } & \multirow{2}{*}{$\begin{array}{l}\text { Adaptability } \\
\text { to Rotor } \\
\text { Geometry }\end{array}$} & \multicolumn{2}{|c|}{ Flaw Detection } & \multirow{2}{*}{$\begin{array}{l}\text { Level of } \\
\text { Difficulty to } \\
\text { Detect Critically } \\
\text { Sized Flaws }\end{array}$} & \multirow[b]{2}{*}{ Comments } \\
\hline & & Surface & Subsurface & & \\
\hline $\begin{array}{l}\text { Dye-enhanced } \\
\text { radiog raphy }\end{array}$ & Excellent & $\mathbf{x}$ & & Moderately low & $\begin{array}{l}\text { Can reveal flaws not visible } \\
\text { by ordinary } X \text {-ray optical or } \\
\text { dye-penetrant methods, Very } \\
\text { promising. }\end{array}$ \\
\hline $\begin{array}{l}\text { Acoustic } \\
\text { microscopy }\end{array}$ & Fair & $\mathbf{x}$ & $\mathbf{x}$ & Low & $\begin{array}{l}\text { Overall quality of component as } \\
\text { well as specific defects can be } \\
\text { observed. Limited to } 3 \text {-mm-thick } \\
\text { specimen in RB, } 6 \text {-mni-thick } \\
\text { specimen in HP technique. }\end{array}$ \\
\hline $\begin{array}{l}\text { Holographic } \\
\text { interferometry }\end{array}$ & Good & $\mathbf{x}$ & $?$ & Moderate & $\begin{array}{l}\text { Probably adaptable to automatic } \\
\text { scanning. }\end{array}$ \\
\hline $\begin{array}{l}\text { Acoustic } \\
\text { emission }\end{array}$ & Fair & $\mathbf{x}$ & $\mathbf{x}$ & High & $\begin{array}{l}\text { Data interpretation very difficult, } \\
\text { relies on flaw population change } \\
\text { during test to release acoustic } \\
\text { energy for flaw indication. }\end{array}$ \\
\hline $\begin{array}{l}\text { Acoustic im- } \\
\text { pact testing }\end{array}$ & Good & $\mathbf{x}$ & $\mathbf{x}$ & High & $\begin{array}{l}\text { Indicates overall component } \\
\text { quality. }\end{array}$ \\
\hline $\begin{array}{l}\text { Internal } \\
\text { friction }\end{array}$ & Poor & $\mathbf{x}$ & $\mathbf{x}$ & High & $\begin{array}{l}\text { Particularly difficult to adapt } \\
\text { to rotor inspection. }\end{array}$ \\
\hline
\end{tabular}

From these preliminary results, the most promising technique examined in terms of cost, effectiveness, and ease of application was found to be dye-enhanced radiography. More effort, however, is needed in this as well as the other two promising techniques (holographic interferometry and acoustic microscopy) to completely establish their effectiveness.

Minimum detectable flaw sizes and reliability have to be established by correlating indications with micrographs showing actual flaws. These techniques have been tried on blade rings and should also be applied to complete duo-density rotors.

From this effort it is apparent that one technique may not be capable of detecting all critical flaws in ceramic rotors. A combination of several techniques for detecting surface and subsurface defects, cracks, and porosity may be necessary to reliably evaluate silicon nitride rotors. 


\section{ACKNOW LEDGMENTS}

We wish to thank G. Dragel and S. Danyluk for their efforts in preparing the micrographs and D. Rudy for his efforts with the holographicinterferometry, acoustic-emission, and acoustic-impact-testing systems. We also wish to thank W. A. Ellingson and K. J. Reimann for their useful suggestions concerning this program and D. Cassidy and A. McLean of the Ford Motor Company for their cooperation in providing the blade rings for this study.

\section{REFERENCES}

1. V. de Blasi, Editor, Ford Runs Uncooled Turbine Engine at $2500^{\circ} \mathrm{F}$, Gas Turbine World (July 1977).

2. A. G. Evans, G. S. Kuro, P. T. Khuri-Yakub, and B. R. Tettmann, Failure Prediction in Structural Cercomics, Mater. Eval., Research Supp. 35, 85 (Apr 1977).

3. T. Derkacs, I. M. Matary, and W. D. Bruetnall, Nondestructive Evaluation of Ceramics, TWR, Inc., Cleveland, Ohio, Final Tech. Report, Contract No. N00019-75-C-0238, prepared for Naval Air Systems Command, Dept. of Navy, Washington, D.C. (July 1976).

4. A. G. Evans and M. Linzer, Failure Prediction in Structural Ceramics Using Acoustic Emission, 'J. Am. Ceram. Soc. 56, 575 (Nov 1973).

5. J. J. Schuldies, AiResearch, Inc., Phoenix, AZ, personal communication.

6. R. K. Erf, editor, Holographic Nondestructive Testing, Academic Press (1974).

7. P. H. Francis and A. Nagy, Deformation Mechanics of Deep Surface Flaw Cracks, final report, Contract NAS9-12012, Southwest Research Institute, San Antonio (July 1972).

8. C. E. Inglis, Trans. Inst. Nav. Archit. $L V(1), 219$ (1913).

9. H. M. Westergaard, J. App1. Mech. 6, 49 (June 1939).

10. G. R. Irwin, J. App1. Mech. 24, 361 (1957).

11. G. R. Irwin, "Fracture," Encyclopedia of Physics, Vol. VI, Springer, Berlin, p. 551 (1958).

12. G. R. Irwin I. A. Kies, and H. Smith, Proc. Am. Soc. Test. Motor. 58, 640 (1958).

13. G. R. Irwin, Structural Mechanics: Proceedings of the First Symposium of Naval Structural Mechanics, 1968, pp. 557-591, Pergamon Press, New York.

14. C. A. Sclammarella and J. A. Gilbert, A Holographic-Moire Technique to Obtain Separate Patterns of Components of Displacement, Exp. Mech. 16(6), 215 (June 1976).

15. J. A. Gilbert, personal communication.

16. C. A. Sciammarella and S. K. Chawla, Holographic-Moire' Technique to Obtain Displacement Components and Derivatives, Mechanics Research Communications (Nov 1977).

17. C. W. Smith, "Use of Three Dimensional Photoelasticity and Progress in Related Areas," Experimental Techniques in Fracture Mechanics 2, edited by A. S. Kobayask1, Iowa UnIversity Press (1977). 
18. R. F. Van Ligten and H. Osterberg, Hoiographic Microscopy, Nature 211, 282 (1966).

19. R. F. Van Ligten and H. Osterberg, J. Opt. Soc. Am. 55, 1467 (1967).

20. F. W. E1lis, Holomicrography, Science 154, 1195 (1966).

21. E. M. Leith and G. Udpanieks, Microscopy by Wave Reconstruction, J. Opt. Soc. Am. 55, 981 (1965).

22. W. Stroke, J. Opt. Soc. Am. 57, 1102 (1967).

23. L. Toth and S. A. Collins, J. Appl. Phys. Letters 13, 7 (1968).

24. M. E. Cox, R. G. Buckles, and D. Whitlow, J. Opt. Soc. Am. 59, 1545 (1969).

25. W. L. Anderson et al., Microscopic Image Reproduction by Holography, Terminal Progress Report, Grant, N-GM. 14256, SWRI Project No. 15-1931, Southwest Research Institute, San Antonio (Dec 1970).

26. J. Monneret, Etude Theoretique et Experimentals nes Phenomenes observables en Interferometric Holographique, Interpretation Des Interferogrames Et Applications a la Metrologia Des Microdisplacements, doctoral thesis, University of Besancon, France (1973).

27. S. K. Chawla, personal communication.

28. C. A. Sciammarella and C. W. Doddington, Effect of Photographic-film NonZinearities on the Processing of Moire Eringe Data, Exp. Mech. 7,398 (Sept 1967).

29. H. Berger, Practical Applications of Nuetron Radiography and Gauging, ASTM Special Technical Publication 586, American Society for Testing and Materials, Philadelphia, Pa., Library of Congress Catalog Card Number 75-13061.

30. S. P. Ying, Characteristics and Mechanisms of Acoustic Emission from Solids Under Applied Stress, Crit. Rev. Solid State Sci. 4, 85 (Dec 1973).

31. M. Mirabile, Acoustic Emission Energy and Mechanisms of Plastic Deformation and Fracture, Nondestr. Test. 8, 77 (Apr 1975).

32. M. Arrington, Acoustic Emission, Br. J. Non-Destr. Test. 17, 10 (Jan 1975).

33. R. R. Corle and J. A. Schbessmann, Flaw Detection and Characterization Using Acoustic Emission, Mater. Eval. 31, 115 (May 1973).

34. R. C. McMaster, editor, Nondestructive Testing Handbcok, Vol... I and II, Ronald Press (1959).

35. R. Schroeer, R. Rowand, and H. Kamm, The Acoustic Impact Technique--A Versatile Tool for Nondestructive Evaluation of Aerospcce Structures and Components, Mat. Eval. 28(11), M237-243 (Nov 1970).

36. P. A. Lloyd, A. B. Johnson, and G. J. Curtis, "Acoustic Impact Testing," Eighth World Conference on Nondestructive Testing, Cannes, France, Paper 3K8 (Oct 6-9, 1976).

37. N. N. Hsu, J. A. Simmons, and S. C. Hardy, An Approach to Acoustic Emission Signal Analysis--Theory and Experiment, Mater. Eval. 35(10), 100 (1977).

38. J. P. Den Hartog, Mechanical Vibrations, McGraw-H111, New York, 4th Edition, (1956).

39. N. F. Fiore and R. M. Brach, Resonance Bar Damping Measurements by the Resonance-Buildup Technique, J. Acoust. Soc. Am. 46, 492 (1969). 
Internai:

E. G. Pewitt

E. J. Croke

P. F. Gustafs on

L. Burris

B. R. T. Frost

R. W. Weeks

F. A. Nichols

L. T. Lloyd

J. F. Schumar

M. F. Adams (4)

M. C. Billone

R. B. Poeppel
T. F. Kassner

L. A. Neimark

H. R. Thresh

A. G. Hins

D. R. Diercks

K. J. Reimann

D. Stahl

M. B. Brodsky

F. Y. Fradin

T. H. Blewitt

K. L. Merkle

H. Wiedersich

U. F. Kocks
R. W. Siegel

M. H. Mueller

D. S. Kupperman (10)

N. P. Lapinski (10)

A. Sather (10)

G. Dragel

S. Danyluk

W. A. Ellingson

A. B. Krisciunas ANL Contract Copy

ANL Libraries (5)

TIS Files (6)

\section{External:}

DOE-TIC, for distribution per UC-95a, 95f, and 96 (337)

Manager, Chicago Operations Office

Chief, Chicago Patent Group

President, Argonne Universities Association

Materials Science Division Review Committee:

G. S. Ansell, Rensselaer Polytechnic Inst.

R. W. Balluffi, Cornell U.

S. L. Cooper, U. Wisconsin

S. Doniach, Stanford U.

H. L. Falkenberry, Tennessee Valley Authority

C. Laird, U. Pennsylvania

D. Lazarus, U. Illinois

M. T. Simnad, General Atomic

A. R. C. Westwood, Martin Marietta Labs. 